\title{
The effect of a flaxseed-oil enhanced diet on the shelf life and sensory characteristics of farmed brook trout (Salvelinus fontinalis)
}

Courtney Anne Simmons

West Virginia University

Follow this and additional works at: https://researchrepository.wvu.edu/etd

\section{Recommended Citation}

Simmons, Courtney Anne, "The effect of a flaxseed-oil enhanced diet on the shelf life and sensory characteristics of farmed brook trout (Salvelinus fontinalis)" (2009). Graduate Theses, Dissertations, and Problem Reports. 4533.

https://researchrepository.wvu.edu/etd/4533

This Thesis is protected by copyright and/or related rights. It has been brought to you by the The Research Repository @ WVU with permission from the rights-holder(s). You are free to use this Thesis in any way that is permitted by the copyright and related rights legislation that applies to your use. For other uses you must obtain permission from the rights-holder(s) directly, unless additional rights are indicated by a Creative Commons license in the record and/ or on the work itself. This Thesis has been accepted for inclusion in WVU Graduate Theses, Dissertations, and Problem Reports collection by an authorized administrator of The Research Repository @ WVU. For more information, please contact researchrepository@mail.wvu.edu. 
The Effect of a Flaxseed-oil Enhanced Diet on the Shelf Life and Sensory Characteristics of Farmed Brook Trout (Salvelinus fontinalis)

\author{
Courtney Anne Simmons
}

Thesis submitted to the Davis College of Agriculture, Forestry, and Consumer Sciences

At West Virginia University In partial fulfillment of the requirements for the degree of

\author{
Master of Science \\ in \\ Human Nutrition and Food
}
Kristen Matak, PhD., Chair Jacek Jaczynski, PhD. Kenneth Semmens, PhD

Division of Human Nutrition and Foods

\author{
Morgantown, West Virginia \\ 2009
}

Key words: omega-3 fatty acids, Brook trout, shelf life, sensory evaluation, lipid oxidation 


\section{ABSTRACT \\ The Effect of a Flaxseed-oil Enhanced Diet on the Shelf Life and Sensory Characteristics of Farmed Brook Trout (Salvelinus fontinalis) \\ Courtney Anne Simmons}

The effect of dietary modification with flaxseed-oil (Flax) enhanced feed on the sensory characteristics and shelf life of brook trout fillets was examined. The diets were composed of a commercial feed supplemented with either fish oil (control diet, CD) or Flax (treatment diet). 


\section{ACKNOWLEDGEMENTS}

This project was funded by the United States Department of Agriculture (\# 2006-34386-17605; Title: Aquaculture Product and Marketing Development, WVU).

I would like to thank the faculty and staff in the Animal and Nutritional Sciences Department at West Virginia University for this opportunity, for their assistance, and for their continuous support. I would like to thank my committee members, Kristen Matak, PhD., Jacek Jaczynski, PhD., Kenneth Semmens, PhD., for their availability and guidance.

Specifically I would like to thank Sarah Beamer for her selflessness and willingness to help. I would also like to thank Professor Jacek Jaczynski, PhD for the use of his lab. Thank you to Rodney Kiser, who filleted many, many fish and was also available to answer questions. I would like to recognize statisticians Gerald Hobbs, PhD, and Desta Fekedulegn, PhD for assisting me in analyzing and understand the data obtained.

Thank you to Kristen Matak, PhD, my advisor and project chair, who was there to answer any minor question that I had and helped me brainstorm when I was unsure of which step to take next. I really appreciate the countless hours of time that she gave up to help figure out the logistics of the project.

Finally, I would like to thank my family that supported me while I was working on this thesis project. They always provided an ear and an optimistic word. 


\section{TABLE OF CONTENTS}

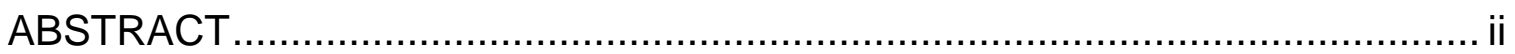

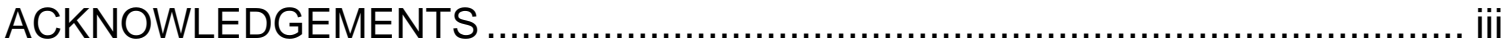

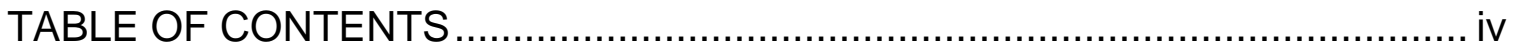

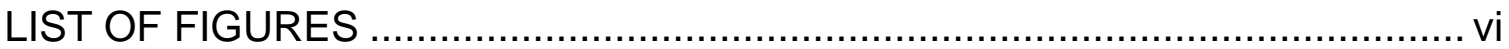

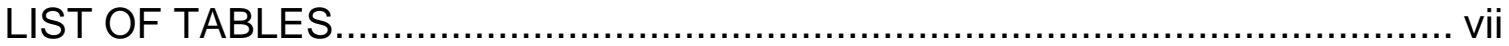

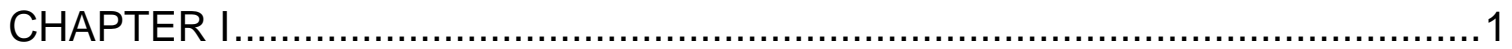

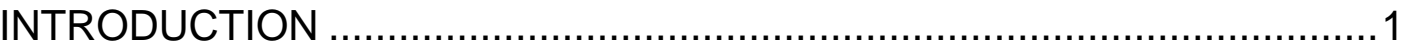

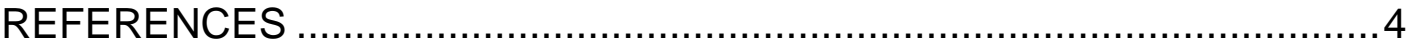

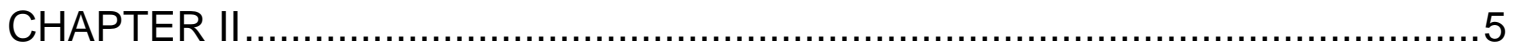

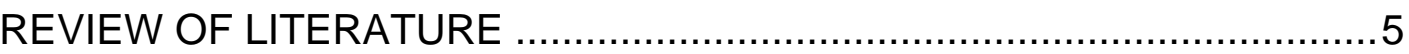

OMEGA-3 POLYUNSATURATED FATTY ACIDS ..............................

FUNCTION OF OMEGA-3 POLYUNSATURATED FATY ACIDS IN THE

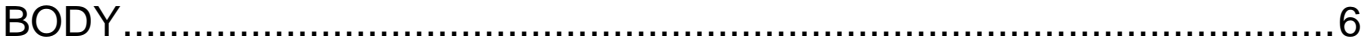

BROOK TROUT AS A VALUE-ADDED FOOD PRODUCT .....................

NUTRIENT ANALYSIS FOLLOWING FLAXSEED- OIL

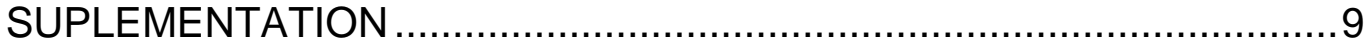

FISH SPOILAGE AND OXIDATION .............................................11

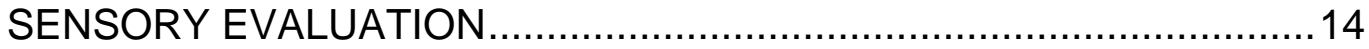

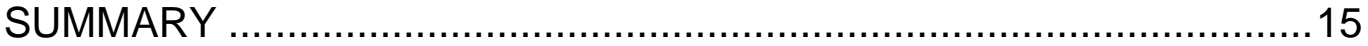

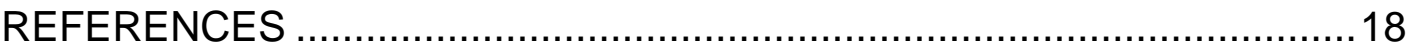

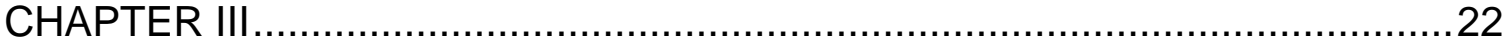

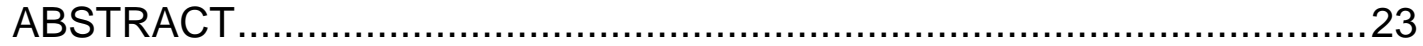

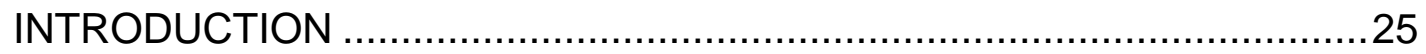

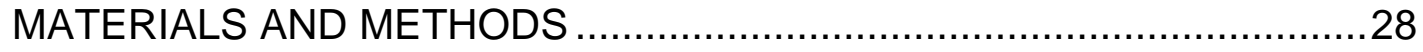

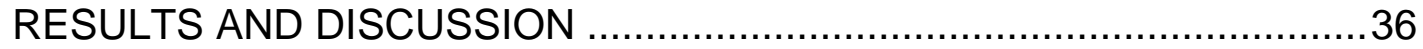

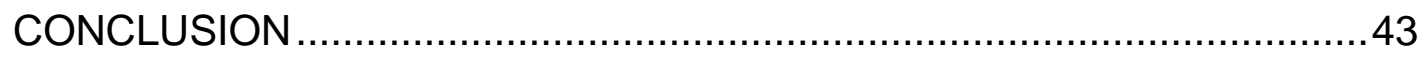

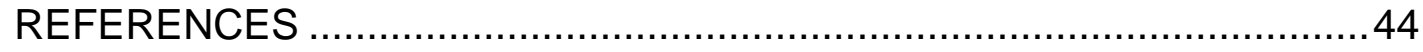

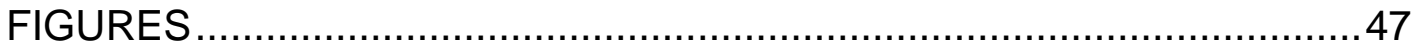

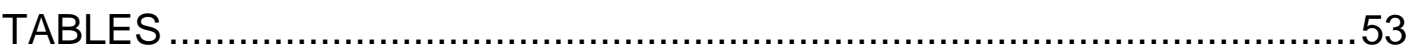




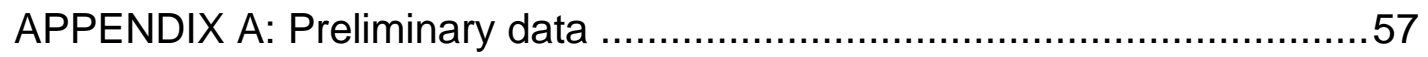

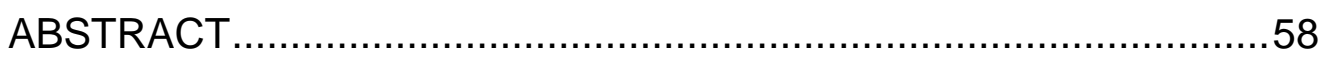

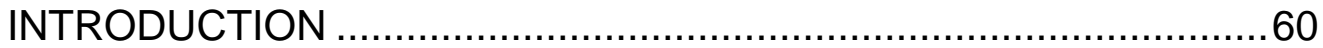

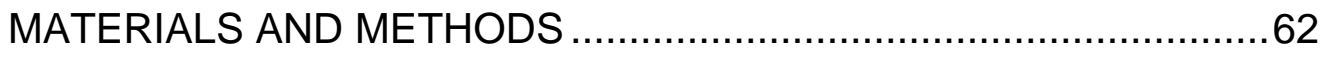

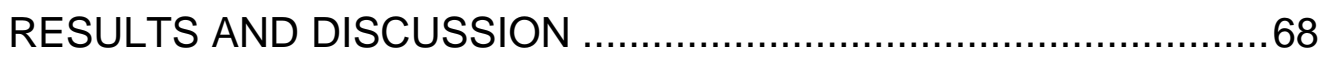

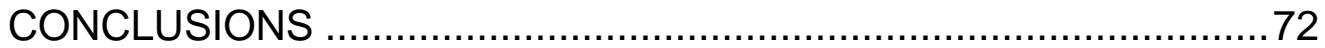

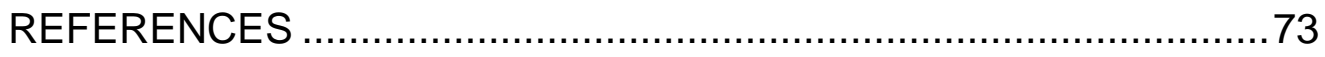

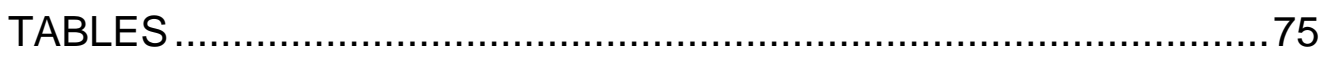

APPENDIX B: Spring-fed gravity flow-through raceway system................81

APPENDIX C: Consent form for participation in sensory attribute

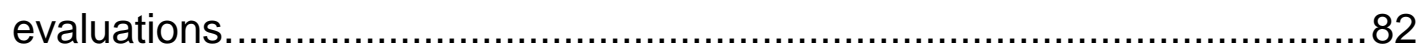

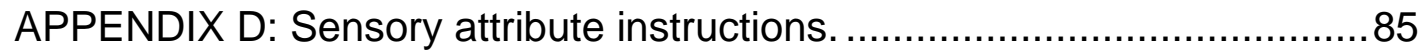

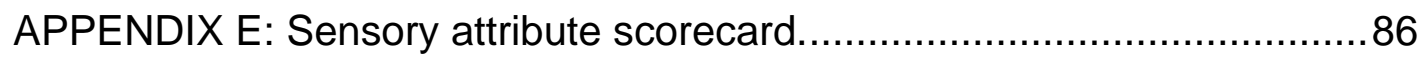

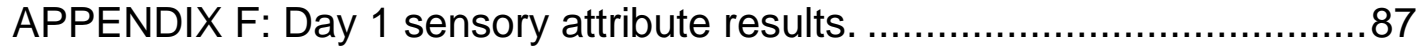

APPENDIX G: Consent form for difference and preference testing............91

APPENDIX H: Sensory card used for triangle test....................................94

APPENDIX I: Sensory card used for preference test................................ 95

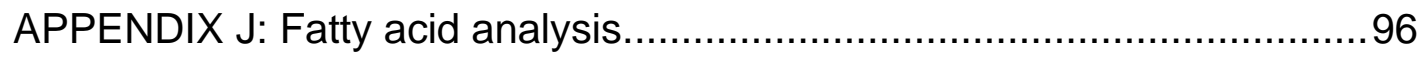

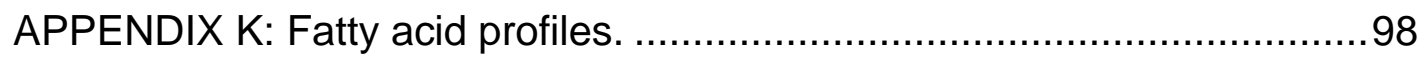

APPENDIX L: Thiobarbituric acid reactive substances test procedure. ....104

APPENDIX M: Statistical analysis of muscle pH (Chapter III).................. 106

APPENDIX N: Statistical analysis of Color L (Chapter III) ........................111 


\title{
LIST OF FIGURES
}

\author{
CHAPTER III
}

Figure 1. Color: $L$ values. Changes in color of fillets from fish fed a control diet (CD) or flaxseed-oil enhanced diet (Flax) were measured over an 11-day storage period at $4^{\circ} \mathrm{C}$. Analyses were conducted at $48 \mathrm{~h}$ intervals from day 1 until day 9 and then again on day 11 .

Figure 2. Color: $a^{*}$ values. Changes in color of fillets from fish fed a control diet (CD) or flaxseed-oil enhanced diet (Flax) were measured over an 11-day storage period at $4^{\circ} \mathrm{C}$. Analyses were conducted at $48 \mathrm{~h}$ intervals from day 1 until day 9 and then again on day 11 . A trend toward increasing $\mathrm{a}^{*}$ values from day 1 to day 11 for $C D$ and Flax fillets is suggested but failed to reach statistical significance. Greater $a^{*}$ values for Flax fillets are also suggested but failed to reach statistical significance $(P>0.05)$.

Figure 3. Color: $b *$ values. Changes in color of fillets from fish fed a control diet (CD) or flaxseed-oil enhanced diet (Flax) were measured over an 11-day storage period at $4^{\circ} \mathrm{C}$. Analyses were conducted at $48 \mathrm{~h}$ intervals from day 1 until day 9 and then again on day 11 . A trend toward increasing $b^{*}$ values from day 1 to day 11 for $C D$ and Flax fillets is suggested but failed to reach statistical significance $(P>0.05)$.

Figure 4. ALA, DHA, and EPA concentrations of control (CD) and flaxseed-oil enhanced (Flax) fillets over a 3 month feeding period. Statistical analysis was not performed on this data

Figure 5. Thiobarbituric acid reactive substances test (TBARS). Color absorbance was read at $532 \mathrm{~nm}$ and TBARS values were reported as $\mathrm{mg}$ malondialdehyde (MDA) per kg sample of control (CD) and flaxseed-oil enhanced (Flax) fillets. A trend toward decreasing production of MDA over 11 days is shown but failed to reach statistical significance $(P>0.05)$. CD fillets had elevated production of MDA but this also failed to achieve statistical significance.

Figure 6. Sensory attributes of control (CD) and flaxseed-oil enhanced (Flax) fillets. Testing was performed on fresh fish fillets stored overnight in a $4^{\circ} \mathrm{C}$ environment. Responses from 11 semi-trained panelists were quantified using a $10 \mathrm{~cm}$ scale with 1 representing a small presence of the attribute and 10 representing a large presence of the attribute. 


\title{
LIST OF TABLES
}

\author{
CHAPTER III
}

Table 1. Feed proximate composition comparison of two diets: flaxseed-oil enhanced (Flax) and control diet (CD). Proximate composition of the feeds

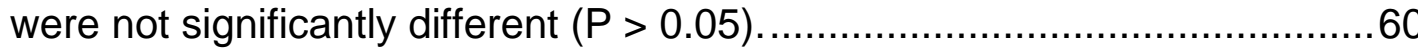

Table 2. Change in muscle $\mathrm{pH}$ of control (CD) and flaxseed-oil enhanced (Flax) fillets over an 11-day storage period. Optimal muscle $\mathrm{pH}$ is $6.2-6.6$.

Table 3. Omega-3 PUFA content of control (CD) and flaxseed-oil enhanced (Flax) fillets.

\section{APPENDIX A}

Table 1. Feed proximate composition comparison of two diets: flaxseed-oil enhanced (Flax) and control diet (CD). Proximate composition of the feeds were not significantly different $(P>0.05)$. Statistical analysis was not performed on the fatty acid profile of the feeds.

Table 2. Sensory attributes of Day 1 and Day 10 control (CD) fillets and flaxseedoil enhanced (Flax) fillets.

Table 3. Texture analysis of cooked trout fillets fed two diets: flaxseed-oil enhanced diet (Flax) and control diet (CD). Texture is expressed as force (g) / weight (g). Results for each diet and day is expressed as the average of one measurement from each of three fillets. Statistical analysis was not performed on this data.

Table 4. Cooking yield (\% Yield) of trout fillets fed two diets: flaxseed-oil enhanced diet (Flax) and control diet (CD). Results are expressed as the average \% yield from 6 fillets for each diet and day. Statistical analysis was not performed on this data.

Table 5. Color analysis $\left(L, a^{*}, b^{*}\right)$ of cooked trout fillets fed two diets: flaxseed-oil enhanced diet (Flax) and control diet (CD). Results for each diet and day are expressed as the average of 2 measurements from each of three fillets. Statistical analysis was not performed over the 10 day storage period. .......86

Table 6. Omega-3 polyunsaturated fatty acid (PUFA) content of control (CD) and

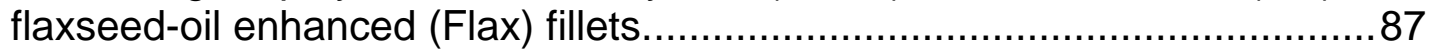




\section{CHAPTER I}

\section{INTRODUCTION}

The functions of omega- 3 polyunsaturated fatty acids ( $\omega-3$ PUFA), such as alpha-linolenic acid (ALA, 18:3n3), eicosapentaenoic acid (EPA, 20:5n3), and docosahexaenoic acid (DHA, 22:6n3) have been extensively researched. Evidence links the $\omega-3$ PUFA with beneficial effects on cardiovascular health, immune function, insulin action, neuronal development, and visual function (Jump 2002; Benatti 2004). The most widely examined benefit of $\omega$-3 PUFA has been associated with a lowered risk of cardiovascular disease. More recently, researchers have been investigating the effect of $\omega$-3 PUFA on other chronic diseases such as diabetes mellitus and the metabolic syndrome (Barre 2007).

Incorporating adequate amounts of $\omega-3$ PUFA into the diet can be achieved by consuming fish, particularly tuna, salmon, sardines, herring, and trout (USDA 2005). These fatty fish are higher in EPA and DHA compared to lean fish. According to the USDA Dietary Guidelines for Americans (2005), it is suggested that consuming approximately two servings of these types of fish per week may reduce the risk of mortality from coronary heart disease. Furthermore, consumption of EPA and DHA may reduce the risk of mortality from cardiovascular disease in people who have already experienced a cardiac event.

In addition to the already high content of EPA and DHA naturally occurring in fish such as trout, it may be of further benefit to human health to consume trout supplemented with flaxseed oil, a rich source of ALA. According to Chen and others (2006), feed enhanced with flaxseed-oil and fed to rainbow trout nearly doubled the $\omega-3$ 
PUFA content of the trout flesh. Furthermore, the flavor of an $\omega-3$ PUFA enhanced food product has been reported to be preferred to the flavor of a non-enhanced product (Romans and others1995). These observations suggest that changing the fatty acid profile of the fish will influence the taste of the fish flesh, as well as provide a higher content of health-beneficial $\omega-3$ PUFA.

On the other hand, altering the fatty acid content of trout may have a negative influence on shelf-life. Omega-3 PUFA are more prone to lipid oxidation due to the greater number of double bonds that they contain. This results in the exposure of a greater number of carbons that are more readily available for attack by free radicals. Increasing the $\omega$-3 PUFA content may also increase the likelihood for development of off-odors and off-flavors due to increased oxidation, resulting in a product that will spoil faster and ultimately become unfavorable (Chen and others 2007; Waagbo and others 1993).

Development of a value-added fish product, such as $\omega$-3 PUFA enhanced brook trout, may offer superior flavor and significant health benefits. Overall satisfaction of such a product may appeal to a particular market segment. West Virginia aquaculture can be characterized by small flowing water systems for the production of trout, yet brook trout are not commonly produced as food fish but rather used in recreational markets. Due to the abundance of brook trout native to the area and the potential health benefits of $\omega-3$ PUFA enhanced brook trout, this type of product may represent a potential niche market for West Virginia producers. However, the effect of increased oxidation must also be taken into account in terms of shelf life, spoilage, and overall desirability of the trout. This study aimed to examine the shelf life and sensory 
characteristics of $\omega-3$ PUFA enhanced trout to determine if such a product would be functional and marketable to consumers, ultimately concluding if such a product could represent a niche market for West Virginia producers expanding into the food fish market. 


\section{REFERENCES}

Barre DE. 2007. The Role of consumption of alpha linolenic eicosapentaenoic and docosahexaenoic acids in human metabolic syndrome and type 2 diabetes- a minireview. JOS. 56(7):319-325.

Benatti P, Peluso G, Nicolai R, Calvani M. 2004. Polyunsaturated fatty acids: biochemical, nutritional and epigenetic properties. Journal of the American College of Nutrition. 23(4):281-302.

Chen Y- C, Nguyen J, Semmens K, Beamer S, Jaczynski J. 2006. Enhancement of omega-3 fatty acid content in rainbow trout. JFS. 71(7):383-389.

Chen Y- C, Nguyen J, Semmens K, Beamer S, Jaczynski J. 2007. Chemical changes in omega-3-enhanced farmed rainbow trout (Oncorhynchus mykiss) fillets during abusivetemperature storage. Food Control. 19(6):599-608.

Jump DB. 2001. The biochemistry of n-3 polyunsaturated fatty acids. JBC. 227(11):8755-8758.

Romans JR, Wulf DM, Johnson RC, Libal GW, Costello WJ. 1995. Effects of ground flaxseed in swine diets on pig performance and on physical and sensory characteristics and omega-3 fatty acid content of pork: II. Duration of $15 \%$ dietary flaxseed. Journal of Anim Sci. 73:1987-1999.

USDA: US Department of Health and Human Services. 2005. Dietary Guidelines for Americans (HHS publication number: HHS-ODPHP-2005-01-DGA-A). Washington, DC: U.S. Government Printing Office.

Waagbo R, Sandness K, Torrissen OJ, Scandvin A, Lie O. 1993. Chemical and sensory evaluation of fillets from Atlantic salmon (Salmo salar) fed three different levels of $n-3$ polyunsaturated fatty acids at two levels of vitamin E. Food Chemistry. 46:361366. 


\section{CHAPTER II}

\section{REVIEW OF LITERATURE}

OMEGA-3 POLYUNSATURATED FATTY ACIDS

Alpha linolenic acid (ALA, 18:3n3) is the predominant plant-derived dietary omega-3 polyunsaturated fatty acid ( $\omega-3$ PUFA) and is a precursor for other $\omega-3$ PUFA, such as docosahexaenoic acid (DHA, 22:6n3) and eicosapentaenoic acid (EPA, 20:5n3) (Jump 2001). Humans are unable to synthesize ALA de novo, owing to the lack of desaturase enzymes that add a double bond to the C-15 position of a fatty acid carbon chain (Surette 2008; Gebauer and others 2005). Therefore, ALA is an essential fatty acid that must be consumed in the diet. The most common food sources that contain ALA are various vegetable oils such as canola oil, soy oil, flaxseed oil, and walnut oil (USDA 2005). Recently, an increased variety of foods that are not traditional sources of ALA, such as baked goods and dairy products, have been fortified with small amounts of this essential fatty acid. This increased availability of $\omega-3$ PUFA in such foods may be derived from newly published dietary intake recommendations in response to the unfavorably high ratio of omega- 6 polyunsaturated fatty acids ( $\omega-6$ PUFA) to $\omega-3$ PUFA $(\omega-6 / \omega-3)$ consumed in the western diet. On average, the typical Western diet contains a 25:1 ratio of $\omega-6 / \omega-3$ PUFA, while the current recommended ratio is 4:1 (Drobná and others 2006). An $\omega-6$ PUFA level greater than $5 \%$ of the total daily energy consumption is undesirable. (Drobná and others 2006).

ALA can be metabolically converted to EPA and DHA, however this conversion appears to be relatively inefficient in humans. This inefficiency is attributed to competition for incorporation into membrane phospholipids among ALA and $\omega-6$ PUFA 
(Aterburn 2006). Due to this low conversion rate it is suggested that, DHA and EPA be consumed in the diet. The most prevalent dietary sources of DHA and EPA for humans are fish and fish oils, especially trout and other types of fatty fish (Surette 2008). Environmental algae, the main source of food for fish, are the underlying producers of EPA and DHA (Arterburn 2006). When fish consume these algae, EPA and DHA are incorporated into their cells and tissue. Similarly, when humans consume fish, EPA and DHA are accumulated into the phospholipids of cell membranes especially in the brain, heart, and testes (Leaf and others 2003).

\section{FUNCTION OF OMEGA-3 POLYUNSATURATED FATY ACIDS IN THE BODY}

Increasing the dietary intake of $\omega-3$ PUFA ultimately alters cell membrane fatty acid composition. This results in an impact on cell and organ function as well as on a wide variety of biological processes (Arteburn 2006). The $\omega-3$ PUFA (ALA, DHA, EPA) and the $\omega-6$ PUFA, particularly arachidonic acid (AA, 20:4n6), all compete to bind the sn-2 position on phospholipids in cell membranes (Surette 2008; Arteburn 2006).

Therefore, the total concentration of $\omega$-3 PUFA plays a significant role in whether they will be incorporated into the cell membrane.

The 25:1 ratio of $\omega-6 / \omega-3$ PUFA, typical of the Western diet, allows for a greater incorporation of $\omega-6$ PUFA into phospholipids in cell membranes. Both AA and EPA can be converted into powerful cell mediators know as eicosanoids, which are involved in many metabolic regulatory and inflammatory processes. The eicosanoids derived from AA are more potent than those derived from EPA. The $\omega-6$ PUFA derived eicosanoids are associated with the activation of leukocytes and platelets, regulation of gastric 
secretion, inducing bronchoconstriction, and signaling pain in nerve cells (Surette 2008).

The production of such cell mediators and inflammatory markers has been associated with an increased risk for cardiovascular disease, certain cancers, and inflammatory diseases (Drobná and others 2006).

Incorporating $\omega-3$ PUFA into the diet results in actions that directly or indirectly regulate the cellular activities associated with inflammation (Surette 2008). Dietary $\omega-3$ PUFA can disrupt AA metabolism by competing with it for enzymes that catalyze the biosynthesis of eicosanoids. A 4:1 ratio of $\omega-6 / \omega-3$ PUFA may limit the amount of $\omega-6$ PUFA incorporated into the cell membranes offering a diminished potential for synthesis of the powerful AA-derived mediators of inflammation and platelet aggregation. (Surette 2008). The production of trout containing a larger amount of $\omega$-3 PUFA will facilitate human consumption of a more favorable $\omega-6 / \omega-3$ ratio similar to the recommended $4: 1$ ratio.

\section{BROOK TROUT AS A VALUE-ADDED FOOD PRODUCT}

Brook trout (Salvelinus fontinalis) are native to freshwater such as streams, creeks, lakes and ponds. They depend on cold, clear, well-oxygenated water for survival and are commercially raised primarily for recreation rather than as a food fish. Freshwater fish are highly efficient at converting ALA to EPA and DHA (Sargent and others 1995). Conversely, Hardy (1990) has shown that the $\omega-3$ PUFA in farmed rainbow trout fillets are typically lower than in wild counterparts. Therefore it may be beneficial for freshwater farmed fish to be fed feeds containing ALA to ensure or increase their levels of EPA and DHA. 
Flaxseed oil and alpha-linolenic polyunsaturated fatty acid. Flaxseed-oil (Flax) contains $53.3 \%$ of ALA and $12.7 \%$ of the $\omega-6$ PUFA linoleic acid (LA, 18:2n6), yielding the highest $\omega-3 / \omega-6$ ratio among plant sources (National Research Counsel 1993). In previous studies partial replacement of fat in a standard diet with Flax resulted in higher $\omega$-3 PUFA concentrations in rainbow trout fillets (Chen and others 2006). Another study examining the dietary effect of $\omega-3$ PUFA on the rib meat of Holstein bulls found that in bulls fed flaxseed, the level of $\omega$-3 PUFA increased linearly with the amount of lipid (Mach and others 2006). In bulls that were fed canola seed, a good source of $\omega-6$ PUFA, there was no change in $\omega-3$ PUFA concentrations. This study also found that the ratio of $\omega-6 / \omega-3$ was lower in the bulls fed flaxseed than those fed canola seed. The evidence provided by this study further exhibits that the $\omega-6 / \omega-3$ ratio can be improved by increasing dietary $\omega-3$ PUFA consumption.

Benefit of a flaxseed-oil enhanced diet. Value added food products include raw or pre-processed commodities whose value has been increased through the addition of ingredients or processes that make them more attractive to the buyer or readily usable by the consumer. The U.S Food and Drug Administration (FDA) has approved health claims that $\omega-3$ PUFA reduce the risk of coronary heart disease thus giving a marketing leverage for functional foods enhanced with $\omega-3$ PUFA (Chen and others 2006). In a study by Castell and others (1972) it was shown that dietary LA and ALA increased the concentrations of these fatty acids in trout fillets and that ALA increased the concentrations of EPA and DHA in the fillets. An effective way to reduce cost and provide great flexibility in modifying the lipid content of the fish fillets to meet the health concerns of the consumers can be achieved by lipid modification in the diet (Chen and 
others 2006). Therefore feeding trout a diet enhanced with Flax and high in ALA may result in a higher level of DHA and EPA in the trout fillet, offering a way to aid consumers in increasing their $\omega-3$ PUFA consumption.

It is expected that the increasing popularity of $\omega-3$ PUFA fortified trout or similar value-added food products will give trout growers using small flowing water systems a more favorable product to market. Specifically, West Virginia producers have access to an abundant amount of native brook trout as aquaculture in this state is characterized by small flowing water systems for the production of trout. Brook trout is not typically available as a food fish therefore producing this type of value-added food product may represent a potential niche market for West Virginia producers allowing for expansion into the food fish market. Developing a brook trout product that offers a value-added benefit may increase profitability to producers and increase the volume of brook trout in the market, while offering a product that is beneficial to consumer health.

\section{NUTRIENT ANALYSIS FOLLOWING FLAXSEED- OIL SUPLEMENTATION}

Numerous studies have been carried out evaluating the effect of enhancing feed with Flax on the proximate composition of a harvested fillet. As shown by Chen and others (2007) in a study examining the effect of a feed enhanced with Flax and alpha tocopherol $(\alpha-T A)$, vacuumed packed fillets were found to have a higher moisture content than the non-vacuum packed fillets stored for 6-days, but not for 8 days. This may be attributed to the fact that when muscle proteins denature during storage they partially lose their function, including water holding capacity (Chen and others 2007). Thus, the longer the trout fillets were stored, the greater the reduction of moisture 
content. This same study also concluded that although moisture is altered by storage, it is not altered due to dietary supplementation of Flax and $\alpha-T A$, or due to packing methods.

As discussed previously, as the amount of $\omega$-3 PUFA in fish feed increases, the $\omega-3$ PUFA composition of the fish will also increase. Chen and others (2006) showed the $\omega$-3 PUFA composition in rainbow trout is directly related to the amount of $\omega$-3 PUFA supplemented in their diet. In this study, the control feed contained zero flaxseed-oil (Flax), and the two treatment feeds contained $8.5 \%$ and 15\% Flax. The $\omega-3$ PUFA composition of trout fed the control feed was not nearly as high as those trout that were fed feed enhanced with 8.5\% Flax. The largest percent increase in composition occurred when the trout were fed 15\% Flax enhanced feed (Chen and others 2006). In addition to this, Wistuba and others (2006) proposed that increasing the proportion of $\omega$ 3 PUFA, such as ALA in ruminant diets may modify the fatty acid composition of ruminant meat and milk. Results of this study showed that enhancing a standard ruminant feed with fish oil, high in $\omega-3$ PUFA, increased proportions of ALA and EPA in the meat.

Supplementation of Flax and $\alpha$-TA, and packing methods also did not affect the fat content of stored fillets (Chen and others 2007). Although supplementing Flax in feed increased the $\omega$-3 PUFA concentrations in trout, it did not affect the total muscle lipid concentration in trout fillets (Chen and others 2006). Sufficient data is available to support the hypothesis that diets containing an increased amount of fat result in a significantly greater concentration of visceral fat (Gelineau and others 2001; Regost and others 2001). However, the intra-muscular fat was not significantly affected by the 
concentration of dietary fat. Additional studies have shown that feeding $\omega-3$ PUFA increase tissue $\omega$-3 PUFA (Castell and others 1972; Chen and others 2006; Mach and others 2006). However, increased tissue $\omega-3$ PUFA concentration may increase susceptibility to oxidation.

\section{FISH SPOILAGE AND OXIDATION}

Shelf life is defined as the period of time, under certain conditions of storage, for which a food product remains safe and fit for human consumption (IFST 1993). Fresh fish is highly susceptible to spoilage during storage. Throughout handling and storage there are many opportunities for the fresh flesh to deteriorate and oxidize, resulting in reduced shelf life (Jeyasekaran 2004). Many markers have been used to assess the shelf life of fish. These include changes in the microbial population, chemical changes, total volatile base nitrogen, trimethylamine content, lipid peroxidation, and changes in sensory attributes (Sallam 2007).

When the fatty acid profile of fish is altered to allow for more $\omega$-3 PUFA, shelf life becomes an issue. Due to the increased susceptibility of $\omega-3$ PUFA to oxidation, shelf life is typically lower in fish with a greater concentration of these fatty acids. Thus, there have been many studies aimed at preserving shelf life. Sallam (2007) evaluated the effect of dipping salmon slices into $2.5 \%$ aqueous solution of sodium acetate, sodium lactate, or sodium citrate and found that all treatments were able to extend shelf life while maintaining chemical quality and most sensory aspects. Findings from a study focusing on the storage temperature and preservative treatment on shelf life of freshwater silver perch (Bidyanus bidyanus), concluded that the lower the storage 
temperature the slower the bacterial development (Gelman and others 2001). Slower bacteria development resulted in a later appearance of off odor and a better estimate, from a quality point of view, of the integrity of the fish.

Lipid oxidation. Malondialdehyde (MDA) is a naturally occurring product of lipid peroxidation formed when unstable lipid peroxides decompose to form a complex series of compounds. MDA is produced as a secondary oxidation reaction product if the original fatty acid contains three or more double bonds, as in the case of $\omega$-3 PUFA (Spanier and Traylor 1991). Measuring Thiobarbituric Acid Reactive Substances (TBARS) is a well-know method for monitoring lipid oxidation and is generally preferred among food scientists for measuring rancidity and food flavor deterioration caused by lipid oxidation. Although other methods are available to measure oxidation levels in meat, Spanier and Traylor (1991) were able to provide sufficient evidence that the rapid TBARS method was just as precise and accurate as the most-widely accepted, yet time consuming and cost ineffective, distillation method of Tarladgis and others (1960).

One of the most undesirable effects on the acceptability of fish is lipid oxidation. It is one of the main problems occurring among fish and other fish-derived food products because oxidation is associated with the loss of nutritional value and flavor deterioration (Chen and others 2007). This flavor deterioration is usually marked by rancidity, particularly after cooking and during storage of such fat-containing foods (Spanier and Traylor 1991). PUFA are oxidized more easily than saturated fatty acids (SFA); therefore food products enhanced with $\omega-3$ PUFA are more prone to oxidation and rancidity. 
The deterioration of sensory characteristics that accompanies this lipid oxidation may prove to be undesirable to consumers and may reduce their demand for these types of products. Chen and others (2007) determined that refrigerated storage of $\omega-3$ PUFA enhanced trout fillets for 10 days resulted in slightly rancid fillets that were still considered acceptable. After 12 days of storage the mg of MDA / $\mathrm{kg}$ of fillets was high enough to deem the fillets unacceptable. This was based on the Ke and others (1984) correlation which proposes that TBARS values for fish products, below $0.58 \mathrm{mg} / \mathrm{kg}$ are perceived as not rancid; 0.58-1.51 mg / kg slightly rancid, but acceptable; and above $1.51 \mathrm{mg} / \mathrm{kg}$ are considered rancid. In addition to measuring the mg MDA / $\mathrm{kg}$ of sample to quantify lipid oxidation, another method used in determining if a fish product is desirable is to measure the level of trimethylamine in that product.

Trimethylamine $\mathrm{N}$-oxide. Trimethylamine $\mathrm{N}$-oxide (TMAO) is abundant in the tissues of marine fish and invertebrates, and is also found in the flesh of few freshwater fish species (Dos Santos and others 1998; Haard 2000). TMAO acts to protect proteins against denaturation in abusive or non-favorable conditions. However, various bacteria can grow anaerobically using TMAO as an alternative terminal electron acceptor. During this reaction TMAO is reduced to volatile trimethylamine (TMA). TMA particularly contributes to the characteristic ammonia-like and 'fishy' off-flavors and odors rendering these products undesirable for human consumption (Gram and Dalgaard 2002).

TMA content in fresh fish has been shown to increase over storage time. During storage, TMAO reduction to TMA begins in the slime of the skin, causing loss of firmness and color in the flesh beneath (McWilliams 1992). Sallam and others (2007) 
noticed that over a 6 day period the TMA content slowly increased in fresh sliced salmon stored at $1^{\circ} \mathrm{C}$. By day 9 and beyond, TMA values increased steadily with a total increase of about $6.00 \mathrm{mg} / 100 \mathrm{mg}$ flesh. In sensory evaluations, fish deemed undesirable by the sensory panel had a TMA value of $<4 \mathrm{mg}$ TMA / $100 \mathrm{~g}$ of salmon flesh. Sallam and others (2007) also proposed that the amount of TMA was low during the edible storage period and increased only rapidly when the fish was near rejection. Therefore this may not necessarily be a good marker for fish spoilage in early stages of stored fish; however it may be effective in later stages.

Yet another marker of fish spoilage is muscle $\mathrm{pH}$. The $\mathrm{pH}$ of live fish is close to 7, and the postmortem $\mathrm{pH}$ of fish muscle can vary between 6.0 to 7.1 , depending on season, species, and other factors (Simeonidou and others 1998; Church 1998). Postmortem $\mathrm{pH}$ decline is caused by lactic acid generated from glycolysis under anoxic conditions (Kamireddy and others 2003). The rate and extent of $\mathrm{pH}$ decline influences meat quality (Ashie and others 1996); whereas during extended storage $\mathrm{pH}$ increases due to ammonia and amines produced by bacteria.

\section{SENSORY EVALUATION}

The most important aspect of sensory evaluation is to remain as consistent as possible throughout the testing in relation to the test room, the product, and the panel (Meilgaard 1999). Controlling for these three aspects is crucial to gathering data that is useful and credible to either support or disprove the hypothesis being tested. The test environment, the preparation of samples, the equipment used, and the procedure used by the panelists when evaluating a sample in question must remain consistent 
(Meilegaard 1999). In order to conduct an objective and effective sensory test on fish products the assessors must be able to perform the sensory tasks required, must be trained in the specific applications of the test method, and must be monitored for their ability to complete the tasks (CODEX 1999).

Consumers make purchases based on quality and cost and up to a certain limit, the benefit of quality outweighs the cost (Bett 1997). It is necessary for sensory characteristics to be evaluated prior to exposing the product to consumers to ensure that quality is up to the required standards. Such qualities include characteristics that are external (appearance, feel), internal (taste, aroma, texture), and technical (nutrition, safety) (Shewfelt 1990). Several studies involving shelf life and sensory evaluation of fish have focused on characteristics such as appearance, odor, fish flavor, aftertaste, tenderness, and juiciness (Sallam 2007; Drobna and others 2006). Other studies have performed triangle tests and difference tests to determine the odd sample, and tests to determine preference of one sample over another (D'Souza and others 2006).

When developing a product focused on modifying the fatty acid composition in fish, the acceptance of that product by the consumers must be ensured. The overall satisfaction of the product will depend on characteristics such as appearance, taste, aroma, and texture however, the product must also offer the benefits that producers claim it offers, whether nutritional, health beneficial, or functional in another way.

\section{SUMMARY}

Enhancing fish feed with an ALA-rich source, such as flaxseed-oil, increases the $\omega-3$ PUFA content of the fish fillets, which in turn may have a positive health benefit for 
the humans that consume these fillets. Chen and others (2006) showed that increased dietary ALA changed the fatty acid profile of rainbow trout. The trout that consumed flaxseed-oil enhanced feed had a higher concentration of $\omega$-3 PUFA than the trout that were fed a control diet. This is significant, as recent research has shown the benefits of $\omega-3$ PUFA on decreasing inflammation associated with various diseases. Human consumption of $\omega-3$ PUFA enhanced fish provides a way to incorporate these fatty acids into the diet and may aid in lowering the $\omega-6 / \omega-3$ ratio from the average $25: 1$, to the recommended 4:1.

On the other hand increasing the $\omega$-3 PUFA content of fish may promote oxidation, causing faster spoilage and a decreased shelf life. The higher amount of double bonds in these fatty acids allow carbons to be more readily available for oxidative attack. Therefore, before a product like this becomes available to consumers, the shelf life stability should be evaluated. Potential consumers need to deem the fish acceptable, or even superior to the original product. All factors, nutritional and healthrelated benefits, sensory characteristics, and shelf life must be investigated in order to develop a marketable product that can compete as a value-added food product.

In addition to nutritional and health-related benefits associated with a valueadded fish product, such as $\omega-3$ PUFA enhanced trout, overall satisfaction of such a product may result in increased demand for that product. This may create opportunity for trout growers using small flowing water systems. However, the effect of increased oxidation must also be taken into account in terms of shelf life, spoilage, and overall desirability of the trout. This study further investigated the shelf life and sensory 
characteristics of $\omega-3$ PUFA enhanced trout to determine if such a product can be developed that will thrive as value-added food product. 


\section{REFERENCES}

Arterburn LM, Hall EB, Oken H. 2006. Distribution, interconversion, and dose response of n-3 fatty acids in humans. Am J Clin Nutr. 83(suppl):1467s-1476s.

Ashie INA, Smith JP, Simpson BK. 1996. Spoilage and shelf-life extension of fresh fish and shellfish. Critical Reviews in Food Science and Nutrition. 36(1\&2):87-121.

Barre DE. 2007. The Role of consumption of alpha linolenic eicosapentaenoic and docosahexaenoic acids in human metabolic syndrome and type 2 diabetes- a minireview. JOS. 56(7):319-325.

Benatti P, Peluso G, Nicolai R, Calvani M. 2004. Polyunsaturated fatty acids: biochemical, nutritional and epigenetic properties. Journal of the American College of Nutrition. 23(4):281-302.

Bett KL. 1997. Flavor-quality control in freshwater aquaculture. The Progressive FishCulturist. 59:149-154.

Castell JD, Sinnhuber RO, Wales JH, Lee J. 1972. Essential fatty acids in the diet of rainbow trout (SaJmo gairdneri): growth, feed conversion and some gross deficiency symptoms. J Nutr. 102 (1):77-85.

Chen Y- C, Nguyen J, Semmens K, Beamer S, Jaczynski J. 2006. Enhancement of omega-3 fatty acid content in rainbow trout. JFS. 71(7):383-389.

Chen Y- C, Nguyen J, Semmens K, Beamer S, Jaczynski J. 2007. Chemical changes in omega-3-enhanced farmed rainbow trout (Oncorhynchus mykiss) fillets during abusivetemperature storage. Food Control. 19(6):599-608.

Chen Y- C, Nguyen J, Semmens K, Beamer S, Jaczynski J. 2007. Physiochemical changes in omega-3-enhanced farmed rainbow trout (Oncorhynchus mykiss) muscle during refrigerated storage. Food Chemistry. 104:1143-1152.

Church N. 1998. MAP fish and crustaceans sensory enhancement. Food Sci Tech Tod. 12(2):73-83. Bull Jap Soc Sci Fish. 24:749-750.

CODEX. 1999. CODEX guidelines for the sensory evaluation of fish and shellfish in laboratories. CAC-GL 31-1999. pp 1-33.

Dos Santos JP, Iobbi-Nivol C, Couillault C, Giordano G, Mejean. 1998. Molecular analysis of the trimethylamine $\mathrm{N}$-oxide (TMAO) reductase respiratory system from a shewanella species. J Molec Biol. 284:421-433. 
Drobná Z, Zelenka J, Mrkvicova E, Kladroba D. 2006. Influence of dietary linseed and sunflower oil on sensory characteristics of rainbow trout (Oncorhynchus mykiss). Czech J Anim Sci. 51(11):475-482.

D'Souza N, Skonberg DI, Stone DAJ, Brown P. 2006. Effect of soybean meal-based diets on the product quality of rainbow trout fillets. JFS 71(4):s337-s342.

Gebauer SK, Psota TL, Harris WS, Kris-Etherton PM. 2005. n-3 Fatty acid dietary recommendations and food sources to achieve essentiality and cardiovascular benefits. Am J Clin Nutr. 83(suppl):s1526-1535s.

Gelineau A, Corraze G, Boujard T, Larroquet L, Kaushil S. 2001. Relation between dietary lipid level and voluntary feed intake, growth, nutrient gain, lipid deposition, and hepatic lipogenesis in rainbow trout. Reproduction Nutrition Development. 41:487-503.

Gelman A, Glatman L, Drabkin V, Harpaz S. 2001. Effects of storage temperature and preservative treatment on shelf life of the pond-raised freshwater fish, silver perch (Bidyanus bidyanus). Journal of Food Protection. 64(10):1584-1591.

Gram L, Dalgaard P. 2002. Fish spoilage bacteria-problems and solutions. Current Opinion in Biotechnology. 13:262-266.

Haard NF, Simpson BK. 2000. Seafood enzymes: utilization and influence on post harvest seafood quality. Boca Raton, Florida: CRC Press LLC.

Hardy RW. 1990. Farmed fish and omega-3 fatty acids. Aquaculture Magazine. 29:6365.

IFST. 1993. Shelf life of foods - guidelines for its determination and prediction. IFST. London.

Jeyasekaran G, Ganesan P, Maheswari K, Jeya Shakila R, Sukumar D. 2004. Effect of delayed icing on the microbiological quality of tropical fish: barracudas (Sphyraena barracuda). JFS. 69 (7):197-200.

Jump DB. 2001. The biochemistry of n-3 polyunsaturated fatty acids. JBC. 227(11):8755-8758.

Ke PJ, Cervantes E, Robles-Martinez C. 1984. Determination of thiobarbituric acid reactive substances (TBARS) in fish tissue by an improved distillation spectrophotometric method. Journal of the Science of Food and Agriculture. 35:12481254.

Leaf A, Kang JX, Xiao YF, Billman GE. 2003. Clinical prevention of sudden cardiac death by $n-3$ polyunsaturated fatty acids and mechanism of prevention of arrhythmias by n-3 fish oils. Circulation: Journal of the American Heart Association. 107:2646-2652. 
Mach N, Devant M, DI'az I, Font-Furnold M, Oliver MA. 2006. Increasing the amount of $\mathrm{n}-3$ fatty acid in meat from young Holstein bulls through nutrition. J Anim Sci.

84(11):3039-48.

Meilgaard M, Civelle GV, Carr BT. 1999. Sensory evaluation techniques. Third ed. Boca Raton, Florida: CRC Press LLC.

National Research Council. 1993. Composition of feed ingredients. Washington, DC: National Academy Press. P64-71.

Regost C, Arzel J, Cardinal M, Laroche M, Kaushik SJ. 2001. Fat deposition and flesh quality in seawater reared, triploid brown trout (Salmo trutta) as affected by dietary fat levels and starvation. Aquaculture. 193:325-345.

Romans JR, Wulf DM, Johnson RC, Libal GW, Costello WJ. 1995. Effects of ground flaxseed in swine diets on pig performance and on physical and sensory characteristics and omega-3 fatty acid content of pork: II. Duration of $15 \%$ dietary flaxseed. Journal of Anim Sci. 73:1987-1999.

Sallam KI. 2007. Chemical, sensory and shelf life evaluation of sliced salmon treated with salts of organic acids. Food Chem. 101(2):592-600.

Sargent JR, Bell JG, Bell WV, Henderson RJ, Tocher DR. 1995. Requirement criteria for essential fatty acids. Journal of Applied Ichthyology. 11 (3-4):183-198.

Shewfelt RL. 1990. Quality of fruits and vegetables. Food technology. 44(6):99-106.

Simeonidou S, Govaris K, and Vareltzis K. 1998. Quality assessment of seven Mediterranean fish species during storage on ice. Food Res Int. 30(7):479-484.

Spanier AM, Traylor RD. 1991. A rapid, direct chemical assay for the quantitative determination of thiobarbituric acid reactive substances in raw, cooked, and cooked/stored muscle foods. Journal of Muscle Foods. 2:165-176.

Surette ME. 2008. The science behind dietary omega-3 fatty acids. CMAJ. 178(2):177180.

Tarladgis BG, Watts BM, Younathan MT, Dugan LR. 1960. A distillation method for the quantitative determination of molonaldehyde in rancid foods. J Amer Oil Chem Soc. 37:44-48.

USDA: US Department of Health and Human Services. 2005. Dietary Guidelines for Americans (HHS publication number: HHS-ODPHP-2005-01-DGA-A). Washington, DC: U.S. Government Printing Office. 
Waagbo R, Sandness K, Torrissen OJ, Scandvin A, Lie O. 1993. Chemical and sensory evaluation of fillets from Atlantic salmon (Salmo salar) fed three different levels of $n-3$ polyunsaturated fatty acids at two levels of vitamin E. Food Chemistry. 46:361366.

Wistuba TJ, Kegley EB, Apple JK. 2006. Influence of fish oil in finishing diets on growth and performance, carcass, characteristics, and sensory evaluation of cattle. J Anim Sci. 84:902-999. 


\section{CHAPTER III}

THE EFFECT OF A FLAXSEED-OIL ENHANCED DIET ON THE SHELF LIFE AND SENSORY CHARACTERISTICS OF FARMED BROOK TROUT (Salvelinus fontinalis) 


\section{ABSTRACT}

The effect of dietary modification with flaxseed-oil (Flax) enhanced feed on the sensory characteristics and shelf life of brook trout fillets was examined. The diets were composed of a commercial feed supplemented either with fish oil (control diet, CD) or Flax (treatment diet). Trout were fed one of the two diets for 165 days before harvesting. Proximate composition (total fat, protein, moisture, and ash) and fatty acid profile (FAP) were determined on boneless, skinless fillets. Sensory evaluation included a triangle test for difference, paired preference test for preference, and an attribute evaluation of fish odor, oxidized odor, juiciness, stickiness, fish flavor, vegetable oil flavor, and aftertaste. Shelf life of vacuum packed fillets was examined over an 11 day period at refrigerated storage $\left(4^{\circ} \mathrm{C}\right)$. Color analysis $\left(\mathrm{L}, \mathrm{a}^{\star}, \mathrm{b}^{\star}\right)$, muscle $\mathrm{pH}$, and thiobarbituric acid reactive substances test (TBARS) were evaluated on days 1 , $3,5,7,9$, and 11 . There were no differences in proximate composition between the Flax and CD fillets. FAP of the Flax fillets showed five times more alpha linolenic acid (ALA, 18:3n3) $(P<0.05)$ compared to CD fillets; however, there was less eicosapentaenoic acid (EPA, 20:5n3) and docosahexaenoic acid (DHA, 22:6n3) $(P<$ $0.05)$ in Flax fillets. Total omega-3 fatty acids were greater in the Flax fillets $(P<0.05)$. Sensory panelists were not able to choose the odd sample in two triangle tests; however, there was a significant preference for the treatment fillets $(P<0.05)$. CD fillets were found to have greater $(P<0.05)$ fish odor and fish flavor than the Flax fillets. Flax fillets showed significant $(P<0.05)$ increases in color $L$ over the 11 day storage period. Color values $\mathrm{a}^{\star}$ and $\mathrm{b}^{\star}$ were not affected by diet or duration of storage. Muscle $\mathrm{pH}$ decreased overtime $(P<0.05)$ and lipid oxidation was controlled during storage as 
indicated by consistent TBARS values $(P>0.05)$; there were no significant differences between the Flax or CD fillets over time $(P>0.05)$. These results indicate that a Flax enhanced diet would have favorable effects on the product quality of farmed brook trout fillets.

Keywords: omega-3 fatty acids; Brook trout; shelf life; sensory evaluation; lipid oxidation 


\section{INTRODUCTION}

Alpha linolenic acid (ALA, 18:3n3) can be metabolically converted to eicosapentanoic acid (EPA, 20:5n3) and docosahexanoic acid (DHA, 22:6n3) however this conversion appears to be relatively inefficient in humans (Voss and others 1991). This inefficiency is attributed to competition for incorporation into membrane phospholipids between ALA and omega- 6 polyunsaturated fatty acids ( $\omega-6$ PUFA) (Aterburn 2006). Due to this low conversion rate, it is suggested that DHA and EPA be consumed in the diet. The most prevalent dietary sources of DHA and EPA for humans are fish and fish oils, especially trout and other types of fatty fish (Surette 2008).

Incorporating adequate amounts of omega- 3 polyunsaturated fatty acids ( $\omega-3$ PUFA) into a diet can be achieved by consuming fish, particularly tuna, salmon, sardines, herring, and trout (USDA 2005). These fatty fish are higher in EPA and DHA compared to lean fish. According to the USDA Dietary Guidelines for Americans (2005), it is suggested that consuming approximately two servings of fish per week may reduce the risk of mortality from coronary heart disease. Furthermore, consumption of EPA and DHA may reduce the risk of mortality from cardiovascular disease in people who have already experienced a cardiac event.

In addition to the already high content of EPA and DHA naturally occurring in fish such as trout, it may be of further benefit to human health to consume trout supplemented with flaxseed-oil (Flax), a rich source of ALA. Flax contains 53.3\% ALA, the highest concentration of ALA among plant-derived oils (National Research Council 1993). According to Chen and others (2006), feed enhanced with Flax and fed to rainbow trout nearly doubled the $\omega$-3 PUFA content of the trout flesh. Furthermore, 
Romans and others (1995) reported that the flavor of an $\omega$-3 PUFA enhanced pork product was preferred to the flavor of a non-enhanced product. These observations suggest that changing the fatty acid profile of the feed by adding Flax may influence the taste of the flesh, as well as provide a higher content of health-beneficial $\omega-3$ PUFA.

Additionally, dietary modification of fish feed with Flax may open up greater opportunities for trout growers using small flowing water systems to produce a valueadded product that is not generally available as food fish. West Virginia aquaculture can be characterized by small flowing water systems for the production of trout, particularly native brook trout. Brook trout have the reputation of having slightly better flesh quality than rainbow trout. Farm raised brook trout are most often used in recreational markets and therefore are not readily available to the food fish market. It is proposed that brook trout fed Flax enhanced feed may represent a potential niche market for West Virginia producers.

Although increasing the $\omega-3$ PUFA content of brook trout fillets may create an opportunity to market the fillets as food fish, it may also increase the likelihood for development of off-odors, off-flavors, and increased oxidation (Chen and others 2007; Waagbo and others 1993). Along with this potential increase in oxidation and spoilage of fish fillets, a subsequent decrease in acceptability among consumers is of concern. There are potential human health risks with increased consumption of oxidized food products (Chen and others 2007; Waagbo and others 1993). Lipid peroxidation may give rise to substances harmful to health such as mutagens, promoters, and carcinogens (Ježek and Buchtová 2007). Common undesirable sensory traits that are 
associated with oxidation and spoilage of seafood include fishy taste or smell, metallic (oxidized) odor, and the presence of a strong aftertaste.

Shelf life is defined as the period of time, under certain conditions of storage, for which a food product remains safe, fit for human consumption, and acceptable (IFST 1993). Fresh fish is highly susceptible to spoilage during storage. Throughout handling and storage there are many opportunities for the flesh to deteriorate and oxidize, resulting in reduced shelf life. When the fatty acid profile of fish is altered to allow for more $\omega-3$ PUFA, oxidation becomes an issue. Due to the relationship between oxidation and the production of off flavors and off odors, the increased susceptibility of $\omega$-3 PUFA to oxidation may reduce shelf life in fish with a greater concentration of these fatty acids.

Development of a value-added fish product, such as $\omega-3$ PUFA enhanced trout, may offer superior flavor and health benefits. Overall satisfaction of such a product may result in a growing market and increased demand for that product, ultimately opening up more opportunities for trout growers using small flowing water systems to expand into the fresh fish market. Brook trout fed Flax enhanced feed may represent a potential niche market for West Virginia producers. However, modifying the $\omega-3$ PUFA concentration of the feed and hence the fatty acid profile of the fillets, may affect rates of oxidation. Oxidation must be taken into account in terms of shelf life, spoilage, and overall desirability and consumer preference for the trout. This study aimed to determine the effect of Flax enhanced feed on the fatty acid profile of brook trout and the consequent effects on shelf life and associated sensory characteristics of the fillets. 


\section{MATERIALS AND METHODS}

\section{Brook Trout and Diets}

Brook trout fingerlings were raised at Reymann Memorial Farm aquaculture facility (Wardensville, WV). The fingerlings were randomly divided into a control group (CD) and a treatment group (Flax). The fish were stocked at nine months old at an average weight of $0.15 \mathrm{~kg}$ and an average length of $230 \mathrm{~mm}$. They were fed dry pelleted commercial feed containing $40 \%$ protein and $21 \%$ fat (Zeigler Brothers Inc., Gardners, PA) (Table 1) for 165 days before harvesting. Upon drying and extrusion, the feed was sprayed with $6.2 \%$ menhaden oil (CD) or $6.4 \%$ flaxseed-oil (Flax). The fish were fed from either one batch of CD feed or one batch of Flax feed. Feed was stored at $40^{\circ} \mathrm{C}$.

Trout were raised in a spring-fed gravity flow-through raceway system with two parallel lanes, each lane with three tanks. Trout groups were separated into the two lanes. Water was aerated as it entered the system at the head of each raceway unit to maintain a dissolved oxygen concentration above $70 \%$ saturation. Water temperature was approximately $12^{\circ} \mathrm{C}$ during the feeding trial. Daily recordings were conducted on each tank including amount of feed administered, oxygen concentration in each tank, and number of mortalities.

Upon reaching an average weight of $0.56 \mathrm{~kg}$ and an average length of $403 \mathrm{~mm}$, approximately 400 days after hatching, the trout were filleted, vacuum packed, and frozen. Fillets were transported to West Virginia University in a temperature-controlled environment and were stored at $-20^{\circ} \mathrm{C}$ until further evaluation. 


\section{Shelf Life Study}

Sample preparation. All shelf life analyses were performed on raw fillets. On day 0 , eighteen $\mathrm{CD}$ and eighteen Flax fillets were removed from storage at $-20^{\circ} \mathrm{C}$ and placed in an incubator set at $4^{0} \mathrm{C}$ to thaw. Analyses were conducted at approximately the same time each day at two-day intervals from day 1 until day 9 and then again on day 11. On each of the test days, three $C D$ and three Flax fillets were removed from the $4^{\circ} \mathrm{C}$ incubator and kept on ice until analyses were conducted.

Color analysis. Colorimetric assessments were performed to monitor the changes of color over an 11-day storage period. Color analyses were conducted on intact fillets. Differences between the CD and Flax fillets were analyzed and compared using a chromameter (Model CR-300; Minolta Camera Co. Ltd., Osaka Japan) calibrated with a standard white plate No.21333180 (CIE L* 93.1; $a^{\star} 0.3135 ; b^{\star} 0.3198$ ). Values of L* (lightness; scale: 0 - 100), $a^{*}$ (intensity in red color; scale: $-60-+60$ ), and $b^{*}$ (intensity in yellow color; scale: $-60-+60$ ) were measured three times at the cranial, caudal, and midsection of the right or left fillet.

Muscle pH. The decline in muscle $\mathrm{pH}$ over the shelf life was monitored. Fillets were skinned and homogenized. Ten grams of homogenate was mixed with $100 \mathrm{~mL}$ distilled, deionized water as described by Rhee and others (1984); Turner and others (1998). The remaining portion of fillet was powdered in liquid nitrogen, vacuum packed and stored at $-80^{\circ}$. The $\mathrm{pH}$ of the slurry was measured using a $\mathrm{pH} /$ ion analyzer (Model 350, Corning Inc.; Corning NY, USA) with a general purpose combination probe. The $\mathrm{pH}$ was measured in triplicate with the slurry agitated between measurements. 
Thiobarbituric acid reactive substances test. Lipid oxidation was quantified in powdered samples of $\mathrm{CD}$ and Flax fillets using the thiobarbituric acid reactive substances (TBARS) test. CD and Flax samples were tested in triplicate using the TBARS test described by Yu and Sinnhuber (1957). The color absorbance was read at $532 \mathrm{~nm}$, and the TBARS value was calculated using the following equation: Sample TBARS $=\mathrm{Ks} \times \mathrm{A} \times 5 / \mathrm{Wt}(\mathrm{A}=$ absorbance of sample, $\mathrm{Wt}=$ exact sample weight, $\mathrm{Ks}=$ constant obtained from the slope of the standard curve.) The results were reported as mg malondialdehyde per $\mathrm{kg}$ sample.

Proximate composition. Proximate composition was determined in triplicate according to the Association of Official Analytical Chemists methods (1995) and was expressed as percent by weight on dry basis.

Fat content in fillets was determined according to the Soxhlet extraction method (AOAC 920.39). Sample size was 1-1.5 g and extraction time was 18-24 hours at a drip rate of 200 drips/ minute. Extractions were performed with petroleum ether.

Moisture content was determined by placing $4.5-5 \mathrm{~g}$ samples in a $70^{\circ} \mathrm{C}$ oven to dry to a constant weight (16 hours). Partial vacuum pressure was equivalent to $20 \mathrm{~mm}$ Hg. Dried samples were placed in a desiccator and cooled to room temperature. Samples were weighed and \% moisture was calculated using the following equation (AOAC 925.09): \% Moisture $=$ [sample weight $(\mathrm{g})-$ dry weight $(\mathrm{g}) /$ sample weight $(\mathrm{g})$ ] *100.

Ash content was quantified by weighing 2-3 $\mathrm{g}$ of sample in a crucible and placing in a muffle furnace ignited at $525^{\circ} \mathrm{C}$ until light gray ash resulted, or until a constant weight was reached (12 hours). Samples were removed and placed in a desiccator to 
cool. Upon reaching room temperature samples were weighed and $\%$ ash was calculated using the following equation (AOAC 932.03): \% Ash = [weight of ash(g) / weight of original sample $(\mathrm{g})] * 100$.

Crude protein was determined using the Kjeldahl method. Two blank tubes were prepared and run in preparation for sample tubes. A sample was weighed $(0.25$ g), folded into Whatman \#1 paper, and placed in labeled Kjeldahl tubes. One Kjeltab was dropped into each tube followed by the addition of $10 \mathrm{~mL}$ of sulfuric acid. Samples were digested for $5-10$ minutes at $420^{\circ} \mathrm{C}$ with maximum airflow. Airflow was then reduced and samples were further digested for 40-45 minutes. Distilled water was added $(75 \mathrm{~mL})$ and the tubes were placed in a Kjeltec 1030 Auto Analyzer to run. Results were recorded in $\mathrm{mL}$ of acid. Crude protein percentage was determined using the following equations:

$\%$ Nitrogen $=(\mathrm{mL}$ acid titrated $*$ normality of $\mathrm{HCl} * 14.01) /[(a * \% \mathrm{DM}) * 10)]$ $\%$ Crude protein $=\%$ Nitrogen $* 6.25$

Fatty acid profile. Fatty acid profile was performed in triplicate at the University of Missouri-Columbia according to the Association of Official Analytical Chemists methods (1995). Fat and fatty acids were extracted from biomass by the acidic hydrolysis method (AOAC 996.06). Pyrogallic acid was added to minimize oxidative degradation of fatty acids during analysis. Triglyceride, triundecanoin (C11:0), was used as internal standard. Fat was extracted into ether, then methylated to fatty acid methyl esters (FAMEs) using boron trifluoride (BF3) in methanol. FAMEs were quantitatively measured by capillary gas chromatography against the C11:0 internal standard. All samples were analyzed on a gas-liquid chromatography (Agilent 
Technologies, Model 7890A) equipped with a 7683B series Injector. Helium was used as the carrier gas with a $0.75 \mathrm{~mL} / \mathrm{min}$ flow rate. The temperature program for separations began at $100^{\circ} \mathrm{C}$, held for $4 \mathrm{~min}$, increased to $240^{\circ} \mathrm{C}$ at $3^{\circ} \mathrm{C} / \mathrm{min}$ and held for $15^{\circ} \mathrm{C}$. Temperatures for injector and detector were 225 and $285^{\circ} \mathrm{C}$ respectively. Peaks were identified by comparing their retention times with references. Total fat was calculated as sum of individual fatty acids expressed as triglyceride equivalents.

\section{Sensory Evaluation}

Thermal processing of fillets. Prior to sensory evaluation, frozen fillets $\left(-20^{\circ} \mathrm{C}\right)$ were placed in an incubator set at $4^{\circ} \mathrm{C}$ to thaw overnight. Refrigerated fillets $\left(4^{\circ} \mathrm{C}\right)$ were baked at $204.4^{\circ} \mathrm{C}$ for 12 minutes or until an internal temperature of at least $65.5^{\circ} \mathrm{C}$ was reached. Samples were cut into $2.54 \mathrm{~cm}$ cubes, placed in 2-oz plastic cups, assigned a random 3-digit code, and fitted with plastic lids. Samples were stored in a warming oven for no more than 45 minutes to maintain an internal temperature of $65.5^{\circ} \mathrm{C}$ until sensory testing occurred.

Difference testing. Difference testing was conducted with a total of 55 panelists, over the age of eighteen years that were recruited from West Virginia University. Two panelists did not correctly fill out their scorecards and their responses were excluded, leaving a total of 53 panelist responses. A triangle test was used to determine if panelists were able to detect a difference between CD and Flax fillets. Generally, 20 to 40 subjects are used for triangle tests, however in this case 55 subjects were recruited to increase significance (Meilgaard and others 1999). Participants performed two successive triangle tests, accounting for replication and representing a 
balanced order of presentation. All combinations of the two samples were presented within each sensory session an equal number of times. Prior to testing, participants were given a brief orientation on the testing methods and were required to complete a consent form, approved by the Institutional Review Board at West Virginia University.

Panelists were informed that two samples were identical and one was different. They were asked to evaluate each sample from left to right, select the odd sample, and record it on a scorecard. Panelists were provided with room temperature water and unsalted crackers and were advised to consume these in-between samples to cleanse their palate. Panelists were asked to base their choice on taste only, and to disregard other sensory characteristics such as moisture or color. Panelists were also offered the option of going back and repeating the evaluation of each in the order of presentation, while the test was in progress.

Preference testing. A preference test immediately followed the triangle test. Panelists were presented with samples from Flax and CD fillets and asked to choose the sample they preferred based on flavor. Samples were coded and presented in a balanced order.

Sensory attribute testing. Sensory attribute testing was performed on fresh fillets that had been stored overnight in a $4^{\circ} \mathrm{C}$ environment. A total of 12 panelists, over the age of eighteen years, were recruited from Davis College of Agriculture, Forestry, and Consumer Sciences to participate in the test. Prior to testing, panelists attended a one-hour training session to become familiar with testing procedures, be instructed on how to properly evaluate samples, and be able to identify the sensory characteristics being tested. 
Panelists evaluated three $C D$ and three Flax samples. Prior to tasting, the conductors of the sensory panel evaluated and scored the sensory characteristics of previously frozen, day 0 fillets to be used as a reference sample for the panelists. Unlimited amounts of reference sample were available to panelists for comparison purposes. Panelists were asked to use the reference fish as a basis for comparison. Panelists were provided with room temperature water and unsalted crackers and were advised to consume these in-between samples to cleanse their palate. $C D$ and Flax samples were blind- coded with a random 3-digit number and were randomly presented to panelists one at a time. Panelists were asked to evaluate the following attributes: fish odor, oxidized odor, juiciness, stickiness, fish flavor, vegetable oil flavor, and aftertaste. Results were recorded on a $10 \mathrm{~cm}$ scale; with 1 representing a small presence of the attribute and 10 representing a large presence of the attribute.

\section{Statistical Design}

All shelf life evaluations were performed in triplicate. A 2x6 factorial experiment in a completely randomized design was performed. Means separation was analyzed using Tukey's Honestly Significant Differences Test $(P<0.05)(J M P 7$, SAS Institute, Cary, NC, USA).

The data for each triangle test was analyzed by the number of correct responses versus the total number of responses. Because 2 sets of 3 samples were presented to each panelist, responses were considered correct only when the panelist was able to identify the odd sample for both presentations. The critical number of correct responses for significance was out of 53. Significance for triangle and preference tests were 
analyzed by probability tables found in Meilgaard and others (1999). Statistical significance was accepted at $P<0.05$. 


\section{RESULTS AND DISCUSSION}

\section{Proximate Composition}

No significant differences $(P>0.05)$ in moisture, protein, fat, or ash content were found among trout fillets from the two diets. This is to be expected as both feeds contained the same macronutrient composition (Table 1). Average values were $77.0 \%$, $18.9 \%, 4.4 \%$, and $1.3 \%$, respectively. Similar results were noted when soybean meal was used as an alternate protein source to fish meal and fed to rainbow trout (D'Souza and others 2006; Adelizi and others 1998).

\section{Shelf Life}

Color analysis. Color and appearance of muscle have direct influence on value and acceptance of most fish species and meat products (Yagiz and others 2007). Total myoglobin content of fish muscle will greatly impact the fillet color (Haard 1992). The various colors in meat are produced based on the relative proportions of forms of myoglobin to hemoglobin. A bright red color appears from an increasing proportion of oxy-myoglobin/hemoglobin; a dark red color appears from an increasing proportion of myoglobin/hemoglobin; and a gray or brownish color appears from an increasing proportion of met-myoglobin/hemoglobin. Denaturation of muscle proteins following slaughter shifts myoglobin initially to the oxidized met-myoglobin/hemoglobin form and then to the irreversibly denatured form, significantly affecting muscle color (Yagiz and others 2007). In terms of $L, a^{\star}$, and $b^{\star}$ values, the denaturation of myoglobin is typically displayed as an increase in $L$ (lightness), and decrease in $\mathrm{a}^{\star}$ (redness) and $\mathrm{b}^{\star}$ (yellowness) of the muscle. Our fillets did experience an increase in $L$ over the storage 
period as myoglobin denaturation set in, however there were no changes in color $\mathrm{a}^{*}$ or color $b^{*}$.

A significant $(P<0.05)$ diet by storage time interaction was observed for $L$ values (Figure 1). Both groups experienced an initial decrease in lightness. CD fillet $L$ values decreased until day 5. A significant increase $(P<0.05)$ in lightness was noted between day 5 and day 7 . Flax fillets experienced a similar decrease in $L$ values until day 3 . On day 5 a significant increase $(P<0.05)$ in lightness was noted. Flax fillets did experience an overall increase $(P<0.05)$ in lightness over the storage period, while an overall increase in lightness failed to reach statistical significance in CD fillets. Similar to these findings, Kamireddy and others (2003) reported darker rainbow trout fillets (lower L values) stored at $0^{\circ} \mathrm{C}$ at day 0 and day 3 than at day 6 and day 9. Ježek and Buchtová (2007) examined the physical and chemical changes of stored fresh chilled carp muscle over a 15 day storage period and reported a similar increase in $L$ values. This increase is attributed to the denaturation of myoglobin and subsequent muscle color change.

Flax fillets were lighter $(P<0.05)$ than CD fillets only at day 5 , indicating a more rapid denaturation of myoglobin than Flax fillets. There was no significant difference between groups for the remaining days. Color values $\mathrm{a}^{\star}$ and $\mathrm{b}^{*}$ were not $(P>0.05)$ affected by diet or duration of storage. A trend toward increasing $a^{*}$ and $b^{\star}$ values from day 1 to day 11 for $C D$ and Flax fillets is shown, but the trend was not statistically significant. There is a trend toward greater $a^{\star}$ values in Flax fillets, but the trend is not statistically significant (Figure 2; Figure 3)

Muscle pH. CD and Flax fillets showed a decrease $(P<0.05)$ in muscle pH at days 9 and 11, with Flax fillets reaching a lower $\mathrm{pH}(P<0.05)$ on these days (Table 2$)$. 
Foegeding and others (1996) indicate a range of 6.2 to 6.6 for ultimate $\mathrm{pH}$ of lean white fish. Over the 11 day shelf life study, the CD fillets remained within this range of acceptable pH until day 11 when $\mathrm{pH}$ dropped to $6.03(P<.0001)$. The Flax fillets dropped below this optimal level to 6.08 beginning at day $9(P<.0001)$.

Initially a slight increase in the muscle $\mathrm{pH}$ of the Flax fillets was observed. During storage autolytic and proteolytic changes take place in muscle tissue of fresh chilled fish (Ježek and Buchtová 2007). The trend toward initial increase in muscle pH is explained by the accumulation of alkaline compounds by means of autolytic and/or microbial mechanisms (Hebard and others 2008). However, as muscle proteins are cleaved to peptide chains, free amino acids, and ammonia, an acidic environment is formed; lowering the muscle $\mathrm{pH}$ as was observed in $\mathrm{CD}$ and Flax fillets. Another mechanism that may cause a decrease in muscle $\mathrm{pH}$ is the formation of carbonic acid and microbial products from the denaturation of muscle. Ježek and Buchtová (2007) reported that over a 15 day storage period the muscle $\mathrm{pH}$ of carp was reduced in response to $\mathrm{CO}_{2}$ diffusion to muscle tissue and parallel formation of carbonic acid. Stenstrom (1985) also found acid products of microflora to decreased muscle $\mathrm{pH}$.

Fatty acid profile. There was a significant difference $(P<0.05)$ in the concentrations of ALA, EPA, and DHA in the CD and Flax fillets (Table 3). Five times more $(P<0.05)$ ALA was found in the Flax fillets when compared to CD fillets. Conversely, there was less $(P<0.05)$ DHA and EPA in the Flax fillets than the CD fillets. These results are consistent with Chen and others (2006) who found that in rainbow trout supplemented with either $8.5 \%$ or $15 \%$ dietary Flax, ALA concentrations were $230.5 \%$ and $447.5 \%$ higher respectively, and EPA and DHA concentrations were 
lower, when compared to trout fed a basal diet containing menhaden oil. It is well known that fish oil contains a great amount of EPA and DHA, and Flax contains a great amount of ALA, the precursor of EPA and DHA. Buzzi and others (1996) claimed that rainbow trout can convert short chain $\omega$-3 PUFA (ALA) to long chain $\omega$-3 PUFA (EPA and DHA). Chen and others (2006) did not witness this conversion, as a decrease in EPA and DHA concentrations and an increase in ALA concentrations was observed over 120 days of feeding. In our study, CD and flax fish ALA, EPA, and DHA concentrations numerically increased over the feeding period (Figure 4). It is speculated that the increases in EPA and DHA in the CD fish were a result of the increased EPA and DHA in the diet from fish oil. In the Flax fish that received a diet lower in EPA and DHA, the increase in these fatty acids may be attributed to the conversion from ALA to EPA and DHA. Despite the differences in ALA, EPA, and DHA concentrations, total $\omega$-3 PUFA were greater $(P<0.05)$ in Flax fillets, mainly in the form of ALA. $3.9 \%$ of total $\omega-3$ PUFA in the CD group and $4.3 \%$ of total $\omega-3$ PUFA were $\omega-3$ PUFA other than ALA, EPA, and DHA.

Results showed that the fatty acid profile of the feed was mirrored in the fatty acid profile of the fillet. Similar results were reported in a study examining the dietary effect of $\omega-3$ PUFAs on rib meat of Holstein bulls. Mach and others (2006) found that in bulls fed flaxseed, the level of $\omega-3$ PUFA in rib meat from the sixth to eighth rib increased linearly with the amount of lipid. On the other hand, Smith (1999) concluded that in swine, the non-functional role that lipids serve in the adipose tissue would make manipulation of the fatty acid content more likely to closely reflect dietary fatty acids; 
while the functional role of fatty acids in muscle tissue membranes may limit the increases obtained through dietary manipulation.

TBARS. Due to the large increase in the amount of $\omega-3$ PUFA in Flax fillets it was proposed that oxidation levels of the fillets would be greater. Despite this difference in fatty acid composition, diet had no effect $(P>0.05)$ on the rate of oxidation over the 11-day storage period. At $4{ }^{\circ} \mathrm{C}$ lipid oxidation was controlled for both $\mathrm{CD}$ and Flax fillets. There was a trend toward decreasing mg MDA / kg sample (Figure 5) for CD and Flax fillets from day 1 to day 11 yet this trend was not significantly different. Figure 5 also shows that the CD fillets had greater mg MDA / $\mathrm{kg}$ sample than Flax fillets likely due to the greater percentage of long chain $\omega$-3 PUFA, but again this was not statistically different.

\section{Sensory Evaluation}

Difference testing. According to Meilgaard and others (1999), triangle testing is particularly useful in situations where treatment effects, such as an altered diet, may have produced product change. In this case, the sensory panel was unable to distinguish a difference between $C D$ and Flax fillets after performing two successive triangle tests. Twelve panelists correctly chose the odd sample for both triangle tests, 20 panelists incorrectly chose the odd sample for both triangle tests, and 22 panelists correctly chose the odd sample for one test and incorrectly chose the odd sample for the second test. Similar to what our sensory panel discovered, López-Ferrer and others (1999) reported that differences in taste were not apparent among chicken breasts from Cobb chicks fed treated feed ( $8.2 \%$ fish oil, linseed oil, or rapeseed oil). After 5 weeks 
of feeding, sensory evaluation of the chicken breast and thigh were performed and any treatment that included fish oil could not be identified as different from a sample enhanced with either linseed or rapeseed oil.

Sensory attribute testing. Semi-trained panelists found CD fillets to have greater $(P<0.05)$ fish odor and fish flavor than Flax fillets (Figure 6). Differences in oxidized odor, juiciness, stickiness, vegetable oil flavor, and aftertaste failed to reach statistical significance. These results remain comparable to López-Ferrer and others (1999), and Miller and others (1969) who found that the poorest sensory quality scores corresponded to chicken breast and thighs derived from chickens fed menhaden oil enhanced feed. In fact, breasts from chicken fed menhaden oil-enhanced feed were rated very poor to poor with questionable flavor, while all other samples were rated either indifferent or acceptable. The use of fish oil caused deterioration in the sensory quality and rendered the cooked meat unacceptable (López-Ferrer and others 1999; Miller and others 1969).

The fillets of the control group fed fish oil-enhanced feed may have been more susceptible to developing off flavors and other undesirable sensory traits. Hargis and others (1993) found that the use of fish oils at high concentrations in poultry diets entailed several organoleptic problems, including unpleasant odor in the final product, compromising the meat. Since vegetable oils, such as Flax, have fewer long-chain $\omega-3$ PUFA and more of the shorter-chained ALA, undesirable traits in these groups may not be as pronounced.

Preference testing. Flax fillets were preferred $(P<0.05)$ over $C D$ fillets. Of the 53 participants, 34 preferred the Flax fillets, while 19 preferred the CD fillets. Preference 
of Flax fillets over the CD fillets may have been due to the greater presence of fish odor and fish flavor found in the CD fillets. Manipulating feed with Flax resulted in an increase in the total amount of $\omega-3$ PUFAs, yet a reduction in the longer and less stable DHA and EPA. This change may have had an effect on sensory characteristics. 


\section{CONCLUSION}

Dietary modification with flaxseed-oil (Flax) on farmed brook trout (Salvelinus fontinalis) resulted in an overall greater percentage of $\omega-3$ PUFA. The fatty acid profile the fillets reflected the fatty acid profile of the feed. CD fillets had a greater percentage of long chain EPA and DHA. Despite this, CD fillets did not experience significantly greater oxidation than Flax fillets over 11 days of storage at $4^{\circ} \mathrm{C}$. CD fillets remained in

the acceptable muscle $\mathrm{pH}$ range until the final day of the study. Flax fillets, with more of the shorter-chain ALA and fewer of the longer-chain EPA and DHA, dropped out of the acceptable $\mathrm{pH}$ range at day 9 . Despite this, sensory evaluations confirm that panelists preferred the taste of the Flax fillets to the CD fillets; and CD fillets exhibit a greater presence of characteristics associated with off-flavors. Based on the many health benefits associated with increasing dietary $\omega-3$ PUFA, it can be concluded that a Flaxenhanced diet would have favorable effects on the product quality of farmed brook trout, and may appeal to the health conscious consumer as a value-added food potentially representing a niche market for West Virginia producers. 


\section{REFERENCES}

Adelizi PD, Rosati RR, Warner K, Wu YV, Meunch TR, White MR, Brown PB. 1998. Evaluation of fish-meal free diets for rainbow trout, Oncorhynchus mykiss. Aquaculture Nutr 4:255-62.

Arterburn LM, Hall EB, Oken H. 2006. Distribution, interconversion, and dose response of n-3 fatty acids in humans. Am J Clin Nutr 83(suppl):1467s-1476s.

Assn of Official Analytical Chemists (AOAC). 1995. Official methods of analysis of the association of official analytical chemists, $16^{\text {th }}$ ed. Wash., DC: Assn of Official Analytical Chemists.

Buzzi M, Henderson RJ, Sargent JR. 1996. The desaturation and elongation of linolenic acid and eicosapentaenoic acid by hepatocytes and liver microsomes from rainbow trout (Oncorhynchus mykiss) fed diets containing fish oil or olive oil. Biochim Biophys Acta 1299:235-44.

Chen Y- C, Nguyen J, Semmens K, Beamer S, Jaczynski J. 2006. Enhancement of omega-3 fatty acid content in rainbow trout (Oncorhynchus mykiss) fillets. JFS. 71(7):383-389.

Chen Y- C, Nguyen J, Semmens K, Beamer S, Jaczynski J. 2007. Effects of dietary alpha-tocopheryl acetate on lipid oxidation and alpha tocopherol content of novel omega-3-enhanced farmed rainbow trout (Oncorhynchus mykiss) fillets. Food Science and Technology. 41:244-253.

D'Souza N, Skonberg DI, Stone DAJ, Brown P. 2006. Effect of soybean meal-based diets on the product quality of rainbow trout fillets. JFS 71(4) s337-s342.

Foegeding EA, Lanier TC, and Hultin HO. 1996. Characteristics of edible muscle tissues. In: O.Fennema, editor. Food Chemistry. New York:Marcel Dekker, Inc. p.915.

Hebard CE, Flick GJ, Martin RE. (1982). Occurance and significance of trimethylamine oxide and its derivatives in fish and shellfish. In: Matrin RE, Flick GJ, Ward DR, editors. Chemistry and biochemistry of marine food products. Westport, Ct.: Avi.

Haard NF. 1992. Biochemistry and chemistry of color and color changes in seafoods. In: Flick GJ, Martin RE, editors. Advances in seafood biochemistry: composition and quality. Lancaster, Pa.: Technomic Publishing Company Inc. p 305-60.

Hargis PS, Van Elswyk ME. 1993. Manipulating the fatty acid composition of poultry meat and eggs for the health conscious consumer. World's Pout Sci J 49: 2251-264. 
IFST. 1993. Shelf Life of Foods - Guidelines for its Determination and Prediction. IFST. London.

Jeyasekaran G, Ganesan P, Maheswari K, Jeya Shakila R, Sukumar D. 2004. Effect of delayed icing on the microbiological quality of tropical fish: barracudas (Sphyraena barracuda). JFS. 69 (7):197-200.

Ježek F, Buchtová H. 2007. Physical and chemical changes in fresh chilled muscle tissue of common carp (Cyprinus capio L.) packed in a modified atmosphere. Acta Vet Brno 76: S83-00.

Kamireddy N, Kenney B, deGraft-Hanson J, Jaczynzki, J. 2003. Time and temperature affects storage stability of rainbow trout (Oncorhynchus mykiss) fillets. Master's thesis, West Virginia University, Morgantown, WV.

López-Ferrer S, Baucells MD, Barroeta AC, Grashorn MA. 1999. n-3 Enhancement of chicken meat using fish oil: alternative substitution with rapeseed and linseed oil. Poultry Science. 78:356-365.

Mach N, Devant M, Dı́az I, Font-Furnold M, Oliver MA. .2006. Increasing the amount of n-3 fatty acid in meat from young Holstein bulls through nutrition. J Anim Sci 84(11):3039-48.

Meilgaard M, Civelle GV, Carr BT. Sensory evaluation techniques. Third ed. Boca Raton, Florida, USA: CRC Press LLC; 1999.

Miller D, Robisch P. 1969. Comparitive effect of herring, menhaden, and safflower oils on broiler tissues fatty acid composition and flavor. Poultry Science 48(6): 2146-2159.

National Research Council. 1993. Composition of feed ingredients. Washington, DC: National Academy Press, pp64-71.

Rhee, K.S., Dutson, T.R., and Smith, G.C. 1984. Enzymatic lipid peroxidation in microsomal fractions from beef skeletal muscle. J. Food Sci. 49: 675-679.

Romans JR, Wulf DM, Johnson RC, Libal GW, Costello WJ. 1995. Effects of ground flaxseed in swine diets on pig performance and on physical and sensory characteristics and omega-3 fatty acid content of pork: II. Duration of $15 \%$ dietary flaxseed. J of Anim Sci 73:1987-1999.

Smith SB. 1991. Dietary modification for altering fat composition of meat. In: Haberstroh E, Morris CE, editors. Fat and cholesterol reduced foods: technologies and strategies. The Woodlands, Tx.: The Portfolio Publishing Company. P 75-97. 
Surette ME 2008. The science behind dietary omega-3 fatty acids. CMAJ. 178(2):177180.

Turner AG, Flick GJ, Conforti FD, Duncan SE, Haugh CG. 1998. The efficacy of using natural antioxidant blends to control oxidative rancidity in headed and gutted, filleted, and minced rainbow trout (Oncorhynchus mykiss) during frozen storage. Master's thesis. Virginia Polytechnic Institute and State University, Blacksburg, VA.

USDA: US Department of Health and Human Services. 2005.Dietary Guidelines for Americans (HHS publication number: HHS-ODPHP-2005-01-DGA-A) Washington, DC: U.S. Government Printing Office.

Voss A, Reinhart M, Sankarappa S, Sprecher H. 1991. The metabolism of 7,10,13,16,19-docosapentaenoic acid to 4, 7, 10,13,16, 19-docosahexanoic acid in rat liver is independent of 4 desaturase. Journal of Biological Chemistry. 266:19995-20000.

Waagbo R, Sandness K, Torrissen OJ, Scandvin A, Lie O. 1993. Chemical and sensory evaluation of fillets from Atlantic salmon (Salmo salar) fed three different levels of $n-3$ polyunsaturated fatty acids at two levels of vitamin E. Food Chemistry. 46:361366.

Yagiz Y, Kristinsson HG, Balaban MO, Marshall MR. 2007. Effect of high pressure treatment on the quality of rainbow trout (Oncorhynchus mykiss) and Mahi Mahi (Coryphaena hippurus). JFS. 72: 509-515.

Yu Tc, Sinnhuber RO. 1957. 2-Thiobarbituric acid method for the measurement of rancidity in fishery products. Food Technol 11:104-108. 


\section{FIGURES}

Figure 1. Color: $L$ values. Changes in color of fillets from fish fed a control diet (CD) or flaxseed-oil enhanced diet (Flax) were measured over an 11-day storage period at $4^{\circ} \mathrm{C}$. Analyses were conducted at $48 \mathrm{~h}$ intervals from day 1 until day 9 and then again on day $11 .^{+}$

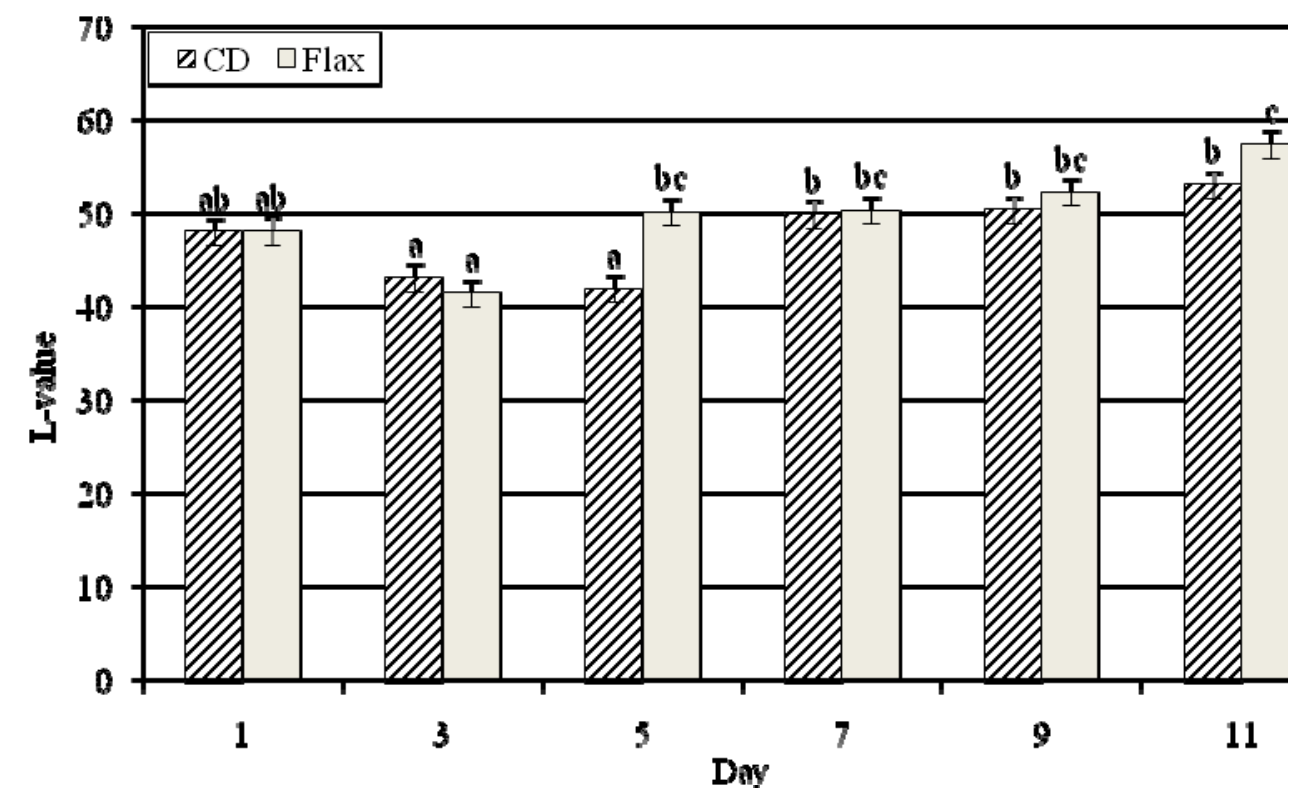

${ }^{+}$Values are mean scores \pm SE $(n=9)$

${ }^{\mathrm{a}, \mathrm{b}, \mathrm{c}}$ Indicates differences among days and between treatments $(P<0.05)$ 
Figure 2. Color: $a^{*}$ values. Changes in color of fillets from fish fed a control diet (CD) or flaxseed-oil enhanced diet (Flax) were measured over an 11-day storage period at $4^{\circ} \mathrm{C}$. Analyses were conducted at $48 \mathrm{~h}$ intervals from day 1 until day 9 and then again on day 11. A trend toward increasing $a^{*}$ values from day 1 to day 11 for $C D$ and Flax fillets is suggested but failed to reach statistical significance. Greater $a^{*}$ values for Flax fillets are also suggested but failed to reach statistical significance $(P>0.05){ }^{+}$

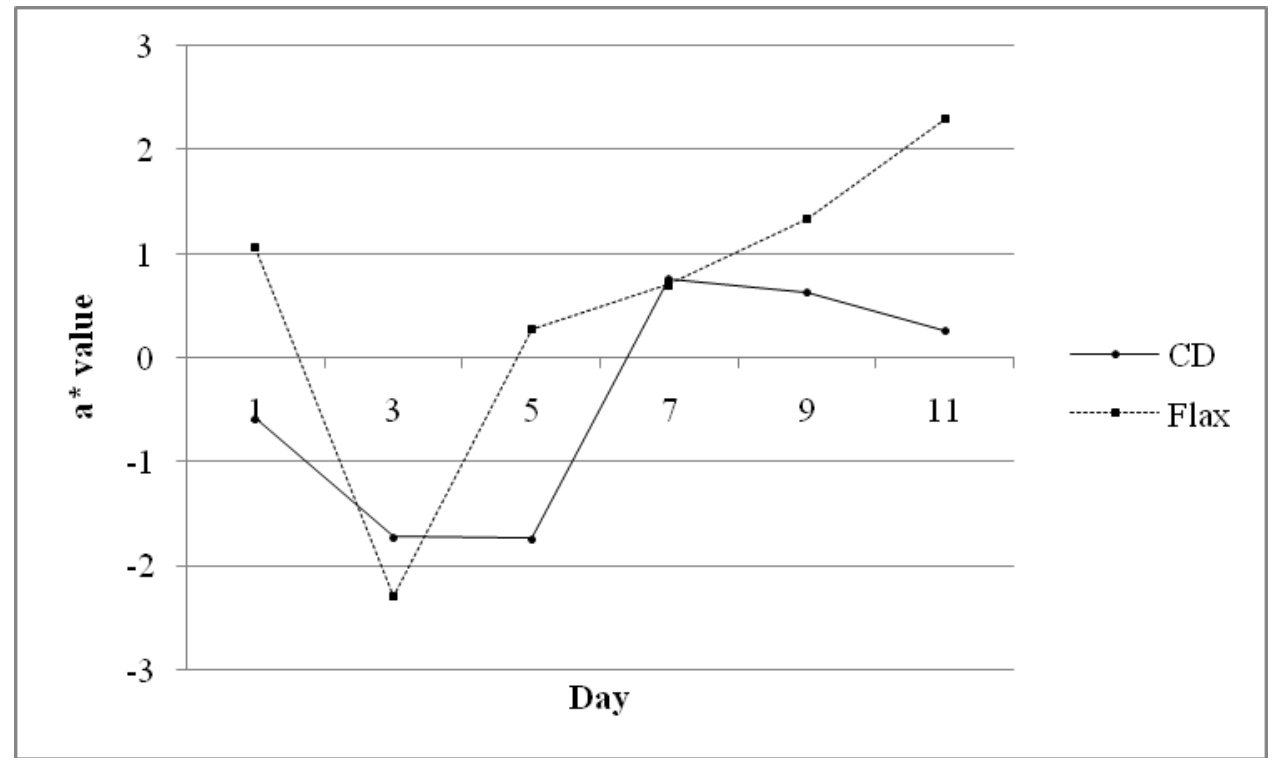

${ }^{+}$Values are mean scores \pm SE $(n=9)$ 
Figure 3. Color: $b^{*}$ values. Changes in color of fillets from fish fed a control diet (CD) or flaxseed-oil enhanced diet (Flax) were measured over an 11-day storage period at $4^{\circ} \mathrm{C}$. Analyses were conducted at $48 \mathrm{~h}$ intervals from day 1 until day 9 and then again on day 11. A trend toward increasing $b^{*}$ values from day 1 to day 11 for $C D$ and Flax fillets is suggested but failed to reach statistical significance $(P>0.05){ }^{+}$

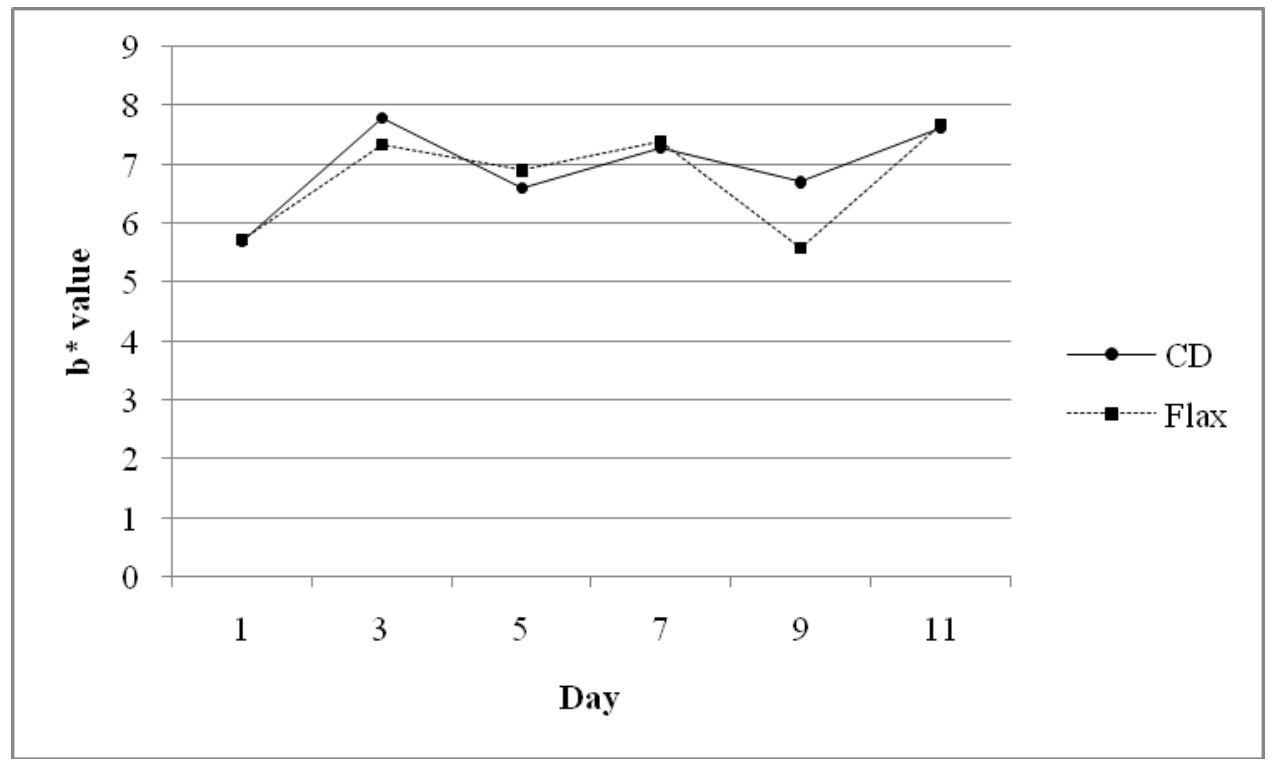

${ }^{+}$Values are mean scores \pm SE $(n=9)$ 
Figure 4. ALA, DHA, and EPA concentrations of control (CD) and flaxseed-oil enhanced (Flax) fillets over a 3 month feeding period. Statistical analysis was not performed on this data.

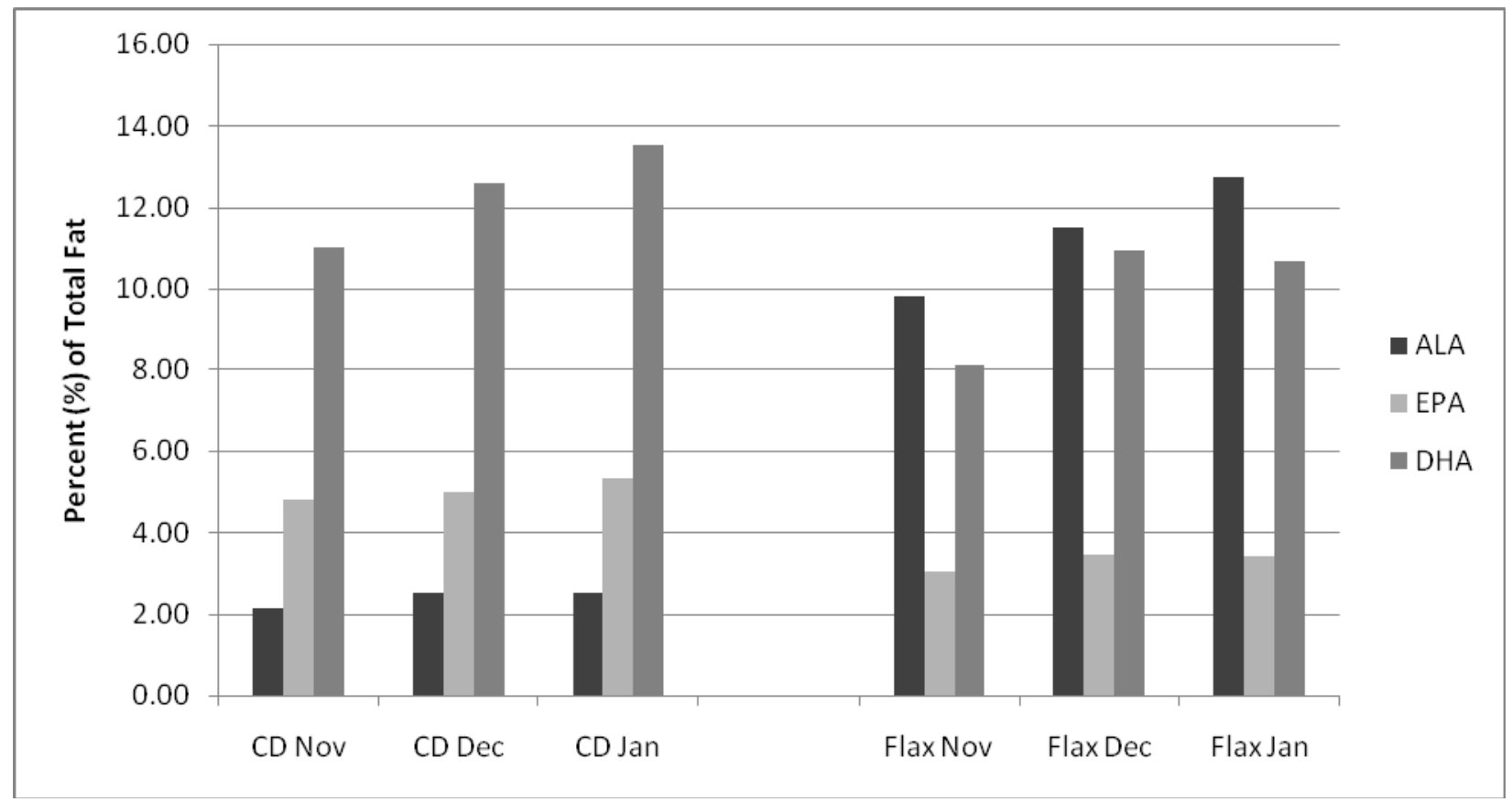


Figure 5. Thiobarbituric acid reactive substances test (TBARS). Color absorbance was read at $532 \mathrm{~nm}$ and TBARS values were reported as mg malondialdehyde (MDA) per $\mathrm{kg}$ sample of control (CD) and flaxseed-oil enhanced (Flax) fillets. A trend toward decreasing production of MDA over 11 days is shown but failed to reach statistical significance $(P>0.05)$. CD fillets had elevated production of MDA but this also failed to achieve statistical significance. ${ }^{+}$

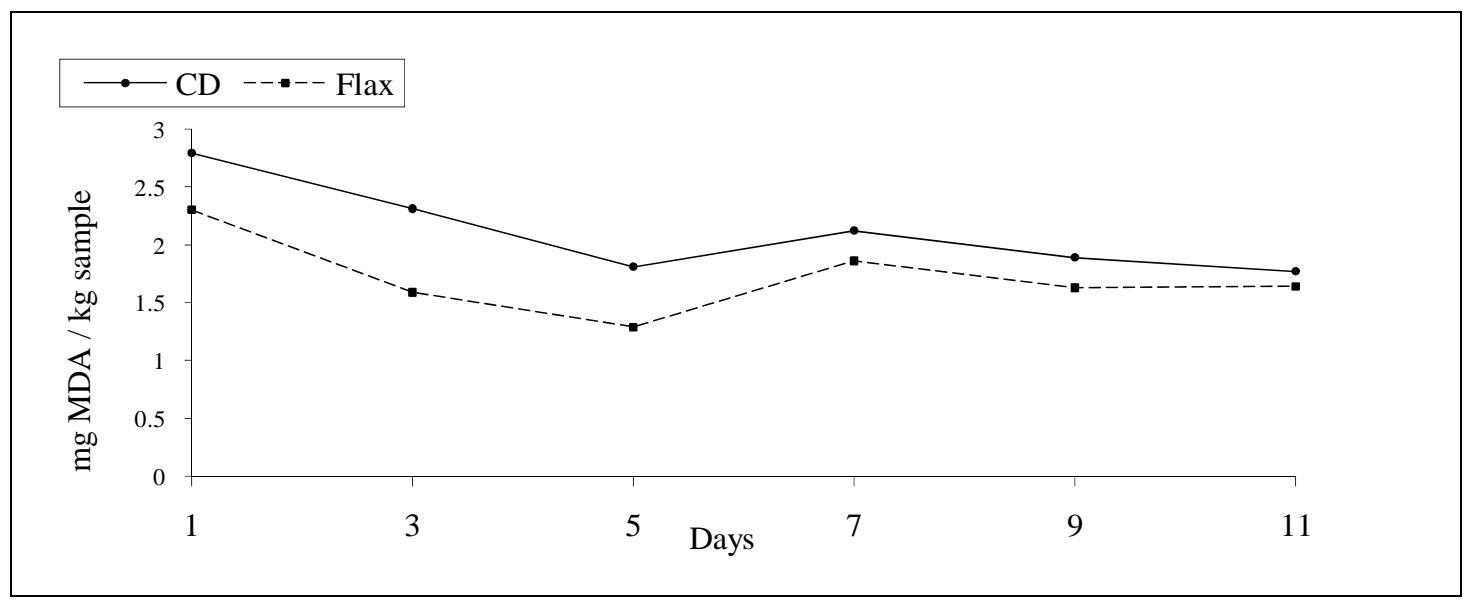

${ }^{+}$Values are mean scores \pm SE $(n=3)$. 
Figure 6. Sensory attributes of control (CD) and flaxseed-oil enhanced (Flax) fillets. Testing was performed on fresh fish fillets stored overnight in a $4^{\circ} \mathrm{C}$ environment. Responses from 11 semi-trained panelists were quantified using a $10 \mathrm{~cm}$ scale with 1 representing a small presence of the attribute and 10 representing a large presence of the attribute. ${ }^{+}$

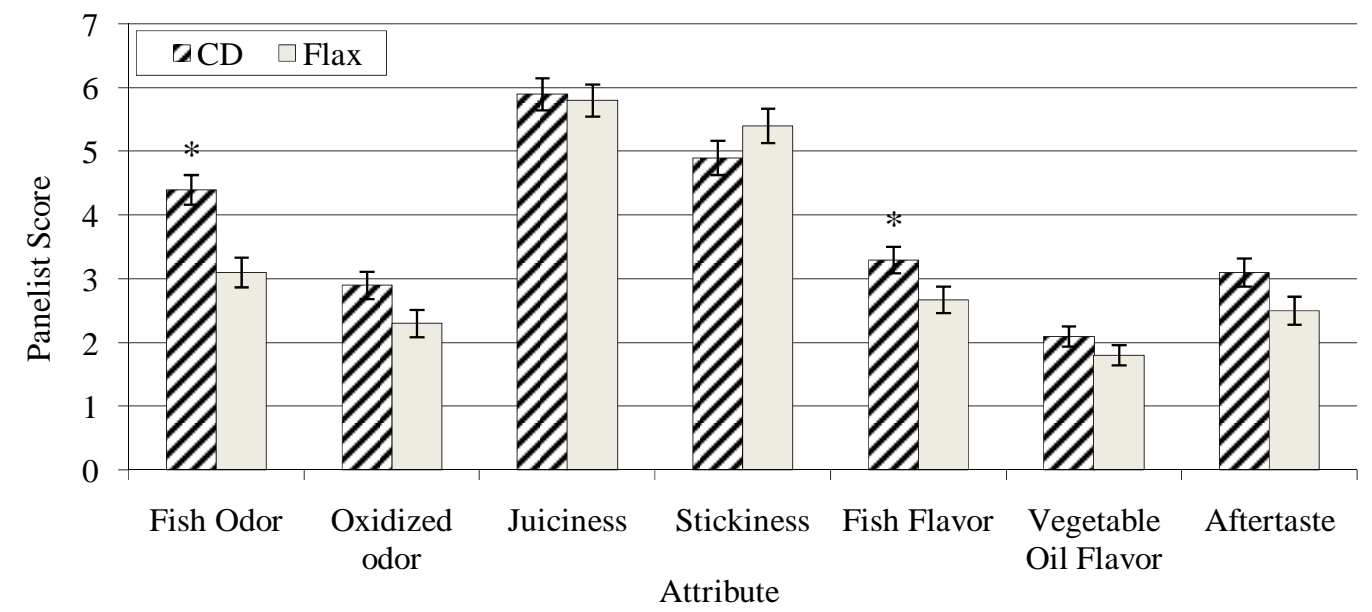

${ }^{+}$Values are mean scores $\pm \mathrm{SE}(\mathrm{n}=11)$ for each attribute.

* Indicates difference between treatments for each attribute $(P<0.05)$ 


\section{TABLES}

Table 1. Feed proximate composition comparison of two diets: flaxseed-oil enhanced (Flax) and control diet $(C D)$. Proximate composition of the feeds were not significantly different $(P>$ 0.05).

\begin{tabular}{ll|l} 
& CD & Flax \\
\hline \% Dry Matter & 93.24 & 93.43 \\
\% Moisture & 6.76 & 6.57 \\
\% Crude protein & 40.29 & 40.26 \\
\% Water soluble carbohydrates & 3.33 & 3.34 \\
\% Starch & 13.31 & 13.23 \\
\% Fat & 20.60 & 20.62 \\
\hline
\end{tabular}


Table 2. Change in muscle $\mathrm{pH}$ of control (CD) and flaxseed-oil enhanced (Flax) fillets over an 11-day storage period. Optimal muscle $\mathrm{pH}$ is $6.2-6.6 .^{+}$

\begin{tabular}{l|rr} 
Day: & \multicolumn{1}{|l}{ Diet: } \\
\hline \multirow{3}{*}{1} & \multicolumn{1}{|c}{ CD } & \multicolumn{1}{c}{ Flax } \\
\cline { 2 - 3 } 3 & $6.4 \pm .02^{\mathrm{a}}$ & $6.39 \pm .02^{\mathrm{a}}$ \\
5 & $6.37 \pm .02^{\mathrm{a}}$ & $6.42 \pm .02^{\mathrm{a}}$ \\
7 & $6.37 \pm .02^{\mathrm{a}}$ & $6.43 \pm .02^{\mathrm{a}}$ \\
9 & $6.33 \pm .02^{\mathrm{a}}$ & $6.41 \pm .02^{\mathrm{a}}$ \\
11 & $6.26 \pm .02^{\mathrm{b}}$ & $6.08 \pm .02^{\mathrm{b}, *}$ \\
& $6.03 \pm .02^{\mathrm{b}}$ & $5.95 \pm .02^{\mathrm{b}, *}$
\end{tabular}

${ }^{+}$Values are mean scores $\pm \mathrm{SE}(\mathrm{n}=9)$ for each treatment on each day

${ }^{\mathrm{a}, \mathrm{b}}$ Differences in a vertical column indicate significant differences over 11 days (least-squared difference test; $P<0.05$ ).

* Differences in a horizontal row indicate significant differences between groups (least-squared difference test; $P<0.05$ ). 
Table 3. Omega-3 PUFA content of control (CD) and flaxseed-oil enhanced (Flax) fillets. ${ }^{+}$

\begin{tabular}{c|c|c|c|c|c} 
& ALA & EPA & DHA & Other $\omega-3$ & Total $\omega-3$ \\
\hline CD & $2.79 \pm 1.02^{\mathrm{a}}$ & $5.17 \pm .31^{\mathrm{a}}$ & $14.45 \pm 0.81^{\mathrm{a}}$ & 3.9 & $26.3^{\mathrm{a}}$ \\
Flax & $13.58 \pm 1.02^{\mathrm{b}}$ & $3.83 \pm 0.31^{\mathrm{b}}$ & $11.09 \pm 0.81^{\mathrm{b}}$ & 4.3 & $32.8^{\mathrm{b}}$
\end{tabular}

${ }^{+}$Values are given as gram / 100 gram sample. Data are given as mean scores \pm SE $(n=9)$ for each treatment for each analysis

${ }^{a, b}$ Differences in a vertical column indicate significant differences (least-squared difference test; $P<0.05)$. Statistics were not performed on other $\omega-3$ PUFA. 


\section{APPENDICES}

APPENDIX A: Preliminary data .............................................. 57

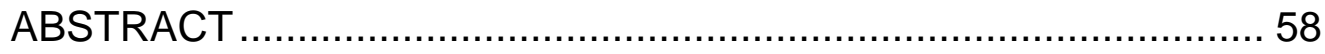

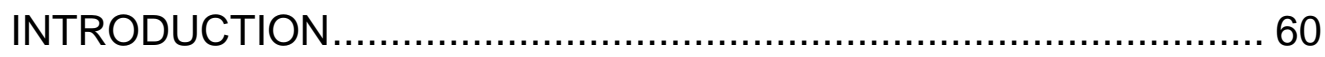

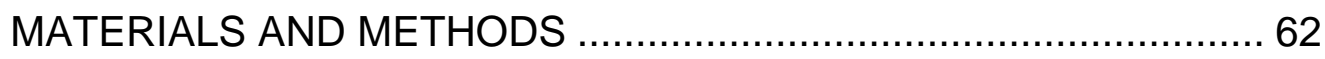

RESULTS AND DISCUSSION ...................................... 68

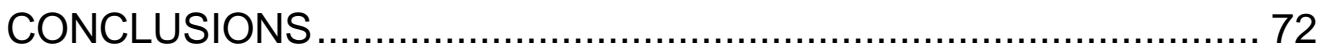

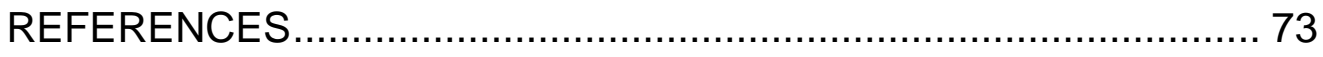

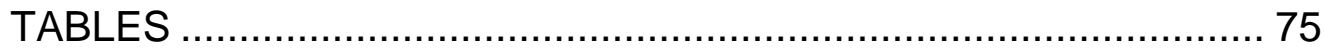

APPENDIX B: Spring-fed gravity flow-through raceway system. ............. 81

APPENDIX C: Consent form for participation in sensory attribute evaluations.

APPENDIX D: Sensory attribute instructions. ............................... 85

APPENDIX E: Sensory attribute scorecard................................. 86

APPENDIX F: Day 1 sensory attribute results.............................. 87

APPENDIX G: Consent form for difference and preference testing. .......... 91

APPENDIX H: Sensory card used for triangle test. ............................. 94

APPENDIX I: Sensory card used for preference test. ......................... 95

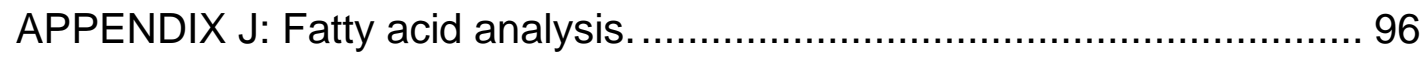

APPENDIX K: Fatty acid profiles........................................... 98

APPENDIX L: Thiobarbituric acid reactive substances test procedure. ... 104

APPENDIX M: Statistical analysis of muscle pH (Chapter III) ............... 106

APPENDIX N: Statistical analysis of Color L (Chapter III) .................... 111 


\author{
APPENDIX A: Preliminary data \\ SENSORY EVALUATION OF SHELF LIFE \\ FOR FARMED BROOK TROUT (Salvelinus fontinalis) \\ FED A FLAXSEED-OIL ENHANCED DIET
}




\section{ABSTRACT}

The sensory characteristics over a 10-day shelf life were evaluated in brook trout (Salvelinus fontinalis). Fingerlings were randomly divided into two groups and were fed either a control diet sprayed with fish oil (CD) or a treatment diet sprayed with flaxseedoil (Flax), for 165 days before harvesting. Each of the two diet groups were further separated into three replications (Rep). Eleven semi-trained panelists evaluated sensory attributes (fish odor, oxidized odor, juiciness, stickiness, fish flavor, vegetable oil flavor, and aftertaste) of CD and Flax fillets from each Rep, at five separate tasting sessions, over a period of ten days (Day 1, 3, 6, 8, and 10). Further analyses on these days included cooking yield and texture. Color, thiobarbituric acid reactive substances test (TBARS), proximate composition (total fat, protein, moisture, and ash), and fatty acid profiles were analyzed on day 1 fillets. After day 1 the temperature of the incubator did not maintain a $4^{\circ} \mathrm{C}$ environment. The effects of this on the fillets are unknown, due to the wide variation of temperature, but it is speculated that the fillets may have frozen during storage, delaying the normal spoilage time. As a result, only day 1 of the sensory attribute testing was considered valid. The effect of this is also unknown on the cooking yield and texture of the fillets. There were no significant differences between the three Reps in each group for color, TBARS, proximate composition and fatty acid profile. Fatty acid profile of the Flax fillets showed five times more alpha linolenic acid (ALA, 18:3n3) $(P<0.05)$ compared to CD fillets; however, there was less eicosapentaenoic acid (EPA, 20:5n3) and docosahexaenoic acid (DHA, 22:6n3) $(P<$ $0.05)$ in Flax fillets. Total omega-3 fatty acids were greater $(P<0.05)$, in the Flax fillets. For further experimentation the fish from the three Reps within each group were 
combined and results from day 1 of the sensory attribute testing are interpreted in Chapter III. 


\section{INTRODUCTION}

Fish and seafood products are often characterized by having a short shelf life. Shelf life is defined as the period of time, under certain conditions of storage, for which a food product remains safe, fit for human consumption, and acceptable (IFST 1993). Fresh fish is highly susceptible to spoilage during storage. Throughout handling and storage there are many opportunities for fish flesh to deteriorate and oxidize, resulting in reduced shelf life.

Seafood products are highly perishable and tend to spoil faster than other muscle foods (Yagiz and others 2007). A seafood product is considered spoiled or undesirable when it develops off flavors and off odors that the consumer no longer deems acceptable. These can be caused by autolytic and proteolytic changes catalyzed by microbial enzymes, lipid decomposition and oxidation, decline in muscle $\mathrm{pH}$, and coloring substance oxidation that takes place in fish muscle tissue (Ježek and Buchtová 2007). Common undesirable sensory traits that are associated with oxidation and spoilage of seafood include fishy taste or smell, metallic (oxidized) odor, and the presence of a strong aftertaste.

According to the USDA Dietary Guidelines for Americans (2005), it is suggested that consuming approximately two servings of fish per week may reduce the risk of mortality from coronary heart disease due to the omega- 3 polunsaturated fatty acid ( $\omega-3$ PUFA) content. In addition to the already high content of eicosapentaenoic acid (EPA, 20:5n3) and docosahexaenoic acid (DHA, 22:6n3) naturally occurring in fatty fish such as trout, it may be of further benefit to human health to consume trout supplemented with flaxseed-oil (Flax), a rich source of alpha linolenic acid (ALA, 18:3n3). Flax 
contains 53.3\% ALA, the highest concentration of ALA among plant-derived oils (National Research Council 1993). Previous research has shown that feeding rainbow trout feed enhanced with Flax increases the total $\omega-3$ PUFA concentration in the fillets (Chen and others 2006). However, when the fatty acid profile of fish is altered to allow for more $\omega$-3 PUFA, oxidation becomes a concern. Due to the relationship between oxidation and the production of off flavors and off odors, the increased susceptibility of $\omega$-3 PUFA to oxidation may reduce shelf life in fish containing a greater concentration of these fatty acids.

Development of such a product that may have increased health benefits may enable trout producers to expand into the food fish market. Currently brook trout are produced for recreation and are not commonly produced as food fish. Brook trout are native to West Virginia. West Virginia aquaculture is characterized by small flowing water systems and producers in this area have abundant resources for production of trout. Increasing the appeal of farm raised brook trout to consumers by improving the $\omega$-3 PUFA concentration may potentially represent a niche market for these producers to expand into the food fish market. This experiment aims to monitor nine sensory attributes that are commonly affected by spoilage and oxidation over a 10-day storage period in farmed brook trout fillets fed flaxseed-oil enhanced feed to determine if such a product would be accepted by potential consumers. 


\section{MATERIALS AND METHODS}

\section{Brook Trout and Diets}

Brook trout fingerlings were raised at Reymann Memorial Farm aquaculture facility (Wardensville, WV). The fish were stocked at nine months old at an average weight of $0.15 \mathrm{~kg}$ and an average length of $230 \mathrm{~mm}$. The fingerlings were randomly divided into a control group (CD) and a treatment group (Flax). The fingerlings from each group were further divided into three groups or replications (Rep). All fish were fed dry pelleted commercial feed containing $40 \%$ protein and $21 \%$ fat (Zeigler Brothers Inc., Gardners, PA) (Table 1) for 165 days before harvesting. Upon drying and extrusion, the feed was sprayed with $6.2 \%$ menhaden oil (CD) or $6.4 \%$ flaxseed-oil (Flax). The fish were fed from either one batch of CD feed or one batch of Flax feed. Feed was stored at $40^{\circ} \mathrm{C}$.

Trout were raised in a spring-fed gravity flow-through raceway system with two parallel lanes, each lane with three tanks. CD and Flax groups were separated into the two lanes and further separated into three tanks for replication. Water was aerated at the head of each raceway unit to maintain a dissolved oxygen concentration above $70 \%$ saturation. Water temperature was approximately $12^{\circ} \mathrm{C}$ during the feeding trial. Daily recordings were conducted on each tank including amount of feed administered, oxygen concentration in each tank, and number of mortalities.

Fillet processing. The trout were harvested upon reaching an average weight of $0.56 \mathrm{~kg}$ and an average length of $403 \mathrm{~mm}$, approximately 400 days after hatching. Twelve CD fish from each of the three Reps and twelve Flax fish from each of the three Reps were stunned, gutted, filleted, wrapped in polyvinyl chloride (PVC) film, and stored 
in an incubator at $4^{\circ} \mathrm{C}$ for 10 days. These 72 fish were used for sensory attribute evaluation of shelf life and additional analyses.

An additional group of fifteen $C D$ trout, to be used as a reference group for sensory evaluation, was also harvested and filleted. These fish were vacuum-packed and stored in $\mathrm{a}-20^{\circ} \mathrm{C}$ freezer. The day before each tasting session three of the reference fillets were placed in an incubator $\left(4^{\circ 0} \mathrm{C}\right)$ for thawing.

\section{Sensory Evaluation of Shelf Life}

Panelist training. To evaluate the shelf life of the CD and Flax trout, sensory attribute tests were performed at 1, 3, 6, 8 and 10 days after slaughter. A total of 12 panelists, over the age of eighteen years, were recruited from Davis College of Agriculture, Forestry, and Consumer Sciences to participate in the sensory panel. One panelist's response was not included in analysis due to inconsistent participation, leaving a total of 11 panelists. Prior to testing, panelists attended a one-hour training session to become familiar with testing procedures, be instructed on how to properly evaluate samples, and be able to identify the sensory characteristics being tested. To eliminate bias, panelists were not informed that shelf life was being evaluated until the study was complete.

Thermal processing of fillets. On each of the test days three reference fillets, six CD fillets (two from each Rep), and six Flax fillets (two from each Rep) were removed from the $4^{\circ} \mathrm{C}$ incubator. Samples were baked at $204.4^{\circ} \mathrm{C}$ for 12 minutes or until an internal temperature of at least $65.5^{\circ} \mathrm{C}$ was reached. Fillets were weighed before and after cooking and percent yield was calculated. Samples were cut into cubes $(2.54 \mathrm{~cm})$ 
and placed in 2-oz plastic cups and fitted with plastic lids. Samples were blind- coded with a random 3-digit number and stored in a warming oven for no more than 45 minutes, to maintain an internal temperature of $65.5^{\circ} \mathrm{C}$, until sensory testing occurred. Sensory analysis. Semi-trained panelists attended five tasting sessions, one on each day (days $1,3,6,8$, and 10). On each day, panelists evaluated three CD and three Flax samples, one from each Rep. Prior to each tasting session, the conductors of the sensory panel evaluated and scored the sensory characteristics of reference fillet samples. Unlimited amount of reference samples were available to panelists for comparison purposes. Panelists were asked to use the reference fish as a basis for comparison, however were instructed not to let it influence the scoring of the successive samples. Panelists were provided with room temperature water and unsalted crackers and were advised to consume these in-between samples to cleanse their palate. Blindcoded samples were randomly presented to panelists one at a time. Panelists were asked to evaluate the following attributes: fish odor, oxidized odor, juiciness, stickiness, fish flavor, vegetable oil flavor, and aftertaste. Results were recorded on a $10 \mathrm{~cm}$ scale; with 1 representing a small presence of the attribute and 10 representing a large presence of the attribute.

\section{Further Analysis}

Texture analysis. On each test day, one fillet from each Rep (three CD fillets and three Flax fillets) was removed from the $4^{\circ} \mathrm{C}$ incubator. Samples were baked at $204.4^{\circ} \mathrm{C}$ for twelve minutes or until an internal temperature of at least $65.5^{\circ} \mathrm{C}$ was reached. A uniform $3.5 \times 8 \mathrm{~cm}$ piece was cut from the dorsal side of a fillet from each Rep. Fillets 
were then skinned and weighed and the shear force value was measured using a texture analyzer (Model TA-Hdi, Texture Technologies Corp.; Scarsdale NY). Samples were placed in a 5-blade Kramer shear press cell, with muscle fibers running perpendicular to the blades. Texture was analyzed once for one fillet from each Rep. Crosshead speed was set at $10 \mathrm{~cm} / \mathrm{min}$ and the shear force was expressed as g peak force / g sample.

Cooking yield. Cooking yield was calculated by expressing cooked fillet weight as a percent of the raw fillet weight. This was performed in duplicate for each Rep on each sensory testing day.

Color analysis. Color analyses were conducted each day on cooked fillets. Differences between the $C D$ and Flax fillets were analyzed and compared using a chromameter (Model CR-300; Minolta Camera Co. Ltd., Osaka Japan) calibrated with a standard white plate No.21333180 (CIE L* 93.1; $\left.a^{\star} 0.3135 ; b^{\star} 0.3198\right)$. Values of $L^{*}$ (lightness; scale: 0 - 100), a* (intensity in red color; scale: $-60-+60$ ), and b* (intensity in yellow color; scale: $-60-+60$ ) were measured three times at the cranial, caudal, and midsection of the right or left fillet.

Thiobarbituric acid reactive substances test. Lipid oxidation was quantified in powdered samples of day $1 \mathrm{CD}$ and Flax fillets using the thiobarbituric acid reactive substances (TBARS) test. CD and Flax samples were tested in triplicate using the TBARS test described by Yu and Sinnhuber (1957). The color absorbance was read at $532 \mathrm{~nm}$, and the TBARS value was calculated using the following equation: Sample TBARS $=\mathrm{Ks} \times \mathrm{A} \times 5 / \mathrm{Wt} .(\mathrm{A}=$ absorbance of sample, $\mathrm{Wt}=$ exact sample weight, $\mathrm{Ks}=$ 
constant obtained from the slope of the standard curve.) The results were reported as mg malondialdehyde per $\mathrm{kg}$ sample.

Proximate composition. Proximate composition of day 1 fillets was determined in triplicate according to the Association of Official Analytical Chemists methods (1995) and was expressed as percent by weight on dry basis.

Fat content in fillets was determined according to the Soxhlet extraction method (AOAC 920.39). Sample size was 1-1.5 g and extraction time was 18-24 hours at a drip rate of 200 drips/ minute. Extractions were performed with petroleum ether.

Moisture content was determined by placing $4.5-5 \mathrm{~g}$ samples in a $70^{\circ} \mathrm{C}$ oven to dry to a constant weight (16 hours). Partial vacuum pressure was equivalent to $20 \mathrm{~mm}$ $\mathrm{Hg}$. Dried samples were placed in a desiccator and cooled to room temperature. Samples were weighed and \% moisture was calculated using the following equation (AOAC 925.09): \% Moisture $=$ [sample weight $(\mathrm{g})-$ dry weight $(\mathrm{g}) /$ sample weight $(\mathrm{g})$ ] *100.

Ash content was quantified by weighing 2-3 $\mathrm{g}$ of sample in a crucible and placing in a muffle furnace ignited at $525^{\circ} \mathrm{C}$ until light gray ash resulted, or until a constant weight was reached (12 hours). Samples were removed and placed in a desiccator to cool. Upon reaching room temperature samples were weighed and $\%$ ash was calculated using the following equation (AOAC 932.03): \% Ash = [weight of ash (g) / weight of original sample $(\mathrm{g})] \star 100$.

Crude protein was determined using the Kjeldahl method. Two blank tubes were prepared and run in preparation for sample tubes. A sample was weighed $(0.25$ g), folded into Whatman \#1 paper, and placed in labeled Kjeldahl tubes. One Kjeltab 
was dropped into each tube followed by the addition of $10 \mathrm{~mL}$ of sulfuric acid. Samples were digested for $5-10$ minutes at $420^{\circ} \mathrm{C}$ with maximum airflow. Airflow was then reduced and samples were further digested for 40-45 minutes. Distilled water was added $(75 \mathrm{~mL})$ and the tubes were placed in a Kjeltec 1030 Auto Analyzer to run. Results were recorded in $\mathrm{mL}$ of acid. Crude protein percentage was determined using the following equations:

$\%$ Nitrogen $=(\mathrm{mL}$ acid titrated * normality of $\mathrm{HCl} * 14.01) /[(\mathrm{a} * \% \mathrm{DM}) * 10)]$

$\%$ Crude protein $=\%$ Nitrogen $* 6.25$

Fatty acid profile. Fatty acid profile of day 1 fillets was performed in triplicate at the University of Missouri-Columbia according to the Association of Official Analytical Chemists methods (1995). Total fat was calculated as sum of individual fatty acids expressed as triglyceride equivalents.

\section{Statistical Analysis}

Three replications from the control and three replications from the treatment groups were used for design purposes. Responses of 11 panelists were averaged for the sensory attribute test. Only day 1 of the sensory attribute test and color analysis was analyzed for statistical significance. Statistical analysis was not performed on cooking yield or texture. Means separation was analyzed using Tukey's Honestly Significant Differences Test $(P<0.05)($ JMP 7 , SAS Institute, Cary, NC, USA). Statistical significance was accepted at $P<0.05$. 


\section{RESULTS AND DISCUSSION}

\section{Sensory Evaluation of Shelf Life}

Although sensory data was collected over a 10 day time period, after day 1 the temperature of the incubator did not maintain a $4^{\circ} \mathrm{C}$ environment. The effects of this on the fillets are unknown, due to the wide variation of temperature, but it is speculated that the fillets may have either frozen during storage, delaying the normal spoilage time, or reached abusive temperatures, promoting faster spoilage. Despite this setback, sensory data from day 1 and day 10 of the shelf life study is reported due to the fact that both $\mathrm{CD}$ and Flax fillets were exposed to the same temperature environment. Therefore, any changes in sensory data were caused by the differences among treatments rather than difference among temperatures.

Fish odor and fish flavor were significantly greater $(P<0.05)$ in CD fillets than Flax fillets (Table 2). These results remain comparable to López-Ferrer and others (1999), and Miller and others (1969) who found that the poorest sensory quality scores corresponded to chicken breast and thighs derived from chickens fed menhaden oil enhanced feed. In fact, breasts from chicken fed menhaden oil-enhanced feed were rated very poor to poor with questionable flavor, while all other samples were rated either indifferent or acceptable. The use of fish oil caused deterioration in the sensory quality and rendered the cooked meat unacceptable (López-Ferrer and others 1999; Miller and others 1969).

Our study reflected this deterioration in sensory quality, suggesting that the $C D$ fillets were more susceptible to developing off flavors and other undesirable sensory traits. Hargis and others (1993) found that the use of fish oils at high concentrations in 
poultry diets entailed several organoleptic problems, including unpleasant odor in the final product, compromising the meat. Since vegetable oils, such as Flax, are lower in long chain $\omega-3$ PUFA and higher in shorter-chained ALA, the production of undesirable traits in these groups may not be as pronounced.

Fish odor, oxidized odor, juiciness, stickiness, fish flavor, and aftertaste decreased in $C D$ fillets from day 1 to day 10, while vegetable oil flavor increased over the 10 day time period (Table 2). All sensory attributes decreased from day 1 to day 10 in Flax fillets. Increases in fish odor, oxidized odor, fish flavor, vegetable oil flavor and aftertaste are all indicators of spoilage. It may be correct to assume that as the storage time increases the presence of these sensory attributes will increase as well. From what was observed in this study, this was not the case. The trout fillets did not follow a normal spoilage process. From the results obtained it seems that the incubator reached low temperatures, causing the fillets to freeze and delay the normal spoilage process.

Within the three CD Reps and the three Flax Reps, there were no significant differences in any of the attributes for the data obtained from day 1 and day 10 . Therefore, the responses from the panelists were averaged for the CD fillets, as well as for the Flax fillets. Responses from day 1 only were further interpreted in Chapter III.

\section{Further Analysis}

Results of texture and cooking yield analyses are presented in Table $\mathbf{3}$ and Table 4, respectively. An increase in shear force was observed in CD and Flax groups from day 1 to day 10. Foegding and others (1996) suggest that firmness of cooked fish meats is related to muscle $\mathrm{pH}$ and water content. As fish are stored, muscle $\mathrm{pH}$ has 
been reported to decline (Hebard and others 2008; Ježek and Buchtová 2007;

Stenstrom 1985). Dryness or loss of moisture is also a characteristic of spoilage. Ando and others (1992) observed softening of rainbow trout during chilled storage. The temperature variation over the 10-day period seemed to have affected shear force measurements as well. It would be expected that the longer the storage period, the softer the fillets would become. Because our fillets became more firm, this supports the speculation that the incubator dropped to freezing temperatures and delayed the normal spoilage process of the fillets.

An increase in cooking loss was observed in $C D$ and Flax groups from day 1 to day 10 . Kamireddy and others (2003) also reported a decrease in cooking yield (increase in loss) over a 14 day time period. Temperature fluctuation over the 10 day storage period may have attributed to the decreased ability of the fillet muscle to retain moisture during cooking.

Statistics were performed on day 1 of the color analysis data only. It was determined that there were no differences $(P>0.05)$ between Reps within each group. Groups were not compared for statistical significance. Although statistics were not performed on the remaining color analysis data, it was observed that from day 1 to day 10 color $\mathrm{L}$ and color $\mathrm{a}^{*}$ increased in $\mathrm{CD}$ and Flax fillets (Table 5). Color $\mathrm{b}^{\star}$ decreased from day 1 to day 10 . This indicates that $C D$ and Flax fillets experienced similar reactions to the temperature environment as they both experienced an increase in lightness and redness, and a decrease in yellowness. Values on each day were similar for CD and Flax fillets.

No significant differences $(P>0.05)$ were found between Reps in each group for 
TBARS. No significant difference $(P>0.05)$ in proximate composition was found among trout fillets from Reps within each group and between groups. This is to be expected as both feeds contained the same macronutrient composition (Table 1). There was a significant difference $(P<0.05)$ in the percentages of ALA, EPA, and DHA in the CD and Flax fillets (Table 6). Five times more $(P<0.05)$ ALA was found in the Flax fillets when compared to CD fillets. Conversely, there was less $(P<$ 0.05) DHA and EPA in the Flax fillets than the CD fillets. Overall, Flax fillets contained a larger amount of total $\omega-3$ PUFA. Total $\omega-3$ PUFA included ALA, EPA, and DHA, as well as other $\omega-3$ PUFA that were not focused on in this experiment. These results further reflect the fatty acid composition of the two feeds (Table 1). No significant differences $(P>0.05)$ in fatty acid profiles were found between Reps in each group. 


\section{CONCLUSIONS}

The original objectives of this study were not met, due to uncontrollable factors. The incubator did not maintain a $4^{\circ} \mathrm{C}$ environment and based on results, neither the $\mathrm{CD}$ nor the Flax fillets spoiled as was expected. This leads to the conclusion that the incubator reached freezing temperatures which in turn caused a delay of the normal spoiling process. Measurements obtained from day 1 fillets were not affected by temperature changes. Differences $(P>0.05)$ were not observed between the three replications of the CD fish fillets for color, $\%$ ash, $\%$ moisture, $\%$ fat, $\%$ protein, TBARs, or fatty acid profile from day 1 fillets. The same was found for the three replications of the day 1 Flax fish fillets. This study showed that the fish from the three CD replications were not significantly different from each other, and that the fish from the three Flax replications were not significantly different from each other. For further study and analysis all replications of control fish were combined and all replications of treatment fish were combined. In addition to this, data from day 1 of the sensory attribute test was used for further interpretation in Chapter III of this document. Finally, it was determined that although Flax fillets were found to have less $(P<0.05)$ DHA and EPA than the CD fillets, overall they contained a larger amount of $\omega$-3 PUFA. Further experimentation on consumer acceptability and shelf life is needed to conclude if such a product may represent a niche market for producers in West Virginia. 


\section{REFERENCES}

Ando M, Toyohara H, and Sakaguchi M. 1992. Post-mortem tenderization of rainbow trout muscle caused by the disintegration of collagen fibers in the pericellular connective tissue. Nippon Suisan Gakkaishi. 58(3):567-570.

Assn of Official Analytical Chemists (AOAC). 1995. Official methods of analysis of the association of official analytical chemists, $16^{\text {th }}$ ed. Wash., DC: Assn of Official Analytical Chemists.

Chen Y- C, Nguyen J, Semmens K, Beamer S, Jaczynski J. 2006. Enhancement of omega-3 fatty acid content in rainbow trout (Oncorhynchus mykiss) fillets. JFS. 71(7):383-389.

Foegeding EA, Lanier TC, and Hultin HO. 1996. Characteristics of edible muscle tissues. In: O.Fennema, editor. Food Chemistry. New York:Marcel Dekker, Inc. p.915.

IFST. 1993. Shelf Life of Foods - Guidelines for its Determination and Prediction. IFST. London.

Hargis PS, Van Elswyk ME. 1993. Manipulating the fatty acid composition of poultry meat and eggs for the health conscious consumer. World's Pout Sci J 49: 2251-264.

Jeyasekaran G, Ganesan P, Maheswari K, Jeya Shakila R, Sukumar D. 2004. Effect of delayed icing on the microbiological quality of tropical fish: barracudas (Sphyraena barracuda). JFS. 69 (7):197-200.

Ježek F, Buchtová H. 2007. Physical and chemical changes in fresh chilled muscle tissue of common carp (Cyprinus capio L.) packed in a modified atmosphere. Acta Vet Brno 76: S83-00.

López-Ferrer S, Baucells MD, Barroeta AC, Grashorn MA. 1999. n-3 Enhancement of chicken meat using fish oil: alternative substitution with rapeseed and linseed oil. Poultry Science. 78:356-365.

Miller D, Robisch P. 1969. Comparitive effect of herring, menhaden, and safflower oils on broiler tissues fatty acid composition and flavor. Poultry Science 48(6): 2146-2159.

National Research Council. 1993. Composition of feed ingredients. Washington, DC: National Academy Press, pp64-71.

USDA: US Department of Health and Human Services. 2005.Dietary Guidelines for Americans (HHS publication number: HHS-ODPHP-2005-01-DGA-A) Washington, DC: U.S. Government Printing Office. 
Yagiz Y, Kristinsson HG, Balaban MO, Marshall MR. 2007. Effect of high pressure treatment on the quality of rainbow trout (Oncorhynchus mykiss) and Mahi Mahi (Coryphaena hippurus). JFS. 72: 509-515.

Yu Tc, Sinnhuber RO. 1957. 2-Thiobarbituric acid method for the measurement of rancidity in fishery products. Food Technol 11:104-108. 


\section{TABLES}

Table 1. Feed proximate composition comparison of two diets: flaxseed-oil enhanced (Flax) and control diet $(C D)$. Proximate composition of the feeds were not significantly different $(P>$ 0.05). Statistical analysis was not performed on the fatty acid profile of the feeds.

\begin{tabular}{lr|r} 
& CD & Flax \\
\hline \% Dry Matter & 93.24 & 93.43 \\
\% Moisture & 6.76 & 6.57 \\
\% Crude protein & 40.29 & 40.26 \\
\% Water soluble carbohydrates & 3.33 & 3.34 \\
\% Starch & 13.31 & 13.23 \\
\% Fat & 20.60 & 20.62 \\
\hline ALA & 2.97 & 25.66 \\
EPA & 7.44 & 1.58 \\
DHA & 6.75 & 1.81 \\
Total $\omega-3$ & 20.83 & 29.88 \\
\hline
\end{tabular}


Table 2. Sensory attributes of Day 1 and Day 10 control (CD) fillets and flaxseed-oil enhanced (Flax) fillets. ${ }^{+}$

\begin{tabular}{|c|c|c|c|c|c|c|c|c|}
\hline Diet: & Day: & $\begin{array}{l}\tilde{0} \\
\overline{0} \\
\frac{1}{n} \\
\end{array}$ & 芯㻤 & 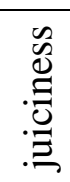 & 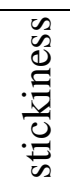 & 氞 & 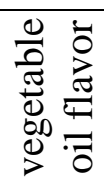 & 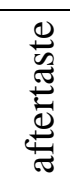 \\
\hline \multirow[t]{2}{*}{ CD } & 1 & $5.2^{\mathrm{a}}$ & 3 & 6.2 & 5.2 & $3.8^{\mathrm{a}}$ & 2.5 & 3.6 \\
\hline & 10 & 3.6 & 2.6 & 5.5 & 4.6 & 2.9 & 5.7 & 2.6 \\
\hline \multirow[t]{2}{*}{ Flax } & 1 & $\overline{7.33^{b}}$ & 2.5 & 6.8 & 5.6 & $2.8^{\mathrm{b}}$ & 2.1 & 3 \\
\hline & 10 & 2.9 & 2.2 & 4.9 & 5.3 & 2.5 & 1.4 & 2 \\
\hline
\end{tabular}

${ }^{+}$Values are mean scores $(\mathrm{n}=11)$ for each attribute. Responses from 11 semi-trained panelists were quantified using a $10 \mathrm{~cm}$ scale with 1 representing a small presence of the attribute and 10 representing a large presence if the attribute.

${ }^{a, b}$ Indicates significant difference between treatments on day $1(P<0.05)$. Statistical analysis was performed on day 1 of this data only. 
Table 3. Texture analysis of cooked trout fillets fed two diets: flaxseed-oil enhanced diet (Flax) and control diet (CD). Texture is expressed as force ( $g$ )/ weight (g). Results for each diet and day is expressed as the average of one measurement from each of three fillets. Statistical analysis was not performed on this data.

\begin{tabular}{|c|ccccc|}
\hline \multirow{2}{*}{} & \multicolumn{5}{|l}{ Force / Weight (g / g) } \\
\cline { 2 - 6 } & Day 1 & Day 3 & Day 6 & Day 8 & Day 10 \\
\hline CD & 248.4 & 225 & 891.9 & 289.7 & 268.6 \\
Flax & 246.3 & 390.5 & 336.3 & 297.5 & 268.5 \\
\hline
\end{tabular}


Table 4. Cooking yield (\% Yield) of trout fillets fed two diets: flaxseed-oil enhanced diet (Flax) and control diet (CD). Results are expressed as the average \% yield from 6 fillets for each diet and day. Statistical analysis was not performed on this data.

\begin{tabular}{|c|ccccc|}
\hline & \%Yield & & & & \\
\cline { 2 - 6 } & Day 1 & Day 3 & Day 6 & Day 8 & Day 10 \\
\hline CD & 86.2 & 89 & 88.9 & 87.4 & 87.9 \\
Flax & 83.4 & 89.9 & 86.8 & 103.2 & 91 \\
\hline
\end{tabular}


Table 5. Color analysis $\left(L, a^{*}, b^{*}\right)$ of cooked trout fillets fed two diets: flaxseed-oil enhanced diet (Flax) and control diet (CD). Results for each diet and day are expressed as the average of 2 measurements from each of three fillets. Statistical analysis was not performed over the 10 day storage period.

\begin{tabular}{|c|cc|cc|cc|}
\hline & \multicolumn{7}{|c|}{ Color and treatment: } \\
\cline { 2 - 7 } & L CD & L Flax & a* CD & a* Flax & b* CD & b* Flax \\
\hline Day 1 & 76.9 & 78.5 & 1.44 & 1.68 & 19.9 & 21.3 \\
Day3 & 63.4 & 70.3 & 4.1 & 3.9 & 16.5 & 18.4 \\
Day 6 & 65.4 & 71.8 & 4 & 3.7 & 15.8 & 18 \\
Day 8 & 67.3 & 73 & 5.2 & 4.2 & 17 & 17 \\
Day 10 & 69.8 & 68.4 & 4.8 & 3.8 & 16.8 & 16.7 \\
\hline
\end{tabular}


Table 6. Omega-3 polyunsaturated fatty acid (PUFA) content of control (CD) and flaxseed-oil enhanced (Flax) fillets.

\begin{tabular}{c|c|c|c|c|c} 
& ALA & EPA & DHA & Other $\omega-3$ & Total $\omega-3$ \\
\hline CD & $2.79 \pm 1.02^{\mathrm{a}}$ & $5.17 \pm .31^{\mathrm{a}}$ & $14.45 \pm 0.81^{\mathrm{a}}$ & 3.9 & $26.3^{\mathrm{a}}$ \\
Flax & $13.58 \pm 1.02^{\mathrm{b}}$ & $3.83 \pm 0.31^{\mathrm{b}}$ & $11.09 \pm 0.81^{\mathrm{b}}$ & 4.3 & $32.8^{\mathrm{b}}$
\end{tabular}

${ }^{+}$Values are given as g / $100 \mathrm{~g}$ lipid. Data are given as mean scores \pm SE $(\mathrm{n}=9)$ for each treatment for each analysis

a,b Differences in a vertical column indicate significant differences (least-squared difference test; $P<0.05)$. Statistics were not performed on other $\omega$-3 PUFA. 
APPENDIX B: Spring-fed gravity flow-through raceway system.*

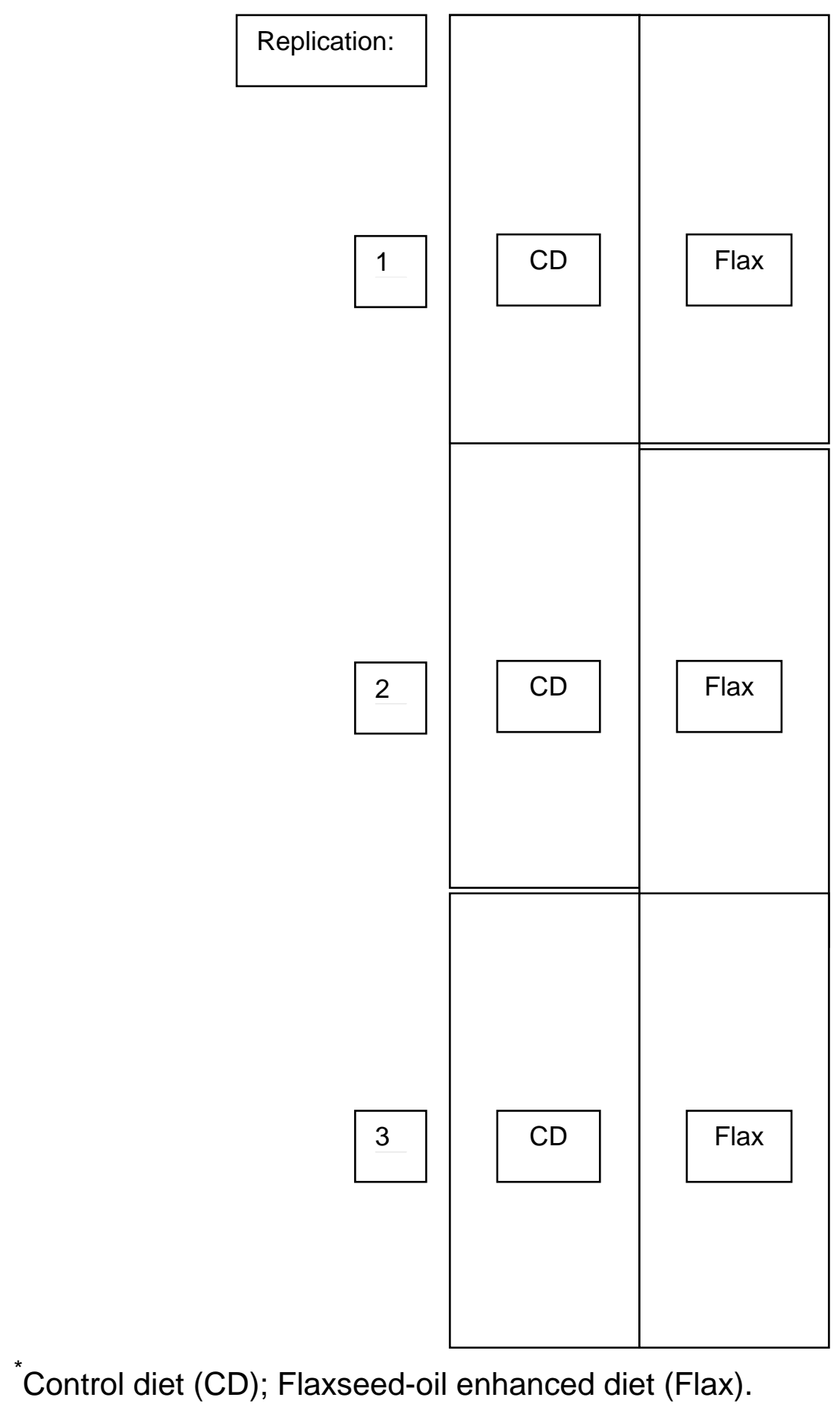




\section{APPENDIX C: Consent form for participation in sensory attribute \\ evaluations.}

\section{West VirginiaUniversity}

Davis College of Agriculture, Forestry and Consumer Sciences

Informed Consent for Participants in Research Projects Involving Human Subjects

Investigators Kristen Matak, Assistant Professor

Division of Animal and Nutritional Sciences

Courtney Simmons, Graduate Student

Human Nutrition and Foods

\section{Purpose of this Research/Project}

\section{Title of Project: Sensory Evaluation of Brook Trout}

The purpose of this research study is to determine whether a difference in sensory characteristics exists between brook trout raised on a traditional diet verses a treatment diet.

\section{Procedures}

There will one training sessions and 5 tasting sessions over a period of 3 weeks involving about 30 minutes at each session. You will be presented with 6 sets of samples and asked to rank certain sensory characteristics of the samples on a scale. Samples may be compared to a previously scored reference sample. As a panelist, it is critical for you complete your session.

The research will be conducted in the test kitchen at room 110 Agricultural Sciences Annex.

\section{Benefits/Risks}

Your participation in the project will provide information about the effect diet on sensory properties of fish. You will have access to the results of the panel at the completion of the study. 
There are no identifiable risks associated with tasting these fish samples.

\section{Extent of Anonymity and Confidentiality}

The results of your performance are strictly confidential. Individual panelists will not be referred to in any publications or reviews.

\section{Compensation}

There is no monetary compensation for participation in this project. However, a candy treat will be offered at the end of the session.

\section{Freedom to Withdraw}

If after becoming familiar with the sensory project you chose not to participate, you may withdraw without penalty. It is essential to the success of the sensory panel that you complete each session; however, there may be circumstances under which that you may chose not to complete your session, you may also withdraw at any time without penalty.

\section{Approval of Research}

This research has been approved by the Institutional Review Board for projects involving human subjects at West Virginia University. The IRB Approval is on file.

Should you have any pertinent questions about this research or its conduct, and research subjects' rights, and whom to contact in the event of a research-related injury to the subject, you may contact:

Kristen Matak (Investigator) Courtney Simmons (Investigator) Paul Lewis (Director ANS) Charles Craig (Director IRB)
Phone: (304) 293-2631 x 4401

Phone: (304) 2293-2631 x 4412

Phone: (302) 293-2231 x 4413

Phone: (304) 293-6094 


\section{Subject's Responsibilities}

I know of no reason that I cannot participate in this study that requires me to taste 6 fish samples in one session.

Signature/date

Please provide an email address and phone number so the investigator may reach you in case of emergency of schedule changes. 


\section{APPENDIX D: Sensory attribute instructions.}

\section{INSTRUCTIONS:}

- Evaluate trout samples for odor, flavor, juiciness, tenderness, stickiness, and aftertaste by placing a vertical mark on the following line scales.

- You may choose to swallow or expectorate the samples into the cup provided.

- Sip water and eat crackers between samples. 


\section{APPENDIX E: Sensory attribute scorecard. ${ }^{*}$}

Sample number:

Fish Odor

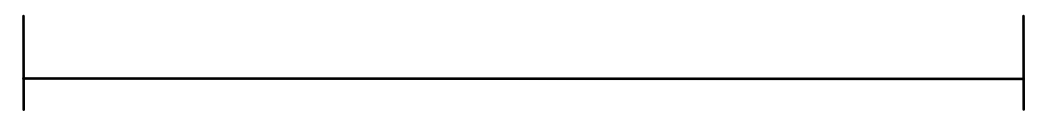
Slight
Strong

Fish Flavor

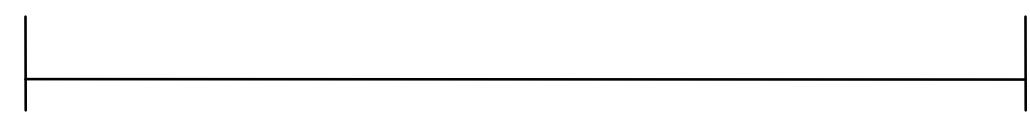

Slight

Strong

Vegetable Oil Flavor

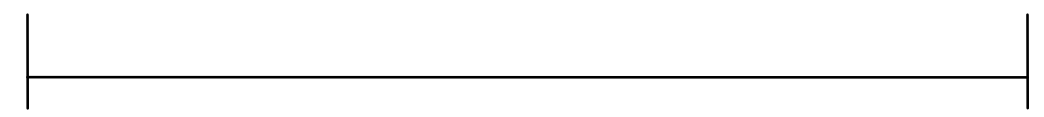

Slight Strong

Juiciness

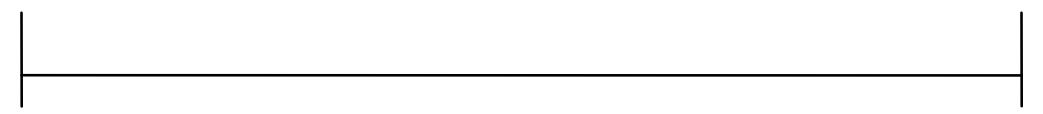

Very Juicy — Dry

Tenderness

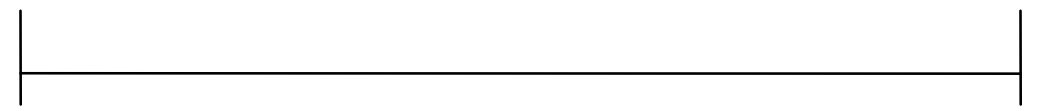

Very Tender

Tough

Stickiness

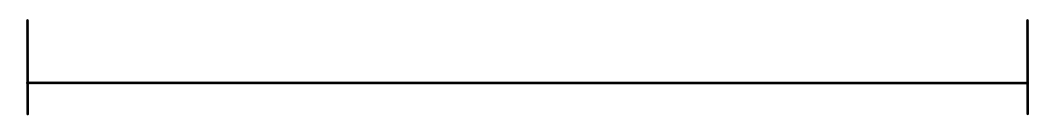

Very Sticky

Not Sticky

Aftertaste

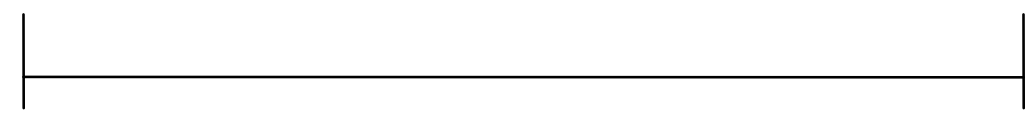

Slight

Strong

${ }^{*}$ Each line is $10 \mathrm{~cm}$ long. 
APPENDIX F: Day 1 sensory attribute results.

Fish Odor

\begin{tabular}{|c|ccc|ccc|}
\hline Panelist & CD 1 & CD 2 & CD 3 & Flax 1 & Flax 2 & Flax 3 \\
\hline 1 & 5.4 & 5.2 & 6.1 & 4.1 & 5.1 & 2.5 \\
2 & 3.5 & 1.4 & 3.9 & 2.6 & 3.7 & 2.8 \\
3 & 3.0 & 8.6 & 3.3 & 4.2 & 3.6 & 2.8 \\
4 & 6.7 & 7.6 & 9.5 & 2.6 & 7.3 & 2.0 \\
5 & 3.6 & 6.6 & 4.6 & 0.8 & 1.1 & 1.4 \\
6 & 9.1 & 7.4 & 5.9 & 4.8 & 5.8 & 8.1 \\
7 & 6.8 & 9.6 & 8.4 & 1.1 & 1.5 & 7.3 \\
8 & 5.9 & 2.5 & 3.0 & 1.4 & 5.8 & 1.2 \\
9 & 1.2 & 5.5 & 2.6 & 1.2 & 0.2 & 5.5 \\
10 & 4.4 & 4.0 & 4.7 & 4.0 & 1.5 & 3.2 \\
11 & 5.9 & 1.6 & 4.9 & 2.9 & 3.3 & 4.8 \\
\hline Average & 5.0 & 5.5 & 5.2 & 2.7 & 3.5 & 3.8 \\
\hline Overall & \multicolumn{7}{|c|}{} & & 3.3 \\
Average & \multicolumn{7}{|c}{5.2} & & \\
\hline
\end{tabular}

\section{Oxidized}

Odor

\begin{tabular}{|c|ccc|ccc|}
\hline Panelist & CD 1 & CD 2 & CD 3 & Flax 1 & Flax 2 & Flax 3 \\
\hline 1 & 2.3 & 2.7 & 0.8 & 3.8 & 0.6 & 3.6 \\
2 & 3.9 & 0.3 & 2.0 & 4.4 & 2.4 & 0.3 \\
3 & 4.7 & 7.8 & 3.4 & 2.7 & 1.9 & 2.1 \\
4 & 2.5 & 2.1 & 5.7 & 1.0 & 6.0 & 0.8 \\
5 & 1.3 & 0.3 & 1.6 & 0.5 & 0.7 & 0.5 \\
6 & 8.9 & 6.4 & 8.0 & 2.2 & 8.2 & 6.9 \\
7 & 1.8 & 1.7 & 1.0 & 2.9 & 3.3 & 4.1 \\
8 & 3.8 & 1.6 & 2.2 & 0.4 & 5.9 & 0.5 \\
9 & 0.2 & 0.7 & 2.1 & 0.1 & 1.3 & 0.2 \\
10 & 1.4 & 6.1 & 5.1 & 1.9 & 0.9 & 2.7 \\
11 & 3.2 & 3.7 & 3.0 & 1.7 & 4.6 & 2.6 \\
Average & 3.1 & 3.0 & 3.0 & 2.0 & 3.3 & 2.2 \\
\hline Overall & & & & & \\
Average & & 3.0 & & \\
\hline
\end{tabular}




\section{Juiciness}

\begin{tabular}{|c|ccc|ccc|}
\hline Panelist & CD 1 & CD 2 & CD 3 & Flax 1 & Flax 2 & Flax 3 \\
\hline 1 & 6.1 & 5.1 & 8.1 & 4.9 & 7.6 & 7.4 \\
2 & 5.8 & 2.5 & 2.1 & 8.7 & 5.7 & 3.4 \\
3 & 9.6 & 8.0 & 7.4 & 9.0 & 8.8 & 7.3 \\
4 & 5.9 & 6.9 & 3.0 & 7.5 & 7.5 & 5.0 \\
5 & 6.1 & 9.8 & 9.1 & 8.2 & 7.7 & 6.9 \\
6 & 1.1 & 4.9 & 7.4 & 8.2 & 8.6 & 2.1 \\
7 & 9.7 & 3.9 & 9.3 & 5.8 & 9.7 & 8.0 \\
8 & 4.2 & 5.0 & 7.8 & 8.5 & 2.2 & 6.0 \\
9 & 6.5 & 7.4 & 5.6 & 6.4 & 5.5 & 9.3 \\
10 & 7.1 & 3.3 & 8.8 & 5.6 & 3.8 & 7.8 \\
11 & 4.1 & 8.5 & 5.9 & 8.6 & 3.8 & 5.8 \\
\hline Average & 6.0 & 5.9 & 6.8 & 7.4 & 6.4 & 6.5 \\
\hline Overall & \multicolumn{7}{r|}{} & & & 6.8 \\
Average & & 6.2 & & &
\end{tabular}

\section{Stickiness}

\begin{tabular}{|c|ccc|ccc|}
\hline Panelist & CD 1 & CD 2 & CD 3 & Flax 1 & Flax 2 & Flax 3 \\
\hline 1 & 6.3 & 5.1 & 8.0 & 5.7 & 5.0 & 6.1 \\
2 & 1.3 & 6.4 & 4.6 & 7.1 & 3.0 & 3.2 \\
3 & 3.2 & 8.0 & 6.7 & 8.0 & 4.9 & 4.0 \\
4 & 8.1 & 2.5 & 7.0 & 9.6 & 9.8 & 6.0 \\
5 & 7.9 & 7.2 & 2.1 & 7.0 & 8.0 & 2.2 \\
6 & 8.1 & 3.8 & 1.5 & 1.7 & 2.3 & 8.8 \\
7 & 5.7 & 8.0 & 3.5 & 5.2 & 8.7 & 6.8 \\
8 & 6.5 & 5.6 & 5.1 & 2.5 & 5.1 & 7.8 \\
9 & 3.2 & 6.2 & 7.4 & 2.5 & 2.0 & 4.9 \\
10 & 3.9 & 3.9 & 1.9 & 8.0 & 7.5 & 3.8 \\
11 & 7.9 & 0.2 & 3.7 & 3.5 & 8.5 & 4.7 \\
\hline Average & 5.6 & 5.2 & 4.7 & 5.5 & 5.9 & 5.3 \\
\hline Overall & \multicolumn{7}{r|}{} & & & \\
Average & & 5.2 & & & \\
\hline
\end{tabular}


Fish Flavor

\begin{tabular}{|c|ccc|ccc|}
\hline Panelist & CD 1 & CD 2 & CD 3 & Flax 1 & Flax 2 & Flax 3 \\
\hline 1 & 6.0 & 2.4 & 1.4 & 1.2 & 4.8 & 1.3 \\
2 & 1.2 & 0.9 & 0.9 & 1.8 & 1.3 & 1.3 \\
3 & 8.0 & 5.8 & 5.7 & 2.7 & 2.8 & 3.4 \\
4 & 7.1 & 6.4 & 5.1 & 5.7 & 6.6 & 6.0 \\
5 & 2.4 & 2.6 & 1.0 & 0.4 & 2.1 & 0.4 \\
6 & 8.4 & 2.5 & 6.4 & 3.2 & 2.1 & 6.0 \\
7 & 1.6 & 1.0 & 7.8 & 1.6 & 1.1 & 3.6 \\
8 & 6.8 & 3.3 & 1.0 & 1.6 & 6.7 & 2.2 \\
9 & 3.7 & 4.1 & 1.1 & 1.4 & 0.7 & 4.3 \\
10 & 0.8 & 3.5 & 2.1 & 2.7 & 2.3 & 3.2 \\
11 & 4.1 & 6.4 & 4.7 & 1.5 & 1.5 & 5.6 \\
\hline Average & 4.6 & 3.5 & 3.4 & 2.2 & 2.9 & 3.4 \\
\hline Overall & \multicolumn{7}{|c|}{} \\
Average & 3.8 & & \\
\hline
\end{tabular}

\section{Vegetable Oil}

Flavor

\begin{tabular}{|c|ccc|ccc|}
\hline Panelist & CD 1 & CD 2 & CD 3 & Flax 1 & Flax 2 & Flax 3 \\
\hline 1 & 3.3 & 2.3 & 1.9 & 2.6 & 2.2 & 2.2 \\
2 & 1.7 & 0.9 & 1.3 & 1.9 & 1.6 & 2.9 \\
3 & 6.2 & 3.2 & 3.7 & 4.5 & 2.9 & 3.0 \\
4 & 0.1 & 1.1 & 4.9 & 0.2 & 0.2 & 0.3 \\
5 & 2.3 & 0.6 & 1.7 & 0.9 & 2.9 & 0.9 \\
6 & 1.4 & 0.5 & 1.8 & 1.6 & 1.5 & 1.2 \\
7 & 3.6 & 6.3 & 1.0 & 1.6 & 3.5 & 0.7 \\
8 & 4.1 & 2.9 & 1.9 & 0.6 & 5.7 & 1.2 \\
9 & 1.7 & 2.3 & 2.7 & 3.3 & 3.4 & 4.3 \\
10 & 2.1 & 3.1 & 1.1 & 1.1 & 1.7 & 2.4 \\
11 & 2.7 & 5.1 & 3.4 & 2.2 & 1.3 & 4.4 \\
\hline Average & 2.7 & 2.6 & 1.9 & 2.4 & 2.1 \\
\hline Overall & \multicolumn{7}{r|}{} & & & 2.1 \\
Average & \multicolumn{7}{|c}{2.5} & & \\
\hline
\end{tabular}




Aftertaste
\begin{tabular}{|c|ccc|ccc|}
\hline Panelist & CD 1 & CD 2 & CD 3 & Flax 1 & Flax 2 & Flax 3 \\
\hline 1 & 5.1 & 2.6 & 1.0 & 2.9 & 3.3 & 1.7 \\
2 & 2.2 & 2.7 & 1.8 & 2.3 & 2.6 & 0.6 \\
3 & 7.2 & 4.9 & 5.4 & 4.2 & 3.6 & 2.8 \\
4 & 2.1 & 5.5 & 9.3 & 8.0 & 3.5 & 6.7 \\
5 & 2.9 & 0.3 & 1.8 & 1.4 & 1.8 & 2.3 \\
6 & 8.1 & 2.4 & 8.1 & 3.2 & 2.1 & 7.2 \\
7 & 0.5 & 3.1 & 7.3 & 6.2 & 0.9 & 2.9 \\
8 & 4.8 & 1.7 & 1.1 & 0.6 & 5.6 & 2.1 \\
9 & 0.3 & 1.9 & 5.0 & 1.8 & 5.5 & 1.4 \\
10 & 2.6 & 0.8 & 4.3 & 4.0 & 0.9 & 0.8 \\
11 & 3.8 & 6.1 & 3.3 & 1.8 & 0.3 & 4.0 \\
\hline Average & 3.6 & 2.9 & 4.4 & 3.3 & 2.7 & 3.0 \\
\hline Overall & \multicolumn{7}{|c}{} & & & 3.0 \\
Average & \multicolumn{7}{|c}{} \\
\hline
\end{tabular}




\section{APPENDIX G: Consent form for difference and preference testing.}

\section{West VirginiaUniversity}

Davis College of Agriculture, Forestry and Consumer Sciences

Informed Consent for Participants in Research Projects Involving Human Subjects

Investigators $\quad$ Kristen Matak, Assistant Professor

Division of Animal and Nutritional Sciences

Courtney Simmons, Graduate Student

Human Nutrition and Foods

\section{Purpose of this Research/Project}

\section{Title of Project: Sensory Evaluation of Brook Trout}

The purpose of this research study is to determine whether a difference in sensory characteristics exists between brook trout raised on a traditional diet verses a treatment diet.

\section{Procedures}

There will one tasting sessions lasting about 30 to 45 minutes. You will be presented with 3 sets of samples. For the first and second set of samples you will be asked to perform a triangle test. For the third sample set you will be asked to perform a preference test. As a panelist, it is critical for you complete your session.

The research will be conducted in the test kitchen at room 110 Agricultural Sciences Annex.

\section{Benefits/Risks}

Your participation in the project will provide information about the effect diet on sensory properties of fish. You will have access to the results of the panel at the completion of the study.

There are no identifiable risks associated with tasting these fish samples. 


\section{Extent of Anonymity and Confidentiality}

The results of your performance are strictly confidential. Individual panelists will not be referred to in any publications or reviews.

\section{Compensation}

There is no monetary compensation for participation in this project. However, a candy treat will be offered at the end of the session, as well as bonus points in HN\&F 171.

\section{Freedom to Withdraw}

If after becoming familiar with the sensory project you chose not to participate, you may withdraw without penalty. It is essential to the success of the sensory panel that you complete each session; however, there may be circumstances under which that you may chose not to complete your session, you may also withdraw at any time without penalty.

\section{Approval of Research}

This research has been approved by the Institutional Review Board for projects involving human subjects at West Virginia University. The IRB Approval is on file.

Should you have any pertinent questions about this research or its conduct, and research subjects' rights, and whom to contact in the event of a research-related injury to the subject, you may contact:

Kristen Matak (Investigator)

Phone: (304) 293-2631 x 4401

Courtney Simmons (Investigator)

Phone: (304) 2293-2631

Paul Lewis (Director ANS)

Phone: (302) 293-2231 x 4413

Charles Craig (Director IRB)

Phone: (304) 293-6094 
VIII. Subject's Responsibilities

I know of no reason that I cannot participate in this study that requires me to taste 8 fish samples in one session.

Signature/date

Please provide an email address and phone number so the investigator may reach you in case of emergency of schedule changes. 


\section{APPENDIX H: Sensory card used for triangle test.}

Panelist Name:

Date:

\section{a. Triangle Test}

\section{Instructions:}

1) Please record the numbers written on your set of samples:

2) Taste samples from left to right. Two are identical; determine which is the odd sample. If no difference is apparent, you must guess.

3) Which sample is the odd sample?

4) Please include any comments or observations about the samples below: 


\section{APPENDIX I: Sensory card used for preference test.}

Panelist Name:

Date:

\section{b. Preference Testing}

\section{Instructions:}

1) Please record the numbers written on your set of samples:

2) Taste the sample on the left first, and the sample on the right second.

3) Now that you have tasted both samples, which one do you prefer?

4) Please comment on the reasons for your choice: 


\section{APPENDIX J: Fatty acid analysis.}

\section{Extraction of Fats}

Homogenized freeze-dried biomass was placed in a Mojonnier flask with pyrogallic acid (100 mg), 2mL triglceride internal standard (C:11, triundecanoin) solution $(5 \mathrm{mg} / \mathrm{mL}$ in $\mathrm{CHCl} 3)$ and boiling granules. Ethanol $(2 \mathrm{~mL})$ was added and mixed until entire test portion was in solution. Ten $\mathrm{mL} \mathrm{HCl}(8.3 \mathrm{M})$ was added and mixed. The flask was then placed in a shaking water bath at $70-80{ }^{\circ} \mathrm{C}$ set at moderate agitation speed and maintained for 40 min. The contents of flask were mixed using a vortex mixer every 10 min to incorporate particulates adhering to the sides of flask. The flask was removed from the water bath and allowed to cool to room temperature $\left(20-25^{\circ} \mathrm{C}\right)$. Ethanol was added until it filled the bottom of the flask reservoir and mixed gently. Diethyl ether $(25 \mathrm{~mL})$ was then added to the flask. The flask was closed off with a stopper, placed in centrifuge basket in wrist action shaker and agitated for 5 min. The stopper was rinsed into flask with diethyl ether-petroleum ether mixture. Petroleum ether $(25 \mathrm{~mL})$ was added, the flask closed off and agitated for another $5 \mathrm{~min}$. The contents of the flask were separated by centrifugation ( 5 min at $600 \times \mathrm{g}$ ) and rest until the upper layer was clear. Again, the stopper was rinsed into flask with diethyl ether-petroleum ether mixture. The top layer (ether) was transferred into $150 \mathrm{~mL}$ beaker and ether was evaporated slowly on steam bath, using nitrogen stream to aid in evaporation. The residue remained in beaker contained extracted fat. 


\section{Methylation}

After complete drying with nitrogen gas, 2-3 mL chloroform and 2-3 mL diethyl ether were added to dissolve the extracted fat residue. This mixture was transferred to a glass vial and evaporated to dryness in $40^{\circ} \mathrm{C}$ water bath under nitrogen stream. Two $\mathrm{mL}, 7 \% \mathrm{BF} 3$ reagent and $1 \mathrm{~mL}$ toluene were added to the vial. The vial was sealed with a screw cap top containing a Teflon/silicone septum and heated in oven $45 \mathrm{~min}$ at $100^{\circ} \mathrm{C}$. The vial was agitated gently every $10 \mathrm{~min}$ and allowed to cool to room temperature $\left(20-25^{\circ} \mathrm{C}\right)$. After addition of 5 $\mathrm{mL} \mathrm{H} 2 \mathrm{O}, 1 \mathrm{~mL}$ hexane and $1 \mathrm{~g} \mathrm{Na} 2 \mathrm{SO} 4$, the vial was capped and agitated $1 \mathrm{~min}$. The contents of vial were allowed to rest so that layer separation could occur. The top layer containing the FAMEs was then transferred to another vial containing $1 \mathrm{~g} \mathrm{Na} 2 \mathrm{SO} 4$. 


\section{APPENDIX K: Fatty acid profiles.}

Control diet (CD) Rep 1:

Fatty Acid Profile (Expressed as Percent of Total Fat)

$\begin{array}{lrrr}\text { Myristic (14:0) } & 3.48 & 3.48 & 3.55 \\ \text { Myristoleic (14:1) } & 0.00 & 0.00 & 0.00 \\ \text { (C15:0) } & 0.00 & 0.00 & 0.00 \\ \text { Palmitic (16:0) } & 17.49 & 17.67 & 17.47 \\ \text { Palmitoleic (16:1) } & 6.57 & 6.52 & 6.70 \\ (17: 0) & 0.00 & 0.00 & 0.00 \\ \text { (17:1) } & 0.00 & 0.00 & 0.00 \\ \text { Stearic (18:0) } & 4.25 & 4.29 & 4.24 \\ \text { Elaidic (18:1t9) } & 0.00 & 0.00 & 0.00 \\ \text { Oleic (18:1n9) } & 16.03 & 15.90 & 16.31 \\ \text { Vaccenic (18:1n7) } & 3.41 & 3.42 & 3.45 \\ \text { Linoleic (18:2) } & 14.86 & 14.65 & 15.19 \\ \text { Linolenic (T18:3) } & \mathbf{2 . 8 2} & \mathbf{2 . 8 0} & \mathbf{2 . 8 9} \\ \text { (T18:4) } & \mathbf{1 . 0 4} & \mathbf{1 . 0 3} & \mathbf{1 . 0 5} \\ \text { Arachidic (20:0) } & 0.00 & 0.00 & 0.00 \\ \text { (20:1n9) } & 1.83 & 1.83 & 1.91 \\ \text { (20:3 T3) } & \mathbf{0 . 0 0} & \mathbf{0 . 0 0} & \mathbf{0 . 0 0} \\ \text { Arachidonic (20:4n6) } & 1.43 & 1.55 & 1.33 \\ \text { Arachidonic (20:4 T3) } & \mathbf{0 . 8 3} & \mathbf{0 . 8 5} & \mathbf{0 . 8 3} \\ \text { (20:5 T3; EPA) } & \mathbf{5 . 4 3} & \mathbf{5 . 5 7} & \mathbf{5 . 1 9} \\ \text { Docosanoic (22:0) } & 0.00 & 0.00 & 0.00 \\ \text { Erucic (22:1n9) } & 0.00 & 0.00 & 0.00 \\ \text { (22:5 T3; DPA) } & \mathbf{2 . 2 4} & \mathbf{2 . 1 6} \\ \text { (22:6 T3; DHA) } & \mathbf{1 5 . 6 2} & \mathbf{1 6 . 2 2} & 0.00 \\ \text { Lignoceric (24:0) } & 0.00 & 0.00 & 0.00 \\ \text { Nervonic (24:1n9) } & 0.00 & 0.00 & \mathbf{1 4 . 9 9} \\ \text { A Abbevian } & & \end{array}$

$\dagger$ Abbreviations: W/W\% or \%, weight/weight percent, or gram/100 gram sample (all are equivalent); ppm, parts per million; IU . international units; $\boldsymbol{g}$, gram; $\boldsymbol{m g}$, milligrams; $\boldsymbol{m c \boldsymbol { g }}$ or $\boldsymbol{\boldsymbol { g }}$, microgram; $\boldsymbol{l} \boldsymbol{b}$, pound; $\boldsymbol{n d} / \mathbf{0 . 0 0}$, not detected; $t r$, trace; <, 'less than' or below method detection limit (MDL); $\boldsymbol{R}$, duplicate run; $\mathbf{m E q} / \mathbf{k g}$, milliequivalents/kg; avg., average. Unless indicated otherwise, all data are presented on an ' $\boldsymbol{a}$ s is' basis. Omega 3 fatty acids (T-3) are bolded. 


\section{Control diet (CD) Rep 2:}

Fatty Acid Profile (Expressed as Percent of Total Fat)

$\begin{array}{lrrr}\text { Myristic (14:0) } & 3.45 & 3.51 & 3.45 \\ \text { Myristoleic (14:1) } & 0.00 & 0.00 & 0.00 \\ \text { (C15:0) } & 0.00 & 0.00 & 0.00 \\ \text { Palmitic (16:0) } & 15.70 & 15.69 & 15.62 \\ \text { Palmitoleic (16:1) } & 7.40 & 7.34 & 7.41 \\ (17: 0) & 0.00 & 0.00 & 0.00 \\ \text { (17:1) } & 0.60 & 0.62 & 0.61 \\ \text { Stearic (18:0) } & 3.83 & 3.82 & 3.81 \\ \text { Elaidic (18:1t9) } & 0.58 & 0.59 & 0.59 \\ \text { Oleic (18:1n9) } & 18.35 & 18.58 & 18.34 \\ \text { Vaccenic (18:1n7) } & 3.37 & 3.40 & 3.37 \\ \text { Linoleic (18:2) } & 16.26 & 16.44 & 16.22 \\ \text { Linolenic (T18:3) } & \mathbf{2 . 6 9} & \mathbf{2 . 7 2} & \mathbf{2 . 6 8} \\ \text { (T18:4) } & \mathbf{1 . 1 1} & \mathbf{1 . 1 2} & \mathbf{1 . 1 1} \\ \text { Arachidic (20:0) } & 0.00 & 0.00 & 0.00 \\ \text { (20:1n9) } & 1.80 & 1.82 & 1.80 \\ \text { (20:3 T3) } & \mathbf{0 . 0 0} & \mathbf{0 . 0 0} & \mathbf{0 . 0 0} \\ \text { Arachidonic (20:4n6) } & 1.29 & 1.27 & 1.29 \\ \text { Arachidonic (20:4 T3) } & \mathbf{0 . 8 2} & \mathbf{0 . 8 1} & \mathbf{0 . 8 2} \\ \text { (20:5 T3; EPA) } & \mathbf{4 . 7 4} & \mathbf{4 . 6 9} & \mathbf{4 . 7 2} \\ \text { Docosanoic (22:0) } & 0.00 & 0.00 & 0.00 \\ \text { Erucic (22:1n9) } & 0.00 & 0.00 & 0.00 \\ \text { (22:5 T3; DPA) } & \mathbf{2 . 1 2} & \mathbf{2 . 1 0} & \mathbf{1 3 . 1 0} \\ \text { (22:6 T3; DHA) } & \mathbf{1 3 . 5 0} & \mathbf{1 3 . 0 8} & 0.00 \\ \text { Lignoceric (24:0) } & 0.00 & 0.00 & 0.00 \\ \text { Nervonic (24:1n9) } & 0.00 & 0.00 & \end{array}$

† Abbreviations: W/W\% or \%, weight/weight percent, or gram/100 gram sample (all are equivalent); ppm, parts per million; IU . international units; $\boldsymbol{g}$, gram; $\boldsymbol{m g}$, milligrams; $\boldsymbol{m} \boldsymbol{c} \boldsymbol{g}$ or $\boldsymbol{\boldsymbol { g }}$, microgram; $\boldsymbol{l} \boldsymbol{b}$, pound; $\boldsymbol{n d} / \mathbf{0 . 0 0}$, not detected; $\boldsymbol{t}$, trace; <, 'less than' or below method detection limit (MDL); $\boldsymbol{R}$, duplicate run; $\mathbf{m E q} / \mathbf{k g}$, milliequivalents/kg; avg., average. Unless indicated otherwise, all data are presented on an ' $\boldsymbol{a}$ s is' basis. Omega 3 fatty acids (T-3) are bolded. 


\section{Control diet (CD) Rep 3:}

Fatty Acid Profile (Expressed as Percent of Total Fat)

$\begin{array}{lrrr}\text { Myristic (14:0) } & 3.17 & 3.22 & 3.23 \\ \text { Myristoleic (14:1) } & 0.00 & 0.00 & 0.00 \\ \text { (C15:0) } & 0.00 & 0.00 & 0.00 \\ \text { Palmitic (16:0) } & 15.41 & 15.25 & 15.57 \\ \text { Palmitoleic (16:1) } & 7.24 & 7.20 & 7.13 \\ (17: 0) & 0.00 & 0.00 & 0.00 \\ \text { (17:1) } & 0.00 & 0.58 & 0.00 \\ \text { Stearic (18:0) } & 3.73 & 3.66 & 3.72 \\ \text { Elaidic (18:1t9) } & 0.00 & 0.55 & 0.00 \\ \text { Oleic (18:1n9) } & 18.55 & 18.45 & 18.35 \\ \text { Vaccenic (18:1n7) } & 3.35 & 3.28 & 3.30 \\ \text { Linoleic (18:2) } & 15.75 & 15.64 & 15.52 \\ \text { Linolenic (T18:3) } & \mathbf{2 . 8 5} & \mathbf{2 . 8 3} & \mathbf{2 . 8 4} \\ \text { (T18:4) } & \mathbf{1 . 1 0} & \mathbf{1 . 1 1} & \mathbf{1 . 0 8} \\ \text { Arachidic (20:0) } & 0.00 & 0.00 & 0.00 \\ \text { (20:1n9) } & 1.97 & 1.96 & 1.96 \\ \text { (20:3 T3) } & \mathbf{0 . 0 0} & \mathbf{0 . 0 0} & \mathbf{0 . 0 0} \\ \text { Arachidonic (20:4n6) } & 1.36 & 1.27 & 1.30 \\ \text { Arachidonic (20:4 T3) } & \mathbf{0 . 8 5} & \mathbf{0 . 8 4} & \mathbf{0 . 8 3} \\ \text { (20:5 T3; EPA) } & \mathbf{5 . 4 1} & \mathbf{5 . 3 2} & \mathbf{5 . 4 8} \\ \text { Docosanoic (22:0) } & 0.00 & 0.00 & 0.00 \\ \text { Erucic (22:1n9) } & 0.00 & 0.00 & 0.00 \\ \text { (22:5 T3; DPA) } & \mathbf{2 . 1 7} & \mathbf{2 . 1 3} & \mathbf{1 4 . 8 8} \\ \text { (22:6 T3; DHA) } & \mathbf{1 4 . 4 9} & \mathbf{1 4 . 0 6} & 0.00 \\ \text { Lignoceric (24:0) } & 0.00 & 0.00 & 0.00 \\ \text { Nervonic (24:1n9) } & 0.00 & 0.00 & \end{array}$

† Abbreviations: W/W\% or \%, weight/weight percent, or gram/100 gram sample (all are equivalent); ppm, parts per million; IU . international units; $\boldsymbol{g}$, gram; $\boldsymbol{m g}$, milligrams; $\boldsymbol{m} \boldsymbol{c} \boldsymbol{g}$ or $\boldsymbol{\boldsymbol { g }}$, microgram; $\boldsymbol{l} \boldsymbol{b}$, pound; $\boldsymbol{n d} / \mathbf{0 . 0 0}$, not detected; $\boldsymbol{t}$, trace; <, 'less than' or below method detection limit (MDL); $\boldsymbol{R}$, duplicate run; $\mathbf{m E q} / \mathbf{k g}$, milliequivalents/kg; avg., average. Unless indicated otherwise, all data are presented on an ' $\boldsymbol{a}$ s is' basis. Omega 3 fatty acids (T-3) are bolded. 
Flaxseed-oil enhanced diet (Flax) Rep 1:

Fatty Acid Profile (Expressed as Percent of Total Fat)

$\begin{array}{lrrr}\text { Myristic (14:0) } & 1.35 & 1.56 & 1.43 \\ \text { Myristoleic (14:1) } & 0.00 & 0.00 & 0.00 \\ \text { (C15:0) } & 0.00 & 0.00 & 0.00 \\ \text { Palmitic (16:0) } & 15.19 & 15.11 & 14.99 \\ \text { Palmitoleic (16:1) } & 2.91 & 3.21 & 3.08 \\ \text { (17:0) } & 0.00 & 0.00 & 0.00 \\ (17: 1) & 0.00 & 0.00 & 0.00 \\ \text { Stearic (18:0) } & 4.77 & 4.73 & 4.74 \\ \text { Elaidic (18:1t9) } & 0.00 & 0.00 & 0.00 \\ \text { Oleic (18:1n9) } & 18.38 & 18.86 & 19.01 \\ \text { Vaccenic (18:1n7) } & 1.95 & 2.02 & 2.00 \\ \text { Linoleic (18:2) } & 17.75 & 18.08 & 18.28 \\ \text { Linolenic (T18:3) } & \mathbf{1 4 . 9 1} & \mathbf{1 4 . 6 8} & \mathbf{1 5 . 1 8} \\ \text { (T18:4) } & \mathbf{2 . 1 7} & \mathbf{2 . 1 8} & \mathbf{2 . 2 2} \\ \text { Arachidic (20:0) } & 0.00 & 0.00 & 0.00 \\ \text { (20:1n9) } & 0.00 & 0.00 & 0.00 \\ \text { (20:3 T3) } & \mathbf{0 . 0 0} & \mathbf{0 . 0 0} & \mathbf{0 . 0 0} \\ \text { Arachidonic (20:4n6) } & 1.71 & 1.73 & 1.61 \\ \text { Arachidonic (20:4 T3) } & \mathbf{1 . 3 4} & \mathbf{1 . 3 3} & \mathbf{1 . 3 1} \\ \text { (20:5 T3; EPA) } & \mathbf{3 . 9 4} & \mathbf{3 . 7 6} & 3.66 \\ \text { Docosanoic (22:0) } & 0.00 & 0.00 & 0.00 \\ \text { Erucic (22:1n9) } & 0.00 & 0.00 & 0.00 \\ \text { (22:5 T3; DPA) } & \mathbf{1 . 3 4} & \mathbf{1 . 2 9} & \mathbf{1 1 . 2 3} \\ \text { (22:6 T3; DHA) } & \mathbf{1 2 . 2 8} & \mathbf{1 1 . 4 6} & 0.00 \\ \text { Lignoceric (24:0) } & 0.00 & 0.00 & 0.00 \\ \text { Nervonic (24:1n9) } & 0.00 & 0.00 & \end{array}$

† Abbreviations: W/W\% or \%, weight/weight percent, or gram/100 gram sample (all are equivalent); ppm, parts per million; IU . international units; $\boldsymbol{g}$, gram; $\boldsymbol{m g}$, milligrams; $\boldsymbol{m} \boldsymbol{c} \boldsymbol{g}$ or $\boldsymbol{\boldsymbol { g }}$, microgram; $\boldsymbol{l} \boldsymbol{b}$, pound; $\boldsymbol{n d} / \mathbf{0 . 0 0}$, not detected; $\boldsymbol{t}$, trace; <, 'less than' or below method detection limit (MDL); $\boldsymbol{R}$, duplicate run; $\mathbf{m E q} / \mathbf{k g}$, milliequivalents/kg; avg., average. Unless indicated otherwise, all data are presented on an ' $\boldsymbol{a}$ s is' basis. Omega 3 fatty acids (T-3) are bolded. 
Flaxseed-oil enhanced diet (Flax) Rep 2:

Fatty Acid Profile (Expressed as Percent of Total Fat)

$\begin{array}{lrrr}\text { Myristic (14:0) } & 1.77 & 1.73 & 1.72 \\ \text { Myristoleic (14:1) } & 0.00 & 0.00 & 0.00 \\ \text { (C15:0) } & 0.00 & 0.00 & 0.00 \\ \text { Palmitic (16:0) } & 13.83 & 13.94 & 3.36 \\ \text { Palmitoleic (16:1) } & 3.39 & 0.00 & 3.57 \\ \text { (17:0) } & 0.00 & 0.00 & 0.00 \\ (17: 1) & 0.00 & 4.22 & 4.00 \\ \text { Stearic (18:0) } & 4.22 & 0.00 & 0.00 \\ \text { Elaidic (18:1t9) } & 0.00 & 19.11 & 19.41 \\ \text { Oleic (18:1n9) } & 19.47 & 2.05 & 2.11 \\ \text { Vaccenic (18:1n7) } & 2.08 & 18.74 & 18.96 \\ \text { Linoleic (18:2) } & 19.03 & \mathbf{1 4 . 8 9} & \mathbf{1 4 . 8 3} \\ \text { Linolenic (T18:3) } & \mathbf{1 5 . 0 3} & \mathbf{2 . 0 4} & \mathbf{2 . 0 1} \\ \text { (T18:4) } & \mathbf{2 . 0 6} & 0.00 & 0.00 \\ \text { Arachidic (20:0) } & 0.00 & 1.37 & 1.41 \\ \text { (20:1n9) } & 1.42 & \mathbf{0 . 0 0} & \mathbf{0 . 0 0} \\ \text { (20:3 T3) } & \mathbf{0 . 0 0} & 1.14 & 1.10 \\ \text { Arachidonic (20:4n6) } & 1.12 & \mathbf{1 . 0 5} & \mathbf{1 . 0 1} \\ \text { Arachidonic (20:4 T3) } & \mathbf{1 . 0 4} & \mathbf{3 . 2 3} & \mathbf{3 . 1 4} \\ \text { (20:5 T3; EPA) } & \mathbf{3 . 2 2} & 0.00 & 0.00 \\ \text { Docosanoic (22:0) } & 0.00 & 0.00 & 0.00 \\ \text { Erucic (22:1n9) } & 0.00 & \mathbf{1 . 2 0} & \mathbf{1 . 1 8} \\ \text { (22:5 T3; DPA) } & \mathbf{1 . 1 9} & \mathbf{9 . 4 8} & \mathbf{9 . 0 2} \\ \text { (22:6 T3; DHA) } & \mathbf{9 . 3 3} & 0.00 & 0.00 \\ \text { Lignoceric (24:0) } & 0.00 & 0.00 & 0.00 \\ \text { Nervonic (24:1n9) } & 0.00 & 9.00\end{array}$

† Abbreviations: W/W\% or \%, weight/weight percent, or gram/100 gram sample (all are equivalent); ppm, parts per million; IU . international units; $\boldsymbol{g}$, gram; $\boldsymbol{m g}$, milligrams; $\boldsymbol{m} \boldsymbol{c} \boldsymbol{g}$ or $\boldsymbol{\boldsymbol { g }}$, microgram; $\boldsymbol{l} \boldsymbol{b}$, pound; $\boldsymbol{n d} / \mathbf{0 . 0 0}$, not detected; $\boldsymbol{t}$, trace; <, 'less than' or below method detection limit (MDL); $\boldsymbol{R}$, duplicate run; $\mathbf{m E q} / \mathbf{k g}$, milliequivalents/kg; avg., average. Unless indicated otherwise, all data are presented on an ' $\boldsymbol{a}$ s is' basis. Omega 3 fatty acids (T-3) are bolded. 
Flaxseed-oil enhanced diet (Flax) Rep 3:

Fatty Acid Profile (Expressed as Percent of Total Fat)

$\begin{array}{lrrr}\text { Myristic (14:0) } & 1.93 & 1.82 & 1.92 \\ \text { Myristoleic (14:1) } & 0.00 & 0.00 & 0.00 \\ \text { (C15:0) } & 0.00 & 0.00 & 0.00 \\ \text { Palmitic (16:0) } & 15.77 & 15.78 & 15.44 \\ \text { Palmitoleic (16:1) } & 3.84 & 3.69 & 3.73 \\ (17: 0) & 0.00 & 0.00 & 0.00 \\ (17: 1) & 0.00 & 0.00 & 0.00 \\ \text { Stearic (18:0) } & 4.61 & 4.59 & 4.53 \\ \text { Elaidic (18:1t9) } & 0.00 & 0.00 & 0.00 \\ \text { Oleic (18:1n9) } & 18.62 & 18.10 & 18.38 \\ \text { Vaccenic (18:1n7) } & 2.35 & 2.35 & 2.40 \\ \text { Linoleic (18:2) } & 16.03 & 15.74 & 16.03 \\ \text { Linolenic (T18:3) } & \mathbf{1 0 . 6 4} & \mathbf{1 0 . 6 5} & \mathbf{1 0 . 7 8} \\ \text { (T18:4) } & \mathbf{1 . 8 3} & \mathbf{1 . 8 0} & \mathbf{1 . 8 8} \\ \text { Arachidic (20:0) } & 0.00 & 0.00 & 0.00 \\ \text { (20:1n9) } & 1.83 & 1.73 & 1.83 \\ \text { (20:3 T3) } & \mathbf{0 . 0 0} & \mathbf{0 . 0 0} & \mathbf{0 . 0 0} \\ \text { Arachidonic (20:4n6) } & 1.40 & 1.45 & 1.41 \\ \text { Arachidonic (20:4 T3) } & \mathbf{0 . 9 5} & \mathbf{1 . 0 2} & \mathbf{1 . 0 0} \\ \text { (20:5 T3; EPA) } & \mathbf{4 . 2 3} & \mathbf{4 . 7 4} & \mathbf{4 . 5 4} \\ \text { Docosanoic (22:0) } & 0.00 & 0.00 & 0.00 \\ \text { Erucic (22:1n9) } & 0.00 & 0.00 & 0.00 \\ \text { (22:5 T3; DPA) } & \mathbf{1 . 5 6} & \mathbf{1 . 7 2} & \mathbf{1 2 . 1 9} \\ \text { (22:6 T3; DHA) } & \mathbf{1 1 . 4 0} & \mathbf{1 3 . 3 8} & 0.00 \\ \text { Lignoceric (24:0) } & 0.00 & 0.00 & 0.00 \\ \text { Nervonic (24:1n9) } & 0.00 & 0.00 & \end{array}$

† Abbreviations: W/W\% or \%, weight/weight percent, or gram/100 gram sample (all are equivalent); ppm, parts per million; IU . international units; $\boldsymbol{g}$, gram; $\boldsymbol{m g}$, milligrams; $\boldsymbol{m} \boldsymbol{c} \boldsymbol{g}$ or $\boldsymbol{\boldsymbol { g }}$, microgram; $\boldsymbol{l} \boldsymbol{b}$, pound; $\boldsymbol{n d} / \mathbf{0 . 0 0}$, not detected; $\boldsymbol{t}$, trace; <, 'less than' or below method detection limit (MDL); $\boldsymbol{R}$, duplicate run; $\mathbf{m E q} / \mathbf{k g}$, milliequivalents/kg; avg., average. Unless indicated otherwise, all data are presented on an ' $\boldsymbol{a}$ s is' basis. Omega 3 fatty acids (T-3) are bolded. 


\section{APPENDIX L: Thiobarbituric acid reactive substances test procedure.}

\section{Instruments}

35-mL screw capped centrifuge tube

$\mathrm{N}_{2}$ gas

Vortex

Centrifuge

Spectrophotomter

Water bath

Ice bath

\section{Chemicals}

1. $0.1 \mathrm{~N} \mathrm{NaOH}: 0.4 \mathrm{~g}$ of $\mathrm{NaOH}$ are diluted to $100 \mathrm{~mL}$ distilled water.

2. $0.6 \mathrm{~N} \mathrm{HCl}: 5 \mathrm{~mL}$ of concentrated $\mathrm{HCl}(12.1 \mathrm{~N})$ are diuted to $100 \mathrm{~mL}$ distilled WATER.

3. $50 \mathrm{~mL}$ of $35 \%$ TCA: Mix $15.6 \mathrm{~mL}$ of $80 \%$ TCA and $34.4 \mathrm{~mL}$ distilled water.

4. TBA solution (69.4 mM): $1 \mathrm{~g}$ of TBA is dissolved in $75 \mathrm{~mL}$ of $0.1 \mathrm{~N} \mathrm{NaOH}$ and diluted to $100 \mathrm{~mL}$ with distilled water. TBA should be stored in the refrigerator.

5. TCA- $\mathrm{HCl}$ reagent: $50 \mathrm{~mL}$ of a $25 \%$ trichloroacetic acid (TCA) solution and $10 \mathrm{~mL}$ of $0.6 \mathrm{~N} \mathrm{HCl}$ are mixed with $430 \mathrm{~mL}$ of distilled water. Toltal volume is $500 \mathrm{~mL}$. TCA should be freshly prepared.

6. Antioxidant mixture: $200 \mathrm{mg}(0.2 \mathrm{~g})$ of tertiary butyl hydroxyl quinine (TBHQ) are dissolved in $1.6 \mathrm{~g}(1.6 \mathrm{~mL})$ of propylene glycol.

7. Chloroform

\section{Procedure}

1. Weigh $200 \mathrm{mg}(0.2000 \mathrm{~g})$ of sample in a screw-capped centrifuge tube. Blank tube is prepared without a sample.

2. Extraction: Add 3 drops of antioxidant mixture followed by $17 \mathrm{~mL}$ of $\mathrm{TCA}-\mathrm{HCl}$ reagent. Flush tube with $\mathrm{N}_{2}$ gas then cap tube. Vortex for 30 seconds.

3. Reaction: Add $3 \mathrm{~mL}$ of TBA solution. Flush tube with $\mathrm{N}_{2}$ gas then cap tube. Gentle vortex. Incubate in $100^{\circ} \mathrm{C}$ water bath for 30 minutes.

4. Stop reaction: Cool tube in ice bath for 5 minutes.

5. Extract reaction product: Add $5 \mathrm{~mL}$ cholorform (use glass pipette) and vortex for 15 seconds. Centrifuge at 3,000 rpm $(1000 \times \mathrm{g}), 4{ }^{\circ} \mathrm{C}$ for 10 minutes.

6. Detection: Transfer top layer (the bottom layer is chloroform) into plastic cuvette and read absorbance at $535 \mathrm{~nm}$.

\section{Calculation}

mg MDA / kg sample

$=($ Abs $/$ molar abs $) \times$ MW of MDA $\times 1000 \mathrm{mg} \times$ (total volume of sample/1000 mL) $\times(1000 \mathrm{~g} / \mathrm{g}$ of sample $)$

$=($ Abs $\times 72 \times 1000 \times 20 \times 1000) /(156,000 \times 1000 \times$ g of sample $)$

Conversion: $\mu$ mole MDA / kg sample $\times 72$ / $1000=$ mg MDA / kg sample 


\section{References}

Wang B, Pace RD, Dessai AP, Bevell-Benjamin A, Phillips B. 2002. Modified extraction method for determining thiobarbituric acid values in meat with increased specificity and simplicity. J Food Sci. 67(8): 2833-2836.

Yu Tc, Sinnhuber RO. 1957. 2-Thiobarbituric acid method for the measurement of rancidity in fishery products. Food Technol 11:104-108.

*In this study absorbancy was read at $532 \mathrm{~nm}$ as suggested by Wang and others (2002). 


\title{
APPENDIX M: Statistical analysis of muscle pH (Chapter III)
}

\author{
Analyses of PH \\ 10:49 Thursday, July 3, 2008121 \\ The GLM Procedure \\ Class Level Information \\ Class Levels Values \\ DIET $2 \mathrm{C} \mathrm{T}$ \\ DAY $\quad 6 \quad 1357911$ \\ Number of Observations Read 36 \\ Number of Observations Used 36 \\ Analyses of PH 10:49 Thursday, July 3, 2008122 \\ The GLM Procedure
}

Dependent Variable: mean

\begin{tabular}{|c|c|c|c|c|c|}
\hline \multicolumn{6}{|c|}{ Sum of } \\
\hline Source & DF & Squares & Mean Square & F Value & $\operatorname{Pr}>F$ \\
\hline Model & 11 & 0.94686265 & 0.08607842 & 72.03 & $<.0001$ \\
\hline Error & 24 & 0.02868148 & 0.00119506 & & \\
\hline Corrected Total & & 0.97554 & & & \\
\hline
\end{tabular}

R-Square Coeff Var Root MSE mean Mean

$\begin{array}{llll}0.970600 & 0.549751 & 0.034570 & 6.288241\end{array}$

\begin{tabular}{lcccccc} 
Source & DF & Type I SS & Mean Square & F Value & Pr $>$ F \\
DIET & 1 & 0.00086698 & 0.00086698 & 0.73 & 0.4028 \\
DAY & 5 & 0.86839784 & 0.17367957 & 145.33 & $<.0001$ \\
DIET*DAY & \multicolumn{7}{c}{5} & 0.07759784 & 0.01551957 & 12.99 & $<.0001$ \\
& & & & & & \\
Source & DF & Type III SS & Mean Square & F Value & Pr $>$ F \\
DIET & 1 & 0.00086698 & 0.00086698 & 0.73 & 0.4028 \\
DAY & 5 & 0.86839784 & 0.17367957 & $145.33<.0001$ \\
DIET*DAY & \multicolumn{7}{c}{5} & 0.07759784 & 0.01551957 & $12.99<.0001$
\end{tabular}

Analyses of PH 10:49 Thursday, July 3, 2008123

The GLM Procedure

Least Squares Means

Adjustment for Multiple Comparisons: Tukey

\begin{tabular}{|c|c|c|c|c|c|}
\hline \multirow[b]{3}{*}{ DIET } & \multicolumn{5}{|c|}{ H0:LSMean1= } \\
\hline & \multicolumn{2}{|c|}{ Standard } & \multicolumn{2}{|c|}{ H0:LSMEAN=0 } & \multirow{2}{*}{$\begin{array}{r}\text { LSMean2 } \\
\operatorname{Pr}>|\mathrm{t}|\end{array}$} \\
\hline & mean LSM & & Error & $\operatorname{Pr}>|t|$ & \\
\hline $\mathrm{C}$ & 6.29314815 & 0.00 & 814815 & $<.0001$ & 0.4028 \\
\hline $\mathrm{T}$ & 6.28333333 & 0.00 & 314815 & $<.0001$ & \\
\hline \multicolumn{4}{|c|}{ Analyses of $\mathrm{PH}$} & \multicolumn{2}{|c|}{ 10:49 Thursday, July 3, 2008124} \\
\hline & $\begin{array}{l}\text { The } \mathrm{C} \\
\text { Least }\end{array}$ & M P & $\begin{array}{l}\text { cedure } \\
\text { Means }\end{array}$ & & \\
\hline
\end{tabular}


Adjustment for Multiple Comparisons: Tukey

\begin{tabular}{|c|c|c|c|c|}
\hline \multirow[b]{2}{*}{ DAY } & \multicolumn{2}{|c|}{ Standard } & LSMEAN & \multirow[b]{2}{*}{ Number } \\
\hline & mean LSM & AN & $\begin{array}{ll}r & \operatorname{Pr}>|t|\end{array}$ & \\
\hline 1 & 6.39722222 & 0.01411301 & $<.0001$ & 1 \\
\hline 3 & 6.39666667 & 0.01411301 & $<.0001$ & 2 \\
\hline 5 & 6.40055556 & 0.01411301 & $<.0001$ & 3 \\
\hline & 6.37111111 & 0.01411301 & $<.0001$ & 4 \\
\hline & 6.17277778 & 0.01411301 & $<.0001$ & 5 \\
\hline 11 & 5.99111111 & 0.01411301 & $<.0001$ & 6 \\
\hline
\end{tabular}

Least Squares Means for effect DAY

$\operatorname{Pr}>|t|$ for H0: LSMean(i)=LSMean(j)

Dependent Variable: mean

$\begin{array}{cccccccc}\mathrm{i} / \mathrm{j} & 1 & 2 & 3 & 4 & 5 & 6 & \\ & & & & & & & \\ 1 & & 1.0000 & 1.0000 & 0.7777 & <.0001 & <.0001 \\ 2 & 1.0000 & & 1.0000 & 0.7925 & <.0001 & <.0001 \\ 3 & 1.0000 & 1.0000 & & 0.6824 & <.0001 & <.0001 \\ 4 & 0.7777 & 0.7925 & 0.6824 & & <.0001 & <.0001 \\ 5 & <.0001 & <.0001 & <.0001 & <.0001 & & <.0001 \\ 6 & <.0001 & <.0001 & <.0001 & <.0001 & <.0001 & \end{array}$

Analyses of PH 10:49 Thursday, July 3, 2008125

The GLM Procedure

Least Squares Means

Adjustment for Multiple Comparisons: Tukey

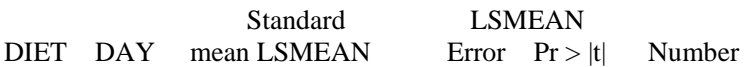

$\begin{array}{llllll}\mathrm{C} & 1 & 6.40000000 & 0.01995881 & <.0001 & 1 \\ \mathrm{C} & 3 & 6.36888889 & 0.01995881 & <.0001 & 2 \\ \mathrm{C} & 5 & 6.36888889 & 0.01995881 & <.0001 & 3 \\ \mathrm{C} & 7 & 6.32888889 & 0.01995881 & <.0001 & 4 \\ \mathrm{C} & 9 & 6.26222222 & 0.01995881 & <.0001 & 5 \\ \mathrm{C} & 11 & 6.03000000 & 0.01995881 & <.0001 & 6 \\ \mathrm{~T} & 1 & 6.39444444 & 0.01995881 & <.0001 & 7 \\ \mathrm{~T} & 3 & 6.42444444 & 0.01995881 & <.0001 & 8 \\ \mathrm{~T} & 5 & 6.43222222 & 0.01995881 & <.0001 & 9 \\ \mathrm{~T} & 7 & 6.41333333 & 0.01995881 & <.0001 & 10 \\ \mathrm{~T} & 9 & 6.08333333 & 0.01995881 & <.0001 & 11 \\ \mathrm{~T} & 11 & 5.95222222 & 0.01995881 & <.0001 & 12\end{array}$

Least Squares Means for effect DIET*DAY

$\operatorname{Pr}>|t|$ for H0: LSMean(i)=LSMean(j)

Dependent Variable: mean

\begin{tabular}{|c|c|c|c|c|c|c|}
\hline $\mathrm{i} / \mathrm{j}$ & 1 & 2 & 3 & 5 & 6 & \\
\hline 1 & & 0.9916 & 0.9916 & 0.3744 & 0.0026 & $<.0001$ \\
\hline 2 & 0.9916 & & 1.0000 & 0.9485 & 0.0342 & $<.0001$ \\
\hline 3 & 0.9916 & 1.0000 & & 0.9485 & 0.0342 & $<.0001$ \\
\hline 4 & 0.3744 & 0.9485 & 0.9485 & & 0.4645 & $<.0001$ \\
\hline 5 & 0.0026 & 0.0342 & 0.0342 & 0.4645 & & $<.0001$ \\
\hline 6 & $<.0001$ & $<.0001$ & $<.0001$ & $<.0001$ & $<.0001$ & \\
\hline 7 & 1.0000 & 0.9984 & 0.9984 & 0.4883 & 0.0042 & $<.0001$ \\
\hline 8 & 0.9989 & 0.7085 & 0.7085 & 0.0795 & 0.0003 & $<.0001$ \\
\hline 9 & 0.9889 & 0.5370 & 0.5370 & 0.0444 & 0.0002 & $<.0001$ \\
\hline 10 & 1.0000 & 0.9022 & 0.9022 & 0.1716 & 0.0008 & $<.0001$ \\
\hline 11 & $<.0001$ & $<.0001$ & $<.0001$ & $<.0001$ & $<.0001$ & 0.7544 \\
\hline 12 & $<.0001$ & $<.0001$ & $<.0001$ & $<.0001$ & $<.0001$ & 0.2592 \\
\hline
\end{tabular}


Least Squares Means for effect DIET*DAY

$\operatorname{Pr}>|t|$ for H0: LSMean(i)=LSMean(j)

Dependent Variable: mean

\begin{tabular}{|c|c|c|c|c|c|c|}
\hline $\mathrm{i} / \mathrm{i}$ & 7 & 8 & 9 & 11 & 12 & \\
\hline 1 & 1.0000 & 0.9989 & 0.9889 & 1.0000 & $<.0001$ & $<.0001$ \\
\hline 2 & 0.9984 & 0.7085 & 0.5370 & 0.9022 & $<.0001$ & $<.0001$ \\
\hline 3 & 0.9984 & 0.7085 & 0.5370 & 0.9022 & $<.0001$ & $<.000$ \\
\hline 4 & 0.4883 & 0.0795 & 0.0444 & 0.1716 & $<.0001$ & $<.00$ \\
\hline 5 & 0.0042 & 0.0003 & 0.0002 & 0.0008 & $<.0001$ & $<.00$ \\
\hline 6 & $<.0001$ & $<.0001$ & $<.0001$ & $<.0001$ & 0.7544 & 0.25 \\
\hline 7 & & 0.9937 & 0.9647 & 0.9999 & $<.0001$ & $<.0001$ \\
\hline 8 & 0.9937 & & 1.0000 & 1.0000 & $<.0001$ & $<.0001$ \\
\hline 9 & 0.9647 & 1.0000 & & 0.9999 & $<.0001$ & $<.0001$ \\
\hline 10 & 0.9999 & 1.0000 & 0.9999 & & $<.0001$ & $<.0001$ \\
\hline 11 & $<.0001$ & $<.0001$ & $<.0001$ & $<.0001$ & & 0.0046 \\
\hline 12 & $<.0001$ & $<.0001$ & $<.0001$ & $<.0001$ & 0.0046 & \\
\hline
\end{tabular}

Analyses of PH ～10:49 Thursday, July 3, 2008127

The GLM Procedure

\begin{tabular}{lrrr}
\multicolumn{2}{l}{$\begin{array}{l}\text { Level of } \\
\text { DIET }\end{array}$} & \multicolumn{3}{c}{ N } & \multicolumn{2}{c}{ Mean } & Std Dev \\
& & & \\
$\mathrm{C}$ & 18 & 6.29314815 & 0.13116607 \\
$\mathrm{~T}$ & 18 & 6.28333333 & 0.20032327
\end{tabular}

$\begin{array}{llll}\text { Level of } & & & \\ \text { DAY } & \text { N } & \text { Mean Std Dev }\end{array}$

$\begin{array}{llll}1 & 6 & 6.39722222 & 0.02924355\end{array}$

$\begin{array}{llll}3 & 6 & 6.39666667 & 0.03141125\end{array}$

$\begin{array}{llll}5 & 6 & 6.40055556 & 0.04265712\end{array}$

$\begin{array}{llll}7 & 6 & 6.37111111 & 0.04960585\end{array}$

$\begin{array}{llll}9 & 6 & 6.17277778 & 0.10231578\end{array}$

$\begin{array}{llll}11 & 6 & 5.99111111 & 0.06955946\end{array}$

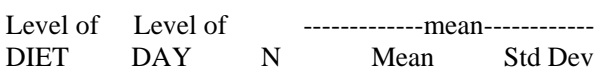

$\begin{array}{llccc}\mathrm{C} & 1 & 3 & 6.40000000 & 0.01201850 \\ \mathrm{C} & 3 & 3 & 6.36888889 & 0.01018350 \\ \mathrm{C} & 5 & 3 & 6.36888889 & 0.03790827 \\ \mathrm{C} & 7 & 3 & 6.32888889 & 0.01503083 \\ \mathrm{C} & 9 & 3 & 6.26222222 & 0.00509175 \\ \mathrm{C} & 11 & 3 & 6.03000000 & 0.05238745 \\ \mathrm{~T} & 1 & 3 & 6.39444444 & 0.04438885 \\ \mathrm{~T} & 3 & 3 & 6.42444444 & 0.00693889 \\ \mathrm{~T} & 5 & 3 & 6.43222222 & 0.01018350 \\ \mathrm{~T} & 7 & 3 & 6.41333333 & 0.02403701 \\ \mathrm{~T} & 9 & 3 & 6.08333333 & 0.04630815 \\ \mathrm{~T} & 11 & 3 & 5.95222222 & 0.06938887\end{array}$

Analyses of PH 10:49 Thursday, July 3, 2008128

The UNIVARIATE Procedure

Variable: residual

Moments

$\begin{array}{lccc}\text { N } & 36 \quad \text { Sum Weights } & 36 \\ \text { Mean } & 0 \quad \text { Sum Observations } & 0 \\ \text { Std Deviation } & 0.0286264 & \text { Variance } & 0.00081947 \\ \text { Skewness } & 0.1307326 \quad \text { Kurtosis } & 0.93618535 \\ \text { Uncorrected SS } & 0.02868148 & \text { Corrected SS } & 0.02868148\end{array}$


Coeff Variation $\quad$. Std Error Mean $\quad 0.00477107$

Basic Statistical Measures

\begin{tabular}{lccc} 
Location & \multicolumn{2}{c}{ Variability } \\
& & & \\
Mean & 0.00000 & Std Deviation & 0.02863 \\
Median & 0.00167 & Variance & 0.0008195 \\
Mode & -0.00889 & Range & 0.13333 \\
& \multicolumn{2}{c}{ Interquartile Range } & 0.02444
\end{tabular}

NOTE: The mode displayed is the smallest of 2 modes with a count of 2 .

Tests for Location: $\mathrm{Mu} 0=0$

Test - -Statistic- -----p Value------

Student's $\mathrm{t} \quad \mathrm{t} \quad 0 \quad \operatorname{Pr}>|\mathrm{t}| \quad 1.0000$

$\begin{array}{llll}\text { Sign } \quad M & 2 & \operatorname{Pr}>=|M| & 0.6177\end{array}$

Signed Rank S $15.5 \operatorname{Pr}>=|\mathrm{S}| \quad 0.8115$

Tests for Normality

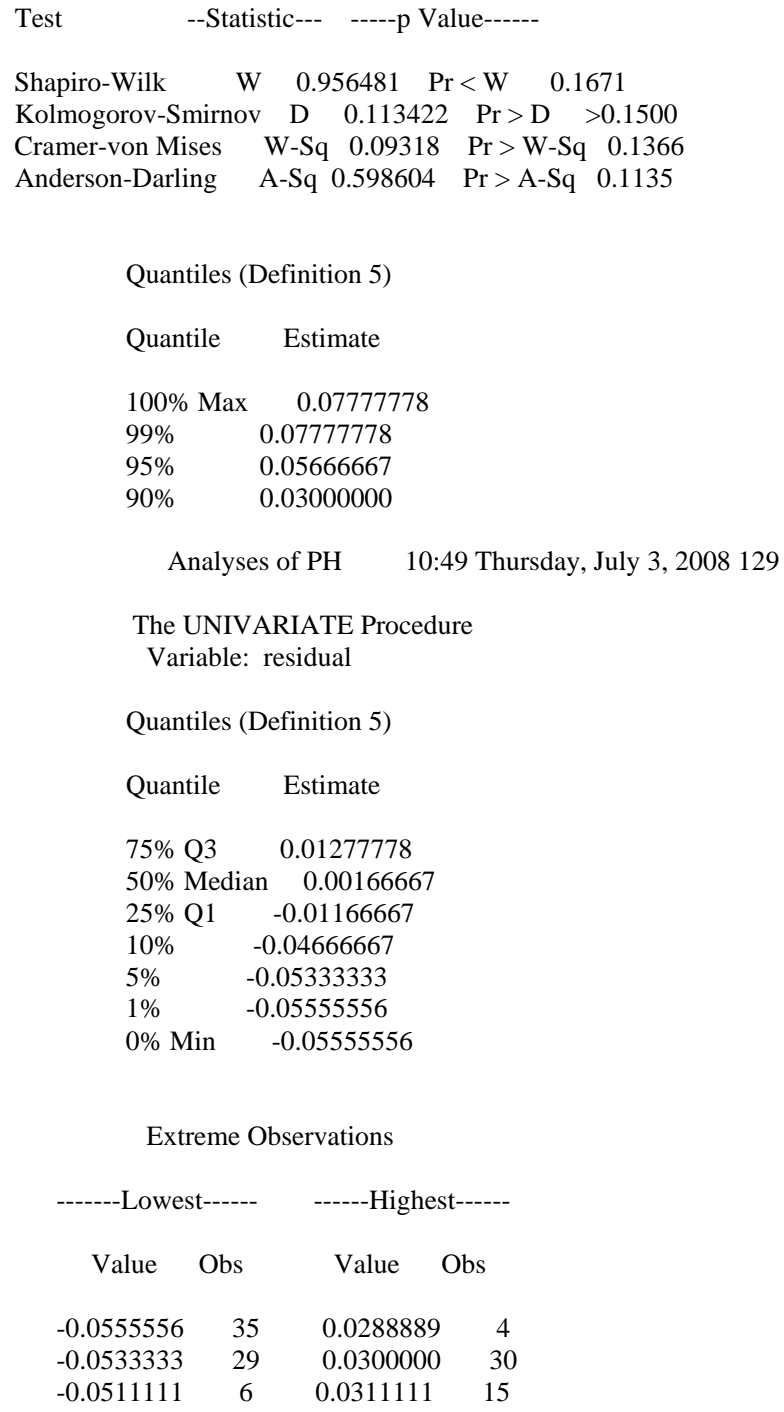




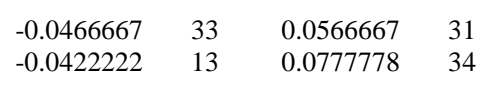

\begin{tabular}{|c|c|c|}
\hline Stem Leaf & \# & Boxplot \\
\hline 78 & 1 & 0 \\
\hline \multicolumn{3}{|l|}{6} \\
\hline 57 & 1 & 0 \\
\hline \multicolumn{3}{|l|}{4} \\
\hline 301 & 2 & | \\
\hline 20239 & 4 & | \\
\hline 101114 & 5 & +-----+ \\
\hline 01123467 & 7 & *--+-_* \\
\hline-0998622 & 6 & $1 \mid$ \\
\hline-1630 & 3 & +-----+ \\
\hline-272 & 2 & | \\
\hline \multicolumn{3}{|l|}{-3} \\
\hline-472 & 2 & | \\
\hline-5631 & 3 & 0 \\
\hline \multicolumn{3}{|c|}{----+----+-----+----+ } \\
\hline Multiply Ste & by & \\
\hline
\end{tabular}

Analyses of PH 10:49 Thursday, July 3, 2008130

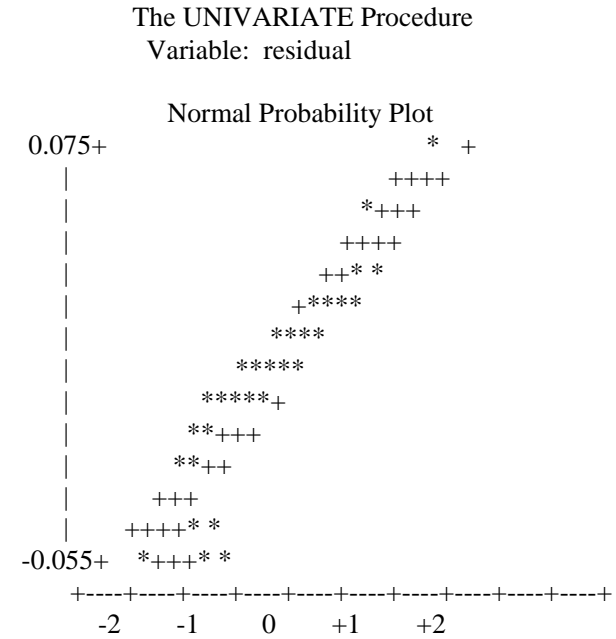




\title{
APPENDIX N: Statistical analysis of Color L (Chapter III)
}

\author{
The GLM Procedure \\ Class Level Information \\ Class Levels Values \\ DIET $2 \mathrm{C} \mathrm{T}$ \\ DAY $\quad 6 \quad 1357911$
}

Analyses of Color L 13:03 Wednesday, July 2, 200824

Number of Observations Read 36

Number of Observations Used 36

Analyses of Color L 13:03 Wednesday, July 2, 200825

The GLM Procedure

Dependent Variable: mean

\begin{tabular}{|c|c|c|c|c|c|}
\hline \multicolumn{6}{|c|}{ Sum of } \\
\hline Source & DF & Squares & Mean Square & F Value & $\operatorname{Pr}>F$ \\
\hline Model & 11 & 731.8135441 & 66.5285040 & 10.42 & $<.0001$ \\
\hline Error & 24 & 153.1939704 & 6.3830821 & & \\
\hline Corrected Total & & 885.00751 & & & \\
\hline
\end{tabular}

R-Square Coeff Var Root MSE mean Mean

$0.826901 \quad 5.184692 \quad 2.526476 \quad 48.72954$

\begin{tabular}{lcccccc} 
Source & DF & Type I SS & Mean Square & F Value & Pr $>$ F \\
DIET & 1 & 44.0084818 & 44.0084818 & 6.89 & 0.0148 \\
DAY & 5 & 592.5215608 & 118.5043122 & 18.57 & $<.0001$ \\
DIET*DAY & \multicolumn{2}{c}{5} & 95.2835015 & 19.0567003 & 2.99 & 0.0311 \\
& & & & & & \\
Source & DF & Type III SS & Mean Square & F Value & Pr $>$ F \\
DIET & 1 & 44.0084818 & 44.0084818 & 6.89 & 0.0148 \\
DAY & 5 & 592.5215608 & 118.5043122 & 18.57 & $<.0001$ \\
DIET*DAY & \multicolumn{7}{c}{5} & 95.2835015 & 19.0567003 & 2.99 & 0.0311
\end{tabular}

Analyses of Color L 13:03 Wednesday, July 2, 200826

The GLM Procedure

Least Squares Means

Adjustment for Multiple Comparisons: Tukey

\begin{tabular}{|c|c|c|c|c|c|}
\hline \multirow[b]{3}{*}{ DIET } & \multicolumn{5}{|c|}{ H0:LSMean1= } \\
\hline & \multicolumn{2}{|c|}{ Standard } & H0:LSN & $\mathrm{EAN}=0$ & LSMean2 \\
\hline & \multicolumn{2}{|c|}{ mean LSMEAN } & Error & $\operatorname{Pr}>|t|$ & $\operatorname{Pr}>|t|$ \\
\hline $\mathrm{C}$ & 47.6238889 & 0.5 & 54962 & $<.0001$ & 0.0148 \\
\hline $\mathrm{T}$ & 49.8351852 & $0.5 \mathrm{~s}$ & 54962 & $<.0001$ & \\
\hline & Analy & s of & Color L & 13:03 We & dnesday, July 2, 2008 \\
\hline & $\begin{array}{l}\text { The } \\
\text { Least }\end{array}$ & & $\begin{array}{l}\text { ocedure } \\
\text { s Means }\end{array}$ & & \\
\hline
\end{tabular}


Adjustment for Multiple Comparisons: Tukey

\begin{tabular}{lcccc} 
& \multicolumn{2}{c}{ Standard } & \multicolumn{2}{c}{ LSMEAN } \\
DAY & mean LSMEAN & Error & $\operatorname{Pr}>|t|$ & Number \\
& & & & \\
1 & 47.9677778 & 1.0314296 & $<.0001$ & 1 \\
3 & 42.2155556 & 1.0314296 & $<.0001$ & 2 \\
5 & 45.9433333 & 1.0314296 & $<.0001$ & 3 \\
7 & 50.0216667 & 1.0314296 & $<.0001$ & 4 \\
9 & 51.1327778 & 1.0314296 & $<.0001$ & 5 \\
11 & 55.0961111 & 1.0314296 & $<.0001$ & 6
\end{tabular}

Least Squares Means for effect DAY

$\operatorname{Pr}>|t|$ for H0: LSMean(i)=LSMean(j)

Dependent Variable: mean

$\begin{array}{cccccccc}\mathrm{i} / \mathrm{j} & 1 & 2 & 3 & 4 & 5 & 6 & \\ & & & & & & \\ 1 & & 0.0071 & 0.7336 & 0.7220 & 0.2877 & 0.0007 \\ 2 & 0.0071 & & 0.1477 & 0.0002 & <.0001 & <.0001 \\ 3 & 0.7336 & 0.1477 & & 0.0927 & 0.0176 & <.0001 \\ 4 & 0.7220 & 0.0002 & 0.0927 & & 0.9714 & 0.0211 \\ 5 & 0.2877 & <.0001 & 0.0176 & 0.9714 & & 0.1084 \\ 6 & 0.0007 & <.0001 & <.0001 & 0.0211 & 0.1084 & \end{array}$

Analyses of Color L 13:03 Wednesday, July 2, 200828

The GLM Procedure

Least Squares Means

Adjustment for Multiple Comparisons: Tukey

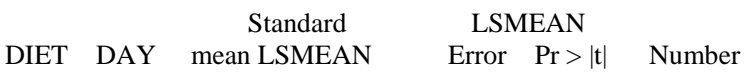

$\begin{array}{llcccc}\mathrm{C} & 1 & 47.9144444 & 1.4586617 & <.0001 & 1 \\ \mathrm{C} & 3 & 43.0377778 & 1.4586617 & <.0001 & 2 \\ \mathrm{C} & 5 & 41.8200000 & 1.4586617 & <.0001 & 3 \\ \mathrm{C} & 7 & 49.7944444 & 1.4586617 & <.0001 & 4 \\ \mathrm{C} & 9 & 50.2488889 & 1.4586617 & <.0001 & 5 \\ \mathrm{C} & 11 & 52.9277778 & 1.4586617 & <.0001 & 6 \\ \mathrm{~T} & 1 & 48.0211111 & 1.4586617 & <.0001 & 7 \\ \mathrm{~T} & 3 & 41.3933333 & 1.4586617 & <.0001 & 8 \\ \mathrm{~T} & 5 & 50.0666667 & 1.4586617 & <.0001 & 9 \\ \mathrm{~T} & 7 & 50.2488889 & 1.4586617 & <.0001 & 10 \\ \mathrm{~T} & 9 & 52.0166667 & 1.4586617 & <.0001 & 11 \\ \mathrm{~T} & 11 & 57.2644444 & 1.4586617 & <.0001 & 12\end{array}$

Least Squares Means for effect DIET*DAY

$\operatorname{Pr}>|t|$ for H0: LSMean(i)=LSMean(j)

Dependent Variable: mean

\begin{tabular}{|c|c|c|c|c|c|c|}
\hline $\mathrm{i} / \mathrm{j}$ & 1 & 2 & 3 & 5 & 6 & \\
\hline 1 & & 0.4633 & 0.1836 & 0.9983 & 0.9897 & 0.4243 \\
\hline 2 & 0.4633 & & 1.0000 & 0.0995 & 0.0632 & 0.0032 \\
\hline 3 & 0.1836 & 1.0000 & & 0.0282 & 0.0171 & 0.0008 \\
\hline 4 & 0.9983 & 0.0995 & 0.0282 & & 1.0000 & 0.9207 \\
\hline 5 & 0.9897 & 0.0632 & 0.0171 & 1.0000 & & 0.9714 \\
\hline 6 & 0.4243 & 0.0032 & 0.0008 & 0.9207 & 0.9714 & \\
\hline 7 & 1.0000 & 0.4327 & 0.1671 & 0.9990 & 0.9929 & 0.4546 \\
\hline 8 & 0.1246 & 0.9995 & 1.0000 & 0.0176 & 0.0106 & 0.0005 \\
\hline 9 & 0.9946 & 0.0760 & 0.0209 & 1.0000 & 1.0000 & 0.9552 \\
\hline 10 & 0.9897 & 0.0632 & 0.0171 & 1.0000 & 1.0000 & 0.9714 \\
\hline 11 & 0.6962 & 0.0092 & 0.0023 & 0.9930 & 0.9990 & 1.0000 \\
\hline 12 & 0.0060 & $<.0001$ & $<.0001$ & 0.0483 & 0.0770 & 0.6260 \\
\hline
\end{tabular}


Least Squares Means for effect DIET*DAY

$\operatorname{Pr}>|t|$ for H0: LSMean(i)=LSMean(j)

Dependent Variable: mean

\begin{tabular}{|c|c|c|c|c|c|c|}
\hline $\mathrm{i} / \mathrm{j}$ & 7 & 8 & 9 & 11 & 12 & \\
\hline 1 & 1.0000 & 0.1246 & 0.9946 & 0.9897 & 0.6962 & 0.0060 \\
\hline 2 & 0.4327 & 0.9995 & 0.0760 & 0.0632 & 0.0092 & $<.0001$ \\
\hline 3 & 0.1671 & 1.0000 & 0.0209 & 0.0171 & 0.0023 & $<.0001$ \\
\hline 4 & 0.9990 & 0.0176 & 1.0000 & 1.0000 & 0.9930 & 0.0483 \\
\hline 5 & 0.9929 & 0.0106 & 1.0000 & 1.0000 & 0.9990 & 0.0770 \\
\hline 6 & 0.4546 & 0.0005 & 0.9552 & 0.9714 & 1.0000 & 0.6260 \\
\hline 7 & & 0.1126 & 0.9965 & 0.9929 & 0.7271 & 0.0068 \\
\hline 8 & 0.1126 & & 0.0130 & 0.0106 & 0.0014 & $<.0001$ \\
\hline 9 & 0.9965 & 0.0130 & & 1.0000 & 0.9976 & 0.0641 \\
\hline 10 & 0.9929 & 0.0106 & 1.0000 & & 0.9990 & 0.0770 \\
\hline 11 & 0.7271 & 0.0014 & 0.9976 & 0.9990 & & 0.3612 \\
\hline 12 & 0.0068 & $<.0001$ & 0.0641 & 0.0770 & 0.3612 & \\
\hline
\end{tabular}

Analyses of Color L 13:03 Wednesday, July 2, 200830

The GLM Procedure

\begin{tabular}{lrrr}
\multicolumn{2}{l}{$\begin{array}{l}\text { Level of } \\
\text { DIET }\end{array}$} & \multicolumn{3}{c}{ N } & Mean & Std Dev \\
& & & \\
$\mathrm{C}$ & 18 & 47.6238889 & 4.72085960 \\
$\mathrm{~T}$ & 18 & 49.8351852 & 5.21382930
\end{tabular}

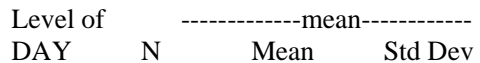

$\begin{array}{llll}1 & 6 & 47.9677778 & 1.38411089\end{array}$

$\begin{array}{llll}3 & 6 & 42.2155556 & 3.61985860\end{array}$

$\begin{array}{llll}5 & 6 & 45.9433333 & 5.03622036\end{array}$

$\begin{array}{llll}7 & 6 & 50.0216667 & 1.18462699\end{array}$

$\begin{array}{llll}9 & 6 & 51.1327778 & 2.22422662\end{array}$

$\begin{array}{llll}11 & 6 & 55.0961111 & 3.42987037\end{array}$

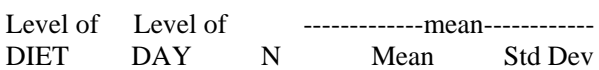

$\begin{array}{llccc}\mathrm{C} & 1 & 3 & 47.9144444 & 1.67750586 \\ \mathrm{C} & 3 & 3 & 43.0377778 & 5.44000545 \\ \mathrm{C} & 5 & 3 & 41.8200000 & 2.12192784 \\ \mathrm{C} & 7 & 3 & 49.7944444 & 1.32870168 \\ \mathrm{C} & 9 & 3 & 50.2488889 & 2.88437232 \\ \mathrm{C} & 11 & 3 & 52.9277778 & 0.79834783 \\ \mathrm{~T} & 1 & 3 & 48.0211111 & 1.40244363 \\ \mathrm{~T} & 3 & 3 & 41.3933333 & 1.06613007 \\ \mathrm{~T} & 5 & 3 & 50.0666667 & 2.81079664 \\ \mathrm{~T} & 7 & 3 & 50.2488889 & 1.26016460 \\ \mathrm{~T} & 9 & 3 & 52.0166667 & 1.30559480 \\ \mathrm{~T} & 11 & 3 & 57.2644444 & 3.82983802\end{array}$

Analyses of Color L 13:03 Wednesday, July 2, 200831

The UNIVARIATE Procedure

Variable: residual

Moments

\begin{tabular}{lccc}
$\mathrm{N}$ & 36 & Sum Weights & 36 \\
Mean & \multicolumn{2}{c}{$0 \quad$ Sum Observations } & 0 \\
Std Deviation & 2.09212107 & Variance & 4.37697058 \\
Skewness & 0.08842509 & Kurtosis & 1.20347887 \\
Uncorrected SS & \multicolumn{1}{c}{153.19397} & Corrected SS & 153.19397
\end{tabular}


Coeff Variation ～～～Std Error Mean 0.34868685

Basic Statistical Measures

\begin{tabular}{|c|c|c|c|}
\hline \multicolumn{2}{|c|}{ Location } & \multicolumn{2}{|l|}{ Variability } \\
\hline Mean & 0.000000 & Std Deviation & 2.09212 \\
\hline Median & 0.140000 & Variance & 4.37697 \\
\hline Mode & · $\quad \begin{array}{r}\mathrm{R} \\
\text { Interc }\end{array}$ & $\begin{array}{l}\text { age } \\
\text { lartile Range }\end{array}$ & $\begin{array}{r}10.88000 \\
2.39722\end{array}$ \\
\hline
\end{tabular}

Tests for Location: $\mathrm{Mu} 0=0$

Test $\quad$-Statistic- -----p Value------

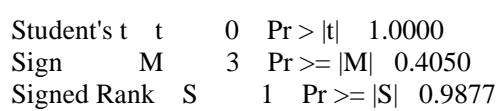

Tests for Normality

Test --Statistic--- -----p Value------

$\begin{array}{lllll}\text { Shapiro-Wilk } \quad \text { W } & 0.976146 & \mathrm{Pr}<\mathrm{W} & 0.6147\end{array}$

$\begin{array}{lllll}\text { Kolmogorov-Smirnov D } & 0.121344 & \mathrm{Pr}>\mathrm{D} & >0.1500\end{array}$

Cramer-von Mises W-Sq $0.06345 \quad \mathrm{Pr}>\mathrm{W}$-Sq $>0.2500$

Anderson-Darling A-Sq 0.39406 Pr $>$ A-Sq $>0.2500$

Quantiles (Definition 5)

Quantile Estimate

100\% Max 5.43556

$99 \% \quad 5.43556$

$95 \% \quad 4.13556$

$90 \% \quad 2.72778$

$75 \%$ Q3 $\quad 1.09222$

$50 \%$ Median $\quad 0.14000$

Analyses of Color L 13:03 Wednesday, July 2, 200832

The UNIVARIATE Procedure

Variable: residual

Quantiles (Definition 5)

Quantile Estimate

25\% Q1 -1.30500

$10 \% \quad-2.44000$

$5 \% \quad-3.42444$

$1 \% \quad-5.44444$

$0 \%$ Min $\quad-5.44444$

Extreme Observations

\begin{tabular}{cccc}
-----Lowest----- & \multicolumn{2}{c}{-----Highest----- } \\
Value & Obs & Value & Obs \\
& & & \\
-5.44444 & 7 & 1.52889 & 1 \\
-3.42444 & 36 & 2.72778 & 26 \\
-3.01889 & 25 & 3.18667 & 16 \\
-2.44000 & 14 & 4.13556 & 35 \\
-2.12667 & 17 & 5.43556 & 9
\end{tabular}




\begin{tabular}{|c|c|c|}
\hline Stem Leaf & \# & Boxplot \\
\hline 54 & 1 & 0 \\
\hline 41 & 1 & | \\
\hline 32 & 1 & | \\
\hline 27 & 1 & | \\
\hline 10024445 & 7 & +------+ \\
\hline 00012334588 & 10 & *--+---* \\
\hline-0871 & 3 & | 1 \\
\hline -1 8543321 & 7 & +-----+ \\
\hline-241 & 2 & | \\
\hline-340 & 2 & i \\
\hline-4 & & \\
\hline-54 & 1 & 0 \\
\hline
\end{tabular}

Analyses of Color L 13:03 Wednesday, July 2, 200833

The UNIVARIATE Procedure

Variable: residual

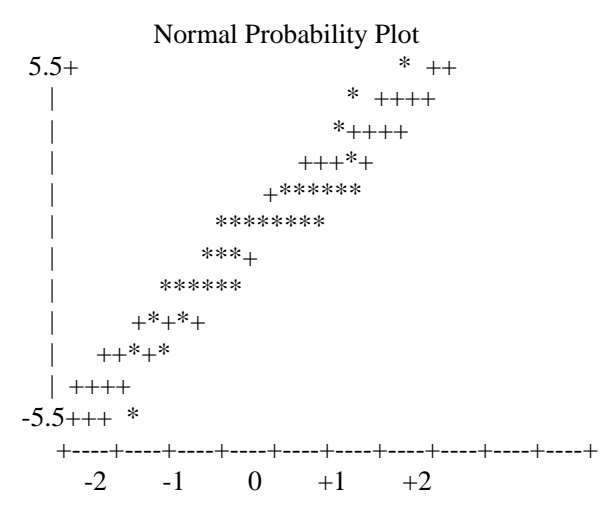

